BRUNA ESTROZI

\title{
Avaliação anatomoclínica e molecular do melanoma cutâneo em pacientes jovens
} (idade 18-30 anos)

Tese apresentada à Faculdade de Medicina da Universidade de São Paulo para obtenção do título de Doutor em Ciências.

Programa de Patologia

Orientador: Prof. Dr. Carlos Eduardo Bacchi

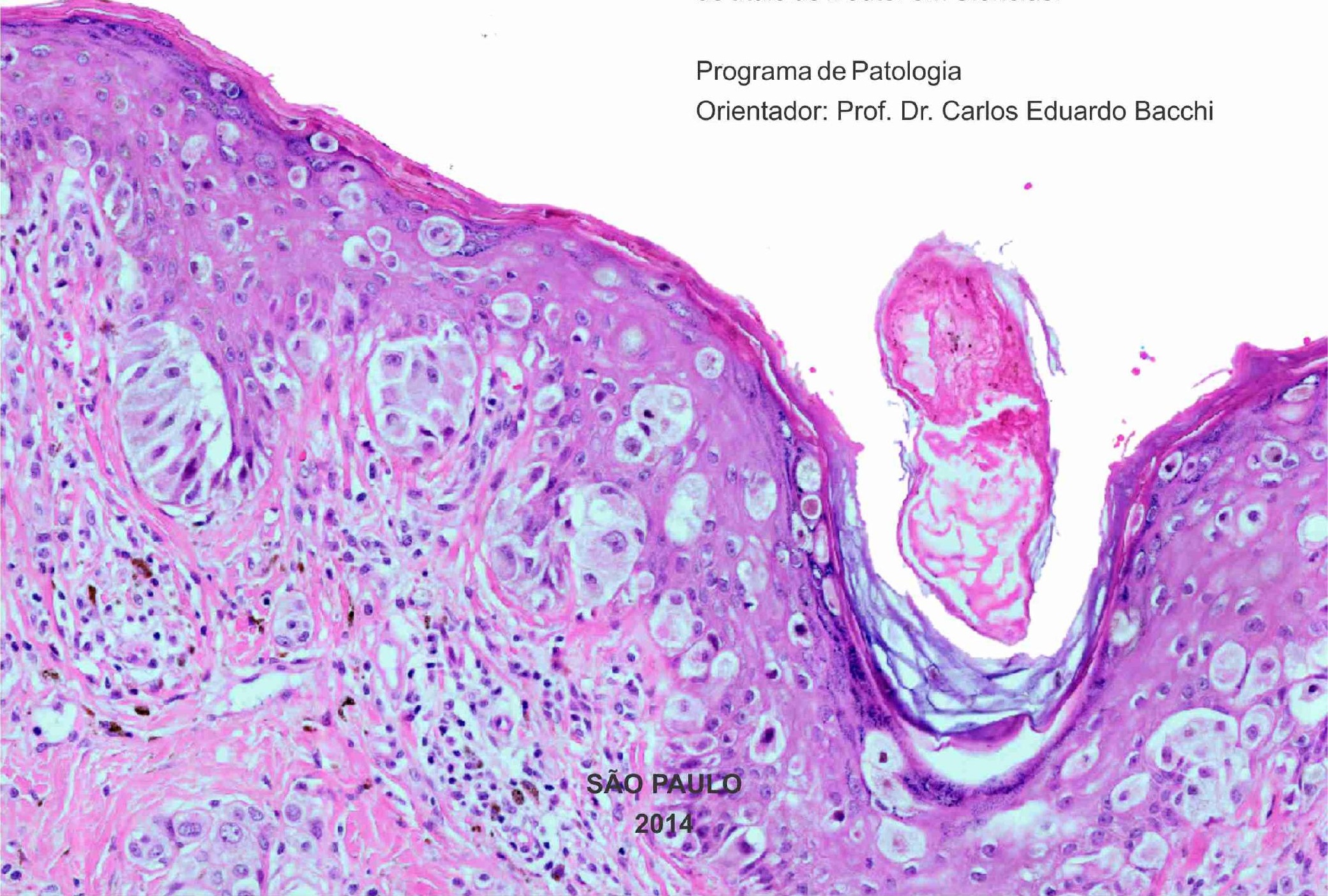




\section{BRUNA EstrozI}

Avaliação anatomoclínica e molecular do melanoma cutâneo em pacientes jovens (idade 18-30 anos)

Tese apresentada à Faculdade de Medicina da Universidade de São Paulo para obtenção do título de Doutor em Ciências.

Programa de Patologia

Orientador: Prof. Dr. Carlos Eduardo Bacchi 


\title{
Dados Internacionais de Catalogação na Publicação (CIP)
}

\author{
Preparada pela Biblioteca da
}

Faculdade de Medicina da Universidade de São Paulo

Creprodução autorizada pelo autor

\section{Estrozi, Bruna}

Avaliação anatomoclínica e molecular do melanoma cutâneo em pacientes jovens (idade 18-30 anos) / Bruna Estrozi. -- São Paulo, 2014.

Tese(doutorado)--Faculdade de Medicina da Universidade de São Paulo. Programa de Patologia.

Orientador: Carlos Eduardo Bacchi.

Descritores: 1.Melanoma 2.Neoplasias cutâneas 3.Adulto jovem 4.Proteínas proto-oncogênicas B-raf 5.Proteínas proto-oncogênicas c-kit 6.Proteínas protooncogênicas p21(ras)

USP/FM/DBD-381/14 
Dedicatária 
Aas mens pais, Claudinei e Marta, lase da minha vida, par me mastrarem a valar da família e pela dedicaçãa para a mew crescimenta cama pessaa.

As minhas irmãs Bianca e Flavia, pela amizade eterna.

Aa mew marida Eduarda, pela campanheirisma, incentiva e paciência.

Aa mew filha, Guilherme, par me mastrar a amar incandicianal. 
Agradecimentas 
Aa praf. dr. Carlas E. Bacchi, agradeça a apartunidade aferecida, confianda na minha capacidade e contribuinda para a mew crescimenta e amadurecimenta, nãa samente neste prajeta, mas em tada a minha vida prafissianal.

Aa dr. Rubens Radrigues, minha gratidãa pela interesse e calabaraçãa em wárias etapas deste prajeta.

A Guliana Machada e a tada a equize da Genepath, pela suparte técnica e intelectual em relaçãa às mutaçães estudadas.

À dra. Maura Bacchi, pela incentiva e apaia.

Aas patalagistas, Carlas David, Cristiane Cancada, Eduarda Queiraga, Gabriela Cualca, Ivisan Mavier, Lisandra Lapes, Livia Bacchi e Sheila Whudarski, pela amizade e camúvia diária.

Aa calega Ivisan Mavier, pela enarme auxília prestada e par campartilhar camiga wárias mamentas desta caminhada.

Aas meus familiares e amigas, par sempre acreditarem em mim.

Aas médicas e pacientes, que, gentilmente, farneceram as infarmaçães par mim salicitadas.

A tadas aqueles que, de alguma farma, cantribuíram para que este prajeta se tarnasse realidade, mew sincera agradecimenta. 
Epigrafe 
"Melanama writes its message in the skin with its aun ink and it is there far all of us ta see. Same see lut da nat camprehend." 
Normalização adotada

Esta tese está de acordo com as seguintes normas, em vigor do momento desta publicação:

Referências: adapatado de International Comittee of Medical Journals Editors (Vancouver)

Universidade de São Paulo. Faculdade de Medicina. Divisão de Biblioteca e Documentação. Guia de Apresentação de Dissertações, Teses e Monografias. Elaborado por: Anneliese Carneiro da Cunha, Maria Júlia de A. L. Freddi, Maria F. Crestana, Marinalva de Souza Aragão, Sueli Campos Cardoso, Valéria Vilhena. Terceira Edição. São Paulo: Divisão de Bibliografia e Documentção; 2011.

Abreviaturas dos títulos dos periódicos de acordo com List of Journals Indexed in Index Medicus. 
Sumária 


\section{LISTA DE TABELAS, FIGURAS E GRÁFICOS \\ RESUMO}

\section{ABSTRACT}

\section{INTRODUÇÃO E REVISÃO DA LITERATURA}

1.1. Melanoma cutâneo: definição, aspectos históricos e situação atual no mundo e no Brasil.

1.2. Melanoma em crianças, adolescentes e adultos jovens

1.3. Fatores etiológicos............................................................. 5

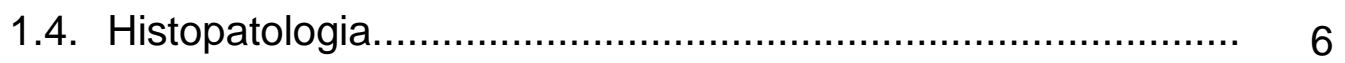

1.5. Indicadores prognósticos..................................................... 8

1.5.1. Parâmetros clínicos................................................... 8

1.5.2. Parâmetros histológicos.............................................. 9

1.6. Aspectos moleculares.......................................................... 13

1.7. Mutações NRAS em melanoma cutâneo.................................. 14

1.8. Mutações no gene BRAF em melanoma cutâneo.................... 18

1.9. Mutações do gene KIT em melanoma cutâneo........................ 22

2. OBJETIVOS $\quad 29$

2.1. Objetivo geral............................................................. 29

2.2. Objetivos específicos........................................................ 29

3. MATERIAL E MÉTODO__ 31

3.1. Aprovação institucional da pesquisa...................................... 31

3.2. Seleção da amostra....................................................... 31

3.2.1. Critérios de inclusão................................................. 31

3.2.2. Critérios de exclusão................................................ 31

3.3. Coleta das variáveis clínicas e anatomopatológicas............... 32

3.3.1. Variáveis clínicas.................................................... 32

3.3.2. Variáveis anatomopatológicas..................................... 33

3.4. Análise molecular........................................................... 34

3.4.1. Isolamento do DNA e viabilidade do material genético.............................................................. 34

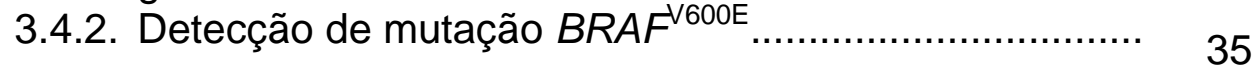

3.4.3. Detecção das mutações $61 \mathrm{~K}, 61 \mathrm{R}$ e $61 \mathrm{~L}$ no gene NRAS.

3.4.4. Deteç̧ão de mutações KIT .......................................... 38

3.5. Análise estatística.................................................................. 40 
4. RESULTADOS

4.1. Descrição geral dos resultados das variáveis clínicas anatomopatológicas e moleculares.

4.1.1. Distribuição quanto ao sexo e idade.

4.1.2. Distribuição quanto à localização anatômica da lesão primária.

4.2. Descrição das variáveis histopatológicas

4.2.1. Tipos histológicos

4.2.2. Distribuição quanto aos níveis de Clark.

4.2.3. Distribuição quanto à espessura tumoral (Breslow).......

4.2.4. Distribuição quanto à fase de crescimento

4.2.5. Distribuição quanto à presença de ulceração.

4.2.6. Distribuição quanto à presença de figura de mitose no componente intradérmico nos casos de melanoma cutâneo invasivo.

4.2.7. Distribuição quanto à presença de invasão angiolinfática...

4.2.8. Distribuição quanto à presença de infiltração

perineural...........................................................

4.2.10. Distribuição quanto à presença de satelitose..............

4.2.11. Distribuição quanto à intensidade do infiltrado inflamatório peritumoral...

4.2.12. Distribuição quanto à intensidade do infiltrado inflamatório intratumoral.

4.2.13. Distribuição quanto à presença de nevo melanocítico associado.

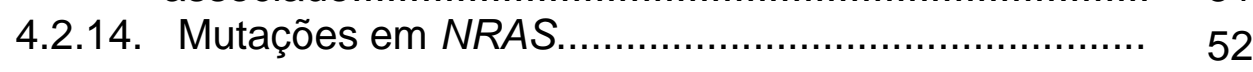

4.2.15. Mutação $B R A F^{\mathrm{V} 600 \mathrm{E}}$............................................... 54

4.2.16. Mutações em KIT................................................... 54

4.3. Correlação entre as variáveis clínicas, histopatológicas e moleculares.

4.3.1. Sexo e idade.

4.3.2. Sexo e localização anatômica.

4.3.3. Sexo e espessura tumoral (Breslow)

4.3.4. Sexo e nível de Clark.

4.4. Relação entre mutação $B R A F^{\mathrm{V} 600 \mathrm{t}} \mathrm{e}$ as variáveis clinicopatológicas.

4.4.1. BRAF ${ }^{\mathrm{V} 600 \mathrm{E}}$ e sexo.

4.4.2. $B R A F^{\mathrm{V} 600 \mathrm{E}}$ e sítio anatômico. 
4.4.3. $B R A F^{\mathrm{V} 600 \mathrm{E}}$ e tipo histológico

4.4.4. BRAF ${ }^{V 600 E}$ e nível de Clark 62

4.4.5. $B R A F^{V 600 E}$ e índice de Breslow 63

4.4.6. $B R A F^{V 600 E}$ e fase de crescimento 65

4.4.7. $B R A F^{V 600 E}$ e infiltrado inflamatório peritumoral. 65

4.4.8. $B R A F^{V 600 t}$ e infiltrado inflamatório intratumoral. 66

4.4.9. $B R A F^{V 600 E}$ e elastose solar. 67

4.4.10. BRAF $F^{V 600 t}$ e ulceração 68

4.4.11. $B R A F^{V 600 t}$ e regressão. 69

4.4.12. $B R A F^{V 600 t}$ e satelitose 69

4.4.13. $B R A F^{V 600 E}$ e invasão angiolinfática 70

4.4.14. $B R A F^{V 600 t}$ e infiltração perineural 71

4.4.15. $B R A F^{V 600 E}$ e presença de mitose no componente intradérmico..

4.4.16. $B R A F^{V 600 E}$ e nevo melanocítico associado. 71

4.4.17. $B R A F^{V 600 E}$ e evolução clínica. 72

4.5. Curvas de sobrevida. 73

5. DISCUSSÃO

6. CONCLUSÕES 77

7. BIBLIOGRAFIA 93 APÊNDICE 97 ANEXOS 


\section{Lista de Tabelas, Figurase Gráficas}




\section{Lista de Tabelas}

Tabela 1 Descrição das sequências dos iniciadores e das sondas utilizadas na detecção da mutação V600E no gene BRAF.

Tabela 2 Descrição das sequências dos iniciadores utilizados na amplificação dos éxons 9, 11, 13 e 17 do gene KIT.

Tabela 3 Distribuição de 132 casos de melanoma cutâneo, em pacientes com idade entre 18 e 30 anos, em relação ao sexo.

Tabela 4 Distribuição de 120 casos de melanoma cutâneo, em pacientes com idade entre 18 e 30 anos, em relação à localização anatômica em ambos os sexos

Tabela 5 Distribuição de 132 casos de melanoma cutâneo, em pacientes com idade entre 18 e 30 anos, em relação ao tipo histológico.

Tabela 6 Distribuição de 132 casos de melanoma cutâneo, em pacientes com idade entre 18 e 30 anos, em relação aos níveis de Clark.

Tabela 7 Distribuição de 132 casos de melanoma cutâneo, em pacientes com idade entre 18 e 30 anos, em relação à espessura (Breslow)

Tabela 8 Distribuição de 132 casos de melanoma cutâneo, em pacientes com idade entre 18 e 30 anos, em relação à fase de crescimento

Tabela 9 Distribuição de 132 casos de melanoma cutâneo, em pacientes com idade entre 18 e 30 anos, em relação à presença de ulceração

Tabela 10 Distribuição de 121 casos de melanoma cutâneo invasivo, em pacientes com idade entre 18 e 30 anos, em relação à presença de figuras de mitose no componente intradérmico.

Tabela 11 Distribuição de 132 casos de melanoma cutâneo, em pacientes com idade entre 18 e 30 anos, em relação à presença de invasão angiolinfática.

Tabela 12 Distribuição de 132 casos de melanoma cutâneo, em pacientes com idade entre 18 e 30 anos, em relação à presença de infiltração perineural.

Tabela 13 Distribuição de 132 casos de melanoma cutâneo, em pacientes com idade entre 18 e 30 anos, em relação à presença de elastose solar. 
Tabela 14 Distribuição de 132 casos de melanoma cutâneo, em pacientes com idade entre 18 e 30 anos, em relação à presença de satelitose.

Tabela 15 Distribuição de 132 casos de melanoma cutâneo, em pacientes com idade entre 18 e 30 anos, em relação à intensidade do infiltrado inflamatório peritumoral..

Tabela 16 Distribuição de 121 casos de melanoma cutâneo, em pacientes com idade entre 18 e 30 anos, em relação à intensidade do infiltrado inflamatório intratumoral.

Tabela 17 Distribuição de 132 casos de melanoma cutâneo, em pacientes com idade entre 18 e 30 anos, em relação à presença de nevo melanocítico.

Tabela 18 Distribuição de 76 casos de melanoma cutâneo, em pacientes com idade entre 18 e 30 anos, em relação à presença de mutação no gene NRAS.

Tabela 19 Mutações do gene NRAS em três casos de melanomas em pacientes jovens

Tabela 20 Distribuição de 93 casos de melanoma cutâneo, em pacientes com idade entre 18 e 30 anos, em relação à presença da mutação $B R A F^{\mathrm{V} 600 \mathrm{E}}$

Tabela 21 Distribuição de 32 casos de melanoma cutâneo, em pacientes com idade entre 18 e 30 anos, em relação à presença da mutação no gene KIT.

Tabela 22 Mutações do gene KIT em três casos de melanomas em pacientes jovens.

Tabela 23 Distribuição de 132 casos de melanoma cutâneo quanto ao sexo em relação à idade.

Tabela 24 Distribuição de 120 casos de melanoma cutâneo quanto ao sexo em relação à localização anatômica.

Tabela 25 Distribuição de 132 casos de melanoma cutâneo quanto ao sexo em relação à espessura tumoral (Breslow).

Tabela 26 Distribuição de 132 casos de melanoma cutâneo quanto ao sexo em relação à espessura média.

Tabela 27 Distribuição de 132 casos de melanoma cutâneo quanto ao sexo em relação ao nível de Clark

Tabela 28 Distribuição de 93 casos de melanoma cutâneo quanto ao sexo em relação à mutação $B R A F^{\vee 600 E}$

Tabela 29 Distribuição de 84 casos de melanoma cutâneo quanto à localização anatômica em relação à mutação BRAF $^{\mathrm{V} 600 \mathrm{E}}$ 
Tabela 30 Distribuição de 93 casos de melanoma cutâneo quanto o tipo histológico em relação à mutação $B R A F^{\mathrm{V} 600 \mathrm{E}}$

Tabela 31 Distribuição de 93 casos de melanoma cutâneo quanto ao nível de Clark em relação à mutação $B R A F^{\vee 600 E}$.

Tabela 32 Distribuição de 93 casos de melanoma cutâneo quanto à medida de Breslow em relação à mutação $B R A F^{V 600 E}$

Tabela 33 Distribuição de 93 casos de melanoma cutâneo quanto à espessura em relação à mutação $B R A F^{\mathrm{V} 600 \mathrm{E}}$

Tabela 34 Distribuição de 93 casos de melanoma cutâneo quanto à fase de crescimento em relação à mutação $B R A F^{\mathrm{V} 600 \mathrm{E}} \ldots . .$.

Tabela 35 Distribuição de 93 casos de melanoma cutâneo quanto ao infiltrado inflamatório peritumoral em relação à mutação $B R A F^{\mathrm{V} 600 \mathrm{E}}$

Tabela 36 Distribuição de 86 casos de melanoma cutâneo quanto ao infiltrado inflamatório intratumoral em relação à mutação $B R A F^{\mathrm{V} 600 \mathrm{E}}$

Tabela 37 Distribuição de 93 casos de melanoma cutâneo quanto à presença de elastose solar em relação à mutação $B R A F^{\vee 600 E}$

Tabela 38 Distribuição de 93 casos de melanoma cutâneo quanto à presença de ulceração em relação à mutação $B R A F^{600 E}$

Tabela 39 Distribuição de 93 casos de melanoma cutâneo quanto à presença de regressão em relação à mutação $B R A F^{\vee V 00 E}$

Tabela 40 Distribuição de 93 casos de melanoma cutâneo quanto à presença de satelitose em relação à mutação BRAF ${ }^{\mathrm{V} 600 \mathrm{E}}$

Tabela 41 Distribuição de 93 casos de melanoma cutâneo quanto à presença de invasão angiolinfática em relação à mutação $B R A F^{\mathrm{V} 600 \mathrm{E}}$

Tabela 42 Distribuição de 93 casos de melanoma cutâneo quanto à presença de infiltração perineural em relação à mutação $B R A F^{V 600 E}$

Tabela 43 Distribuição de 86 casos de melanoma cutâneo invasivo quanto à presença de figuras de mitose no componente intradérmico em relação à mutação $B R A F^{\vee 600 E}$

Tabela 44 Distribuição de 93 casos de melanoma cutâneo quanto à presença de nevo melanocítico associado em relação à mutação $B R A F^{\mathrm{V} 600 \mathrm{E}}$ 
Tabela 45 Distribuição de 50 casos de melanoma cutâneo invasivo quanto ao prognóstico em relação à mutação

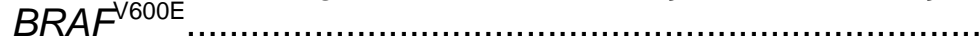

Tabela 46 Principais estudos avaliando o gene $B R A F$ e as frequências encontradas. 


\section{Lista de Figuras}

Figura 1 Esquema das principais vias de sinalização alteradas no

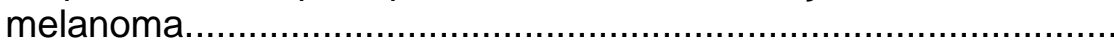

Figura 2 Representação esquemática do receptor KIT e as frequências das mutações descritas em melanoma.

Figura 3 Eventos genéticos associados à progressão de melanócitos normais para melanoma

\section{Lista de Gráficos}

Gráfico 1 Distribuição de 120 casos de melanoma cutâneo, em pacientes com idade entre 18 e 30 anos, em relação à localização anatômica e sexo.

Gráfico 2 Curva de sobrevida geral dos pacientes com melanoma cutâneo invasivo com idade entre 18 e 30 anos.

Gráfico 3 Curva de sobrevida de pacientes com melanoma cutâneo invasivo com idade entre 18 e 30 anos em relação à presença ou não de mutação $B R A F^{1600 E}$ 
Resuma 
Estrozi B. Avaliação anatomoclínica e molecular do melanoma cutâneo em pacientes jovens (idade 18-30 anos) [tese]. São Paulo: Faculdade de Medicina, Universidade de São Paulo; 2013.

A incidência do melanoma cutâneo em pacientes adultos jovens tem aumentado consideravelmente nos últimos anos. Há, contudo, carência de conhecimentos clinicopatológicos e moleculares sobre os melanomas que ocorrem nessa faixa etária. O presente estudo teve por objetivo avaliar 132 casos de melanoma cutâneo primário em pacientes com idade entre 18 e 30 anos, com ênfase no estudo das características clínicas, histopatológicas e avaliação molecular das mutações nos genes BRAF, NRAS e KIT. Em relação aos achados clínicos e histopatológicos, houve predomínio de indivíduos do sexo feminino $(61,4 \%)$, sendo o tronco o sítio anatômico mais comumente envolvido $(44,3 \%)$ e o melanoma extensivo superficial o tipo histológico predominante $(79,5 \%)$. A mutação V600E no gene BRAF $\left(B R A F^{V 600 E}\right)$ foi analisada em 93 casos, utilizando-se a técnica de RT-PCR. Essa mutação foi identificada em 38,7\% (36/93) e, estatisticamente, associada à fase vertical de crescimento $(p=0,01)$, infiltrado inflamatório discreto $(p=0,02)$ e presença de mitose intradérmica $(p=0,004)$. Houve, ainda, forte indício de associação com a presença de ulceração $(p=0,05)$. Todas essas variáveis apresentaram associação com pior prognóstico do melanoma cutâneo. Observou-se predomínio da mutação $B R A F^{\mathrm{V} 600 \mathrm{E}}$ em regiões anatômicas relacionadas à exposição solar intermitente. Nenhum caso de melanoma com fenômeno de regressão apresentou mutação 
$B R A F^{V 600 E}(p<0,05)$. Não houve associação significativa entre $B R A F^{V 600 E} \mathrm{e}$ sexo, tipo histológico, nível de Clark, índice de Breslow, elastose solar, invasão angiolinfática e perineural, satelitose, nevo melanocítico coexistente e sobrevida. A pesquisa de mutações NRAS, pela técnica de RT-PCR, detectou frequência de 3,95\% (3/76). As três mutações encontradas foram do tipo $61 \mathrm{~K}$ e ocorreram em pacientes do sexo masculino e em região de cabeça e pescoço. As mutações $B R A F^{\mathrm{V} 600 \mathrm{E}}$ e $N R A S$, quando presentes, eram mutuamente exclusivas. A frequência de mutações $K I T$, analisadas por sequenciamento, foi de $11,1 \%$ (3/27). As três mutações identificadas estavam localizadas no éxon 9 (G510, G498S e 489I). Houve concomitância de casos com mutação KIT tanto com NRAS, como com BRAF ${ }^{\mathrm{V} 600 \mathrm{E}}$. Devido ao pequeno número de casos com mutação em KIT e NRAS, não foi possível estabelecer correlações clínicas e histopatológicas com esses genes. Este estudo é o primeiro a descrever as mutações G510D e G498S no gene KIT em melanomas cutâneos. No presente estudo, a mutação $B R A F^{\mathrm{V} 600 \mathrm{E}}$, em melanomas cutâneos de adultos jovens, correlacionou-se com características anatomoclínicas de pior prognóstico em relação aos melanomas selvagens para $B R A F^{\mathrm{V} 600 \mathrm{E}}$.

Descritores: 1. Melanoma 2. Neoplasias cutâneas 3. Adulto jovem 4. Proteínas proto-oncogênicas B-raf 5.Proteínas proto-oncogênicas c-kit 6.Proteínas proto-oncogênicas p21(ras) 
Alestract 
Estrozi B. Clinicopathologic and molecular evaluation of cutaneous melanoma in young patients (age 18-30). [thesis]. São Paulo: Faculdade de Medicina, Universidade de São Paulo; 2013.

The incidence of cutaneous melanoma in young adults has dramatically increased in recent years. However, there is scarce data about the clinicopathological and molecular characteristics on the melanomas occurring at this age group. The present study aimed to evaluate 132 patients aged between 18 and 30 years with primary cutaneous melanoma with emphasis on the study of clinical, histopathological characteristics and molecular evaluation of mutations in BRAF, NRAS and KIT genes. Regarding the clinical and histopathological findings, the following results were found: female predominance $(61.4 \%)$, trunk was the most commonly anatomical site involved $(44.3 \%)$ and superficial spreading melanoma, was the most common histological type $(79.5 \%)$. The V600E mutation in $B R A F\left(B R A F^{\mathrm{V} 600 \mathrm{E}}\right)$ gene was analyzed in 93 cases, using RT-PCR. It was present in 38.7\% (36/93) and statistically related to the vertical growth phase $(p=0.01)$, mild inflammatory infiltration $(p=0.02)$ and the presence of intradermal mitosis $(p=0.004)$. There was, also, strongly evidence of an association with the presence of ulceration ( $p$ $=0.05)$. Worse prognosis was associated with these variables. There was a predominance of $B R A F^{\mathrm{V} 600 \mathrm{E}}$ mutation in anatomical regions related to intermittent sun exposure. No cases of melanoma with $B R A F^{\mathrm{V} 600 \mathrm{E}}$ mutation showed regression phenomenon $(p<0.05)$. There was no significant association between $B R A F^{\mathrm{V} 600 \mathrm{E}}$ and gender, histological type, Clark level, Breslow thickness, solar elastosis, angiolymphatic and perineural invasion, 
sattelitosis, coexisting melanocytic nevus and survival. The presence of a mutation in NRAS, by RT-PCR was seen in $3.95 \%(3 / 76)$ of the cases. All these three mutations were of type $61 \mathrm{~K}$, occurred in male patients and the head and neck region. $B R A F^{\mathrm{V} 600 \mathrm{E}}$ and $N R A S$ mutations, when present, were mutually exclusive. The frequency of KIT mutations, analyzed by sequencing, was $11.1 \%$ (3/27). The three mutations identified in this gene were located in exon 9 (G510, G498S and 489I). Concomitant mutations were found between KIT and NRAS and $B R A F^{\mathrm{V} 600 \mathrm{E}}$. Due to the small number of $K I T$ and NRAS mutated cases, it was not possible to establish clinical and histopathological correlations and mutation status in these genes. This study was the first to describe the G510D and G498S mutations in KIT gene in cutaneous melanomas. In the present study, $B R A F^{\mathrm{V} 600 \mathrm{E}}$ mutation in cutaneous melanoma of young adults correlated with anatomic and clinical features of worse prognosis compared to wild type.

Descriptors: 1.Melanoma 2.Skin neoplasms 3.Younf adult 4.Proto-oncogene proteins B-raf 5.Proto-oncogene proteins c-kit 6.Proto-oncogene proteins p21(ras) 


\section{Intraduçãa e Revisãa da Literatura}




\subsection{Melanoma cutâneo: definição, aspectos históricos e situação atual no mundo e no Brasil}

A palavra MELANOMA tem origem grega. Melas significa escuro e o sufixo oma, tumor. Melanoma é uma neoplasia maligna que ocorre mais comumente na pele, embora possa se originar também em outras localizações anatômicas, incluindo mucosa e meninge. O melanoma cutâneo é um tipo de câncer de pele que tem origem provável em melanócitos ou em células totipotentes da camada basal da epiderme, com frequência preferencial em adultos brancos.

Acredita-se que o melanoma tenha sido descrito, pela primeira vez, no século 5 a.C., por Hipócrates, que o descreveu como lesão negra, do tipo herpética (Giblin and Thomas 2007). Em 1806, o inventor do estetoscópio, Renné Theophile Hyacinthe Laennec, descreveu o melanoma como entidade. Em 1812, a denominação melanose foi introduzida pela primeira vez na literatura (Denkler and Johnson 1999).

Em 1820, William Norris publicou o primeiro caso de melanoma na literatura de língua inglesa, com referência a tumor fungoide. Tratava-se de homem de 59 anos que apresentava o que foi descrito como um "sinal" entre o umbigo e o púbis, de cor acastanhada, que, subsequentemente, evoluiu com formação tumoral. Poucos meses após o aparecimento do tumor, surgiram pequenos nódulos ao redor da lesão principal. $\mathrm{O}$ componente 
dominante da lesão foi removido, mas, após seis meses, houve recidiva local e comprometimento sistêmico e o paciente evoluiu para o óbito. O relato de Norris foi importante por ter sido o primeiro manuscrito a levantar a questão da hereditariedade envolvendo a doença, já que o pai do paciente havia falecido, 30 anos antes, com quadro clínico semelhante. Adicionalmente, pai, irmãos e filhos eram também portadores de múltiplos nevos (Silvers and Gorham 1982).

As descrições originais de melanoma da mão, pé, vulva e melanoma metastático para o coração e intestino foram atribuídas a Jean Cruveilhier em publicações entre os anos de 1829 e 1842 (Denkler and Johnson 1999). Em 1838, o termo melanoma foi consagrado por Robert Carswell (Denkler and Johnson 1999).

Embora o câncer de pele seja o mais frequente no Brasil e corresponda a $25 \%$ de todos os tumores malignos registrados no país, o melanoma representa apenas $4 \%$ das neoplasias malignas do órgão, sendo, contudo o mais grave, devido à sua alta possibilidade de metástase. Atualmente, o melanoma representa aproximadamente 4 e $5 \%$ de todos os novos tumores malignos em mulheres e homens e é o sétimo e quinto câncer mais comum nos Estados Unidos da América (EUA), respectivamente, em termos de novos casos estimados para 2014 (American Cancer Society, Surveillance Research, 2014). De acordo com dados do INCA (Instituto Nacional do Câncer), a estimativa de novos casos para 2014, no Brasil, é de 5.890 (2.960 homens e 2930 mulheres), sendo a Região Sul aquela com as maiores taxas estimadas. O número de mortes relacionadas ao melanoma, em 2009, no Brasil, foi de 1.392, sendo 827 homens e 565 mulheres. Saliente-se que esses dados de incidência e de mortalidade no Brasil provavelmente estão subestimados. De acordo com dados 
atuais, as taxas de incidência para o melanoma cutâneo, em caucasianos, elevaram-se mais do que qualquer outra neoplasia maligna nos últimos 30 anos (Giblin and Thomas 2007). Ainda, a taxa de mortalidade por essa neoplasia tem aumentado nos homens, mas é estável e parece estar diminuindo nas mulheres (Jemal, Siegel et al. 2010).

O melanoma maligno tem grande potencial de disseminação e altas taxas de mortalidade quando o diagnóstico é feito tardiamente. Atualmente, a taxa de sobrevida tem melhorado substancialmente, principalmente devido à detecção precoce.

\subsection{Melanoma em crianças, adolescentes e adultos jovens}

Melanoma infantil é definido como aquele que se desenvolve antes do início da puberdade. Da puberdade até 18-20 anos de idade, considera-se melanoma em adolescentes. Melanoma em adultos jovens é aquele que se inicia até os 30 anos de idade. A incidência de melanoma em pacientes pré-púberes é muito baixa, com estimativa de aproximadamente $0,4 \%$ entre todos os casos de melanomas (Boddie, Smith et al. 1978). Em adolescentes, essa incidência é de 2\% (Wu and Lambert 1997) e em pacientes até 30 anos de idade é de 3,3\% (Borbola, Banfalvi et al. 2005). Nos EUA, o melanoma cutâneo é o segundo câncer mais comumente diagnosticado entre os adolescentes e adultos jovens com idade inferior a 30 anos, precedido de linfoma (Bleyer, Viny et al. 2006).

A incidência dessa neoplasia entre os adolescentes e jovens adultos está aumentando nos EUA, no Canadá e em outras partes do mundo onde a 
população é predominantemente caucasiana (Jemal, Devesa et al. 2001; Alston, Rowan et al. 2007; Purdue, Freeman et al. 2008; Weir, Marrett et al. 2011).

Os principais fatores de risco de melanoma em jovens têm sido atribuídos ao número de nevos atípicos, nevos congênitos de grandes dimensões, história familiar de melanoma, xeroderma pigmentoso, imunossupressão, tipo de pele e, ainda, queimaduras solares repetitivas ou graves na infância (LeBoit 2006). tronco é a localização preferencial do melanoma nestas faixas etárias (LeBoit 2006).

As características clínicas são semelhantes ao melanoma em pacientes mais velhos. Livestro et al. (2007) demonstraram que a sobrevida e os fatores prognósticos em pacientes jovens com melanoma eram semelhantes aos dos pacientes-controles idosos, com a mesma espessura tumoral (Livestro, Kaine et al. 2007). Há, ainda, estudos relatando que os pacientes jovens têm um percentual maior de melanomas espessos, tipo histológico nodular e aumento do risco de metástases em linfonodos, em relação aos pacientes mais velhos (Ferrari, Bono et al. 2005; Livestro, Kaine et al. 2007; Moore-Olufemi, Herzog et al. 2011). Esses resultados sugerem que o melanoma pode não ser uma entidade homogênea, sendo possível que em pessoas mais jovens seja doença biologicamente distinta daquela que ocorre em pacientes mais velhos. É possível, ainda, que, devido à raridade desse tumor em faixas etárias menores, ele pode não ser facilmente reconhecido clinicamente, resultando em atraso no tratamento definitivo (Wu and Lambert 1997). 


\subsection{Fatores etiológicos}

Tanto fatores ambientais como familiares têm papel importante na etiologia do melanoma. Entre os fatores familiares/genéticos incluem-se tipo de pele, presença de nevos melanocíticos em grande número, nevos clinicamente atípicos e história familiar de câncer de pele (LeBoit 2006). Dentre os fatores ambientais, a exposição intermitente aos raios ultravioleta é o fator de risco mais importante, especialmente em combinação com fatores endógenos (predisposição genética e peles tipo I e II) (Armstrong and Kricker 1993). Melanomas cutâneos parecem se originar a partir de diferentes vias. Melanomas que acometem cabeça e pescoço apresentam íntima relação à exposição solar crônica, enquanto aqueles que se originam no tronco ocorrem em associação com numerosos nevos melanocíticos (Whiteman, Watt et al. 2003).

O melanoma afeta, predominantemente, pacientes adultos e idosos, com pico de incidência ao redor da sexta década de vida. Contudo, nos últimos anos, essa neoplasia tem sido cada vez mais reconhecida em adultos de meia-idade e jovens, sendo, ainda, observada em crianças e adolescentes (Spatz, Ruiter et al. 1996; Milton, Shaw et al. 1997; Scalzo, Hida et al. 1997; Berk, LaBuz et al. 2010). O melanoma apresenta aspectos clínicos variáveis, dependendo do tipo, estágio de evolução do tumor e localização anatômica. Melanomas podem se originar de novo, isto é, sem evidência de lesão precursora, ou podem se desenvolver em nevo melanocítico preexistente (Okun, Di Mattia et al. 1974; Kaddu, Smolle et al. 2002), sendo nevo melanocítico congênito e nevo displásico os mais comumente associados. O principal sítio de envolvimento, em ambos os sexos, é a face (Franceschi, Levi et al. 1996; Green, McCredie et al. 1999), com 
altas taxas de incidência em dorso e ombros (tronco) nos homens e em membros inferiores nas mulheres.

\subsection{Achados Histológicos}

O conceito de fase radial (horizontal) e fase vertical de crescimento é fundamental para compreensão da classificação histológica dos melanomas cutâneos (Clark, Elder et al. 1989; Barnhill and Mihm 1993). Pela definição atual, fase radial inclui todo melanoma in situ e melanomas com microinvasão da derme papilar. Acredita-se que não há potencial metastático significante no estágio microinvasivo e, consequentemente, está associado a excelente prognóstico. Histologicamente, fase radial microinvasiva é caracterizada pela presença de células isoladas ou pequenos agregados de células de melanoma semelhantes às células do componente in situ, formando ninhos menores do que os ninhos de melanomas presentes na epiderme. Figuras de mitose são, invariavelmente, ausentes. Fase vertical de crescimento é definida como a presença, na derme, de ninhos, placas ou nódulos de células neoplásicas maiores do que aqueles presentes na epiderme e/ou presença de pelo menos uma figura de mitose no componente intradérmico. As células neoplásicas infiltrativas são diferentes daquelas do componente in situ. Crescimento vertical implica em alteração do comportamento biológico com capacidade de invasão angiolinfática e disseminação metastática (Clark, Elder et al. 1989; Barnhill and Mihm 1993). 
De acordo com a Organização Mundial da Saúde (OMS) (2006), os melanomas cutâneos são classificados em quatro tipos principais. A classificação baseia-se nos achados histológicos, localização anatômica e grau de dano actínico para a distinção entre os grupos. Três tipos são definidos com base no padrão de crescimento intraepidérmico (fase radial): melanoma extensivo superficial, lentigo maligno melanoma e melanoma lentiginoso acral. $\mathrm{O}$ quarto tipo, melanoma nodular, é uma categoria à parte, pois não apresenta fase radial significativa.

1. Melanoma extensivo superficial: frequentemente observado em pacientes jovens, ocorrendo em áreas de exposição solar intermitente com prognóstico relativamente favorável. É caracterizado pela proliferação assimétrica de melanócitos geralmente epitelioides, formando ninhos ou dispostos isoladamente em todas as camadas da epiderme, à semelhança da doença de Paget. Ao contrário do lentigo maligno, há poucos danos actínicos visíveis. Desmoplasia e neurotropismo são incomuns.

2. Lentigo maligno melanoma: comum em região de cabeça e pescoço, pacientes idosos, com prognóstico relativamente favorável. É caracterizado pela proliferação de melanócitos atípicos, dispostos ao longo da junção dermoepidérmica. As células neoplásicas apresentam artefatos de retração, com núcleos hipercromáticos e angulados, orientados perpendicularmente à epiderme. Envolvimento de anexos cutâneos é achado característico. Origina-se em localização anatômica de grande exposição solar e, por isso, geralmente a epiderme é atrófica com elastose solar na derme. Quando invasivo (lentigo maligno melanoma), é caracteristicamente multifocal e as células geralmente são fusiformes. Desmoplasia e neurotropismo são frequentemente encontrados 
neste tipo de melanoma. Excepcionalmente, esse tipo de tumor é amelanótico, tanto clinicamente, como histologicamente.

3. Melanoma lentiginoso acral: ocorre nas regiões palmares e plantares e nos leitos ungueais. É o tipo mais comum em pacientes negros. Em estágios iniciais, as alterações são muito sutis, caracterizadas por hiperplasia da epiderme com escassos melanócitos atípicos localizados na camada basal. As células apresentam pleomorfismo nuclear, hipercromasia e artefatos de retração do citoplasma. Observa-se com frequência denso infiltrado inflamatório em banda, na derme. As células do componente invasivo são geralmente fusiformes.

4. Melanoma nodular: tipo de melanoma mais agressivo, apresenta-se como nódulo de crescimento rápido, geralmente com ulceração e sangramento. Frequentemente observado em regiões do corpo com exposição intermitentemente à luz solar. Por definição, não é precedido por fase radial de crescimento, ou seja, desde o início se apresenta em fase vertical. Nesse tipo de melanoma não se encontra proliferação melanocítica intraepidérmica além de três cristas epidérmicas de cada lado do tumor.

\subsection{Indicadores prognósticos}

Os indicadores prognósticos incluem parâmetros clínicos, características morfológicas e medições do tumor.

\subsubsection{Parâmetros clínicos}

Os parâmetros clínicos incluem idade, sexo e localização do tumor primário (Clark, Evans et al. 1991; Zettersten, Shaikh et al. 2003). Pacientes 
idosos têm pior prognóstico do que pacientes jovens e homens têm piores perspectivas de cura do que mulheres (Austin, Cruse et al. 1994; Schuchter, Schultz et al. 1996; Unger, Flaherty et al. 2001; Zettersten, Shaikh et al. 2003). Dorso, membros superiores, pescoço e couro cabeludo são sítios anatômicos de alto risco. A região acral está associada a pior prognóstico.

\subsubsection{Parâmetros histológicos}

- Espessura do tumor (Breslow):

A espessura de Breslow é o indicador prognóstico isolado mais importante. É medida a partir da camada granular até o ponto mais profundo de invasão. Em lesões ulceradas a neoplasia é medida a partir da base da úlcera. De acordo com a American Joint Committee on Cancer (AJCC, 2009), o limiar das espessuras para o estadiamento do melanoma é de 1,00, 2,00 e 4,00 mm (Buzaid, Ross et al. 1997; Balch, Buzaid et al. 2001; Balch, Gershenwald et al. 2009). É considerado melanoma fino aquele no qual a espessura máxima é igual ou menor que $1,00 \mathrm{~mm}$.

- Nível de invasão histológica (nível de Clark):

O nível de invasão do tumor é classificado de acordo com o nível de Clark:

- Nível I: melanoma in situ.

- Nível II: invasão da derme papilar por células neoplásicas isoladas ou pequenos ninhos.

- Nível III: tumor invasivo formando nódulos expansivos na interface da derme reticular.

- Nível IV: invasão da derme reticular. 
- Nível V: invasão de tecido celular subcutâneo.

O nível de Clark fornece informações prognósticas independentes para tumores finos (espessura menor que 1,00 mm), sem valor prognóstico naqueles melanomas espessos (Balch, Soong et al. 2001; Masback, Olsson et al. 2001).

- Ulceração:

A ulceração também é indicador prognóstico independente. A presença de ulceração está associada ao risco significativamente aumentado de metástase. Deve-se excluir, contudo, a ulceração devido a trauma prévio ou perda artefatual da epiderme.

- Infiltrado inflamatório:

Infiltração linfocitária é um fator prognóstico independente. Os melanomas cutâneos mostram graus variados de infiltrado linfocitário, principalmente na fase radial de crescimento, situado ao redor de vasos do plexo superficial ou formando faixa na derme papilar (infiltrado liquenoide). Quando a lesão atinge a fase vertical de crescimento, a densidade do infiltrado tende a diminuir, podendo limitar-se à periferia do tumor (peritumoral). Menos frequentemente, os linfócitos podem penetrar entre as células neoplásicas, caracterizando o infiltrado intratumoral. A intensidade do infiltrado inflamatório peritumoral varia de discreta a intensa nos melanomas, sendo que maior densidade das células inflamatórias está relacionada com menor índice de recidivas. Infiltrado linfocitário denso costuma ser característico de melanomas finos, enquanto a ausência de resposta linfocitária é geralmente observada em melanomas espessos. Em relação aos melanomas que apresentam fase vertical de crescimento, quando os linfócitos penetram o tumor, o prognóstico é mais favorável (Massi, Franchi et al. 
1999). De acordo com Clark, o grau de intensidade do infiltrado inflamatório, nos melanomas em fase vertical, deve ser mencionado no laudo do exame anatomopatológico (Clark, Elder et al. 1989). Na graduação, o termo ausente é utilizado nos casos em que não há infiltrado inflamatório ou naqueles em que o infiltrado é somente peritumoral, ou seja, não infiltra o tumor. Classifica-se como infiltrado inflamatório presente e ativo, quando as células inflamatórias permeiam o tumor em toda a sua base e/ou estão presentes entre as células neoplásicas. Quando os linfócitos são vistos somente em alguns focos da neoplasia, classifica-se o infiltrado inflamatório como presente e inativo.

- Regressão:

Embora a importância dos achados de regressão como determinante de comportamento biológico ainda seja objeto de discussão na literatura, muitos autores consideram que, em melanomas finos (espessura $\leq 1,00 \mathrm{~mm}$ ), esse achado correlaciona-se com pior prognóstico (Sagebiel 1985; Slingluff and Seigler 1992). As características histológicas de regressão são particularmente observadas na derme e incluem ausência ou número reduzido de melanócitos neoplásicos, presença de células apoptóticas e infiltrado inflamatório crônico (Sagebiel 1985; Blessing and McLaren 1992). Em estágios mais avançados, é possível, ainda, identificar melanófagos, ninhos de células tumorais isoladas e vasos telangiectásicos. Clinicamente, esses achados se apresentam como áreas acinzentadas, brancacentas ou rosadas.

- Índice mitótico:

Índice mitótico é determinado pelo número de figuras de mitose $/ \mathrm{mm}^{2}$ em áreas do tumor invasivo onde há maior atividade mitótica. Alguns autores 
acreditam que tumores que apresentam alto índice mitótico estão associados a pior prognóstico (Clark, Elder et al. 1989; Karjalainen, Eskelinen et al. 1998; King, Googe et al. 2000). Outros associam o índice mitótico com a espessura do tumor (Owen, Sanders et al. 2001; Zettersten, Shaikh et al. 2003).

- Satelitose:

Lesão satélite é definida como presença de nódulo medindo $0,05 \mathrm{~mm}$ ou mais de diâmetro, separado da massa tumoral principal. É encontrada em tumores espessos e associada com aumento do risco de recorrência local, metástases para linfonodos regionais e diminuição da sobrevida (Day, Harrist et al. 1981; Leon, Daly et al. 1991). A presença de lesão satélite estadia o tumor como N2c (sem linfonodo sentinela positivo) e N3, quando associado a linfonodo sentinela positivo, pelo sistema de estadiamento de melanomas da AJCC (American Joint Committee on Cancer, 2009), (Balch, Gershenwald et al. 2009).

- Invasão angiolinfática:

A presença de invasão angiolinfática correlaciona-se com desenvolvimento de metástases em trânsito (Leon, Daly et al. 1991). Em alguns estudos, invasão angiolinfática tem se correlacionado com a diminuição da sobrevida (Thorn, Ponten et al. 1994; Straume and Akslen 1996; Kashani-Sabet, Sagebiel et al. 2001; Zettersten, Sagebiel et al. 2002).

- Infiltração perineural:

Infiltração perineural/intraneural é encontrada mais frequentemente em variantes desmoplásicas, respondendo, em parte, pelo aumento do risco de recorrência. 
- Linfonodo sentinela:

A biópsia de linfonodo sentinela soma informações de grande valor prognóstico (Morton, Wen et al. 1992; Gershenwald, Thompson et al. 1999; Cochran, Roberts et al. 2003; Leong 2003). O status do linfonodo sentinela provavelmente representa o fator mais importante em determinar a probabilidade de recorrência do tumor e sobrevida do paciente nos estágios I e II da doença (Gershenwald, Thompson et al. 1999). O valor terapêutico desse procedimento ainda é incerto, mas pode poupar o paciente de ressecções desnecessárias de linfonodos regionais (Leong 2003). Biópsia de linfonodo sentinela é, atualmente, recomendada para todos os tumores com 1,00 $\mathrm{mm}$ ou mais de espessura.

\subsection{Aspectos moleculares}

É notável a ampla variação clínica e histopatológica que os melanomas apresentam. A tentativa de agrupar as lesões melanocíticas em subgrupos biologicamente uniformes, em bases clínicas e morfológicas, apresentou baixo impacto sobre o manejo clínico, em especial nos melanomas metastáticos. Nos últimos anos, dados moleculares passaram a fornecer apoio genético na tentativa de classificar os melanomas em subconjuntos biologicamente distintos (Whiteman, Pavan et al. 2011). Com a valorização da natureza heterogênea das neoplasias melanocíticas há maior chance no progresso do desenvolvimento de terapias e prevenções em relação a essa neoplasia. 


\subsection{Mutações NRAS em melanoma cutâneo}

RAS foi o primeiro oncogene relacionado ao melanoma a ser identificado, sendo o NRAS (neuroblastoma rat sarcoma oncogene) o membro da família RAS mais frequentemente alterado (Albino, Le Strange et al. 1984; Albino, Nanus et al. 1989). Os proto-oncogenes RAS pertencem à superfamília RAS de proteínas de ligação-GTP, envolvidas na regulação de diferentes processos intercelulares, incluindo proliferação e diferenciação celular, geração de oxidase e controle da formação do citoesqueleto (Bokoch and Der 1993). Essa família de proto-oncogenes (HRAS, NRAS e KRAS) codifica proteínas que são estrutural, funcional e imunologicamente semelhantes. Uma vez ativado, o gene RAS estimula diferentes vias efetoras, uma das quais é a via RAF/MEK/ERK (Figura 1). A ativação dos genes RAS tem sido detectada em aproximadamente $20 \%$ dos tumores em seres humanos (Bos 1989). Mutações em KRAS perfazem aproximadamente $85 \%$ de todas as mutações $R A S$, enquanto mutações $N R A S$ são encontradas em, aproximadamente, 15\% e HRAS em menos de $1 \%$ das neoplasias, em geral (Downward 2003). 


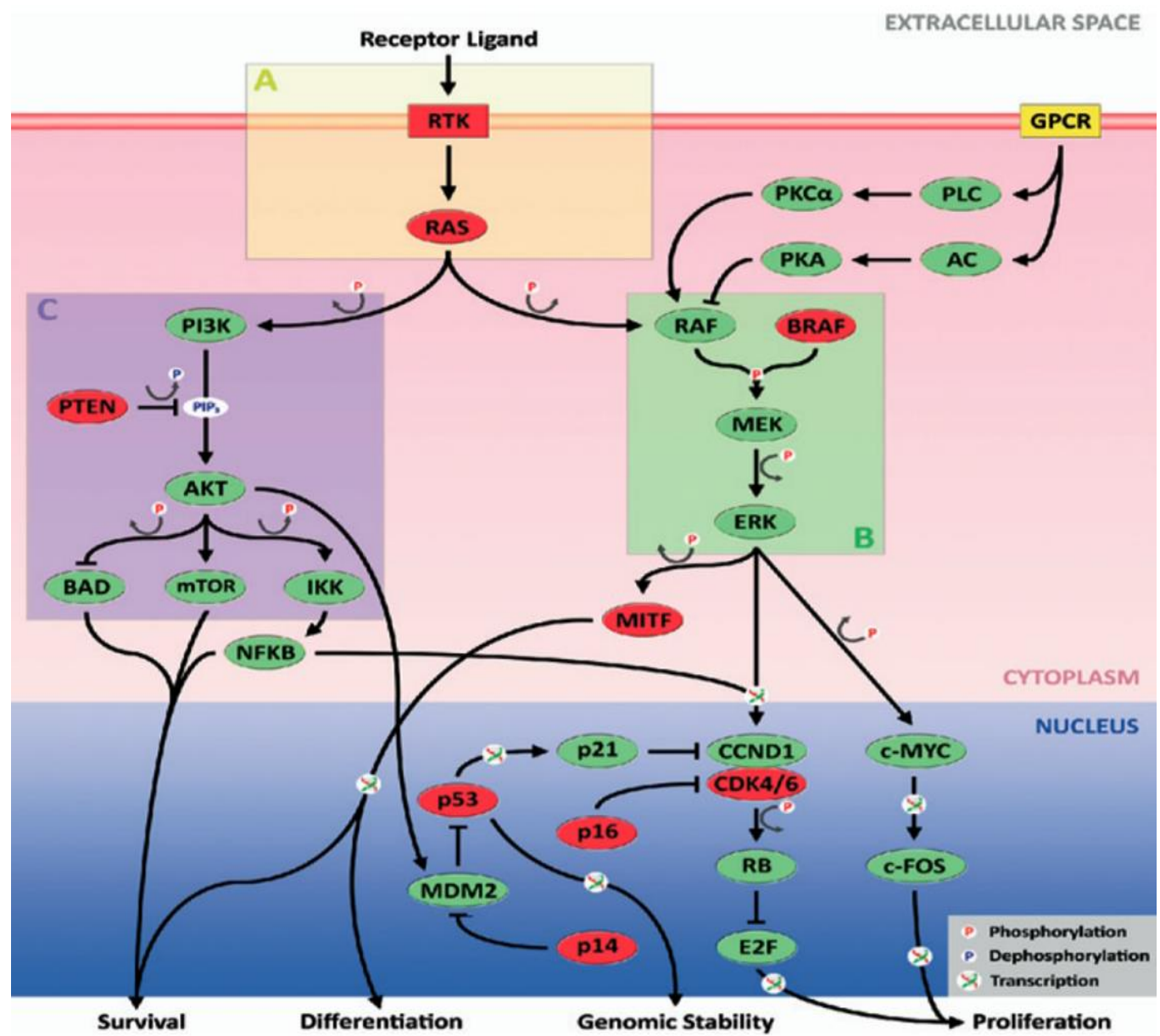

Fonte: Haluska, Pemberton et al., 2007.

Figura 1 - Esquema das principais vias de sinalização alteradas no melanoma. As vias estão concentradas nos compartimentos A, B, e C. (A) RTK/RAS; (B) BRAF/MEK/ERK; (C) PI3K/PTEN/AKT. As moléculas mutadas ou geneticamente anormais são mostradas em vermelho

Mutações envolvendo os genes RAS, principalmente NRAS, foram previamente descritas em melanomas metastáticos e linhagens celulares (Albino, Le Strange et al. 1984; Padua, Barrass et al. 1985; Raybaud, Noguchi et al. 1988). Desde então, grande número de relatos de mutações RAS em melanomas têm sido descritos na literatura. Em geral, os estudos apontam para o códon 61 do gene NRAS como a mutação RAS mais frequente em pacientes com melanoma primário esporádico, com frequência variando entre 4 a $50 \%$. As mutações no códon 61 do gene NRAS mais comumente observadas são Q61R 
(CAA/CGA) e Q61K (CAA/AAA), alterações estas que levam a substituição de glutamina por arginina ou lisina, respectivamente (Platz, Egyhazi et al. 2008). Mutações nos genes HRAS e KRAS, em melanomas cutâneos, são eventos raros.

A correlação do estado mutacional do gene NRAS com as variáveis clínicas do melanoma cutâneo foi primeiramente analisada por van't Veer et al. (1989), que constataram a associação da mutação com a exposição solar contínua (van 't Veer, Burgering et al. 1989). Posteriormente, outros estudos também detectaram a associação entre melanoma maligno NRAS mutado com a exposição solar crônica, sendo as extremidades e a região de cabeça e pescoço os sítios anatômicos mais comumente envolvidos por melanomas cutâneos com tal mutação (Ball, Yohn et al. 1994; van Elsas, Zerp et al. 1995; Edlundh-Rose, Egyhazi et al. 2006; Poynter, Elder et al. 2006; Devitt, Liu et al. 2011; Lee, Choi et al. 2011). Essa associação pode ser explicada devido ao fato do códon 61 do gene NRAS apresentar hotspot para radiação ultravioleta (Lee, Choi et al. 2011). Por outro lado, não foi encontrada por outros autores (Carr and Mackie 1994; Wagner, Ockenfels et al. 1995; Saldanha, Potter et al. 2006).

Estudos apontam que melanomas com mutação em NRAS apresentam uma tendência a ocorrer em pacientes com idades mais avançadas do que os melanomas NRAS selvagem ou com mutações em BRAF (Goel, Lazar et al. 2006; Devitt, Liu et al. 2011; Si, Kong et al. 2012). A presença de mutações NRAS em nevos melanocíticos, principalmente em nevos congênitos, levanta a hipótese de que essas mutações, isoladamente, seriam irrelevantes para a transformação maligna em lesões melanocíticas, sendo necessárias interações 
com outros oncogenes (Carr and Mackie 1994; Omholt, Karsberg et al. 2002; Bauer, Curtin et al. 2007).

Em relação aos parâmetros histopatológicos prognósticos, a maioria dos estudos encontrou correlação entre maior espessura tumoral e mutação em NRAS (Ball, Yohn et al. 1994; Omholt, Karsberg et al. 2002; Edlundh-Rose, Egyhazi et al. 2006). Esse achado reflete a maior porcentagem de mutações no gene NRAS em melanomas do tipo nodular (Jafari, Papp et al. 1995; van Elsas, Zerp et al. 1995; Devitt, Liu et al. 2011; Lee, Choi et al. 2011; Jakob, Bassett et al. 2012). Em estudo recente, houve associação entre a presença de mutação no gene NRAS e maior frequência de ulceração (Si, Kong et al. 2012).

Não houve impacto na sobrevida geral na maioria dos estudos que associaram esse parâmetro com o efeito da mutação $N R A S$, a partir do momento da doença primária (van Elsas, Zerp et al. 1995; Omholt, Karsberg et al. 2002; Akslen, Angelini et al. 2005; Edlundh-Rose, Egyhazi et al. 2006; Ellerhorst, Greene et al. 2011). Porém, em dois estudos em que a sobrevida global foi avaliada a partir de biópsia da doença avançada, mutações NRAS foram associadas com melhor sobrevida, quando comparado com tumores com mutação BRAF ou do tipo selvagem para ambos os genes (Omholt, Platz et al. 2003; Ugurel, Thirumaran et al. 2007). Devitt et al. (2011) publicaram o primeiro estudo mostrando resultados clínicos com menor taxa de sobrevida melanomaespecífica em pacientes com NRAS mutado comparado com o gene selvagem (Devitt, Liu et al. 2011). Posteriormente, Si et al., (2012), em estudo avaliando população asiática, também identificaram menor sobrevida geral em pacientes que apresentavam melanoma NRAS mutado (Si, Kong et al. 2012). 
O oncogene NRAS desempenha um papel central na biologia de melanomas que contêm mutações nesse gene. Embora, atualmente, não existam terapias-alvos direcionadas ao gene NRAS, há uma série de ensaios clínicos promissores sobre como a via de sinalização NRAS pode ser traduzida em novas estratégias terapêuticas (Kelleher and McArthur 2012; Fedorenko, Gibney et al. 2013).

\subsection{Mutações no gene BRAF em melanoma cutâneo}

A possibilidade de avaliar o genoma humano criou oportunidades para a identificação de prováveis genes mutados em cânceres humanos. Sabendo-se da importância da transdução de sinal na regulação do crescimento celular, genes relacionados a essas vias passaram a ser objetos de pesquisa. Seguindo esta lógica, há pouco mais de uma década, Davies et al. (2002) descobriram mutações ativadoras no gene BRAF (Davies, Bignell et al. 2002).

Membro da família RAF (rapidly accelerated fibrosarcoma), o gene BRAF ( V-raf murine sarcoma viral oncogene homolog B1) codifica uma proteína serinatreonina-quinase que atua na via $M A P K$ com transdução de sinais reguladores de $R A S$ para MEK1/2 e, posteriormente, para ERK. Quando ativada, ERK fosforila diferentes alvos citoplasmáticos e nucleares, essenciais para a regulação do ciclo celular. Essa cascata controla a proliferação, diferenciação celular e a apoptose (Figura 1). Em mamíferos, são conhecidas três proteínas RAF: ARAF, BRAF e CRAF (também referida como RAF-1). A proteína BRAF é encontrada principalmente em tecido neural e testicular (Barnier, Papin et al. 
1995). As proteínas $R A F$ diferem na forma em que são ativadas, sendo $B R A F$ a que possui maior atividade basal. Mutações no gene BRAF aumentam significativamente a atividade quinase, induzindo a proliferação celular contínua, favorecendo o crescimento neoplásico (Omholt, Platz et al. 2003). Em melanoma, mutações no gene BRAF são as mais frequentemente encontradas (60-80\%), sendo que mais de $90 \%$ destas envolvem o éxon 15 e são identificadas como transversões T1796A, que modificam o códon selvagem GTG (valina) para GAG (ácido glutâmico) na posição 599 (V599E). Posteriormente, essa mutação foi alterada para $V 600 E$, devido a discrepância de um códon no éxon 1 da sequência do gene BRAF (Davies, Bignell et al. 2002). Essa transversão não é o tipo de mutação comumente relacionada à exposição crônica à radiação ultravioleta, não sendo, portanto, considerada como assinatura ultravioleta (Davies, Bignell et al. 2002; Pollock, Harper et al. 2003). Mutações V600K e V600R também são descritas em melanomas em 6 e 1\%, respectivamente (Ascierto, Kirkwood et al. 2012).

Mutações no gene BRAF são encontradas, em frequência baixa a moderada, em uma variedade de tumores em humanos, incluindo carcinoma colorretal (12\%), tumores borderlines de ovário (14\%) e, com maior frequência, em melanomas (66\%) (Davies, Bignell et al. 2002). Por outro lado, essas mutações também são observadas em um número significante de nevos melanocíticos, sugerindo que, apesar de mutação em BRAF e ativação da via MAPK serem passos cruciais na iniciação da neoplasia melanocítica, eventos moleculares adicionais seriam necessários para a transformação maligna (Dong, Phelps et al. 2003; Pollock, Harper et al. 2003; Lang and MacKie 2005; Saldanha, Potter et al. 2006). 
Estudos correlacionando o estado mutacional do gene BRAF com características clínicas identificaram que melanomas com mutação em $B R A F$ são mais frequentes em sítios de exposição solar intermitente (tronco e extremidades inferiores), ou seja, sem dano solar importante (Lang and MacKie 2005; Poynter, Elder et al. 2006; Liu, Kelly et al. 2007; Platz, Egyhazi et al. 2008; Bauer, Buttner et al. 2011; Ellerhorst, Greene et al. 2011; Si, Kong et al. 2012). Contudo, esse achado não necessariamente indica que mutações no gene $B R A F$ não estejam relacionadas à exposição solar crônica, já que podem ser detectadas em melanomas associados a dano actínico (18,2\%) e que mutações $B R A F$, em lesões melanocíticas, poderiam surgir a partir de danos no DNA induzidos por radiação ultravioleta (Thomas, Berwick et al. 2006). Em relação ao sítio de origem, mutações em BRAF são menos frequentes em melanomas acrais e de mucosa (Curtin, Fridlyand et al. 2005; Platz, Egyhazi et al. 2008). Características clínicas como idade e sexo não apresentam correlação significante com a presença de mutação em BRAF (Omholt, Platz et al. 2003; Saldanha, Potter et al. 2006; Si, Kong et al. 2012).

A associação entre mutação no gene $B R A F$ e prognóstico ainda é pouco estabelecida. A maioria dos estudos não aponta papel relevante da mutação BRAF em relação à sobrevida (Maldonado, Fridlyand et al. 2003; Deichmann, Thome et al. 2004; Shinozaki, Fujimoto et al. 2004; Akslen, Angelini et al. 2005; Edlundh-Rose, Egyhazi et al. 2006; Ellerhorst, Greene et al. 2011). Por outro lado, uma meta-análise recente mostrou aumento do risco de mortalidade em melanomas com mutação BRAF. Em estudo prospectivo demonstrou-se tendência para a diminuição da sobrevida em melanomas com a mutação $B R A F$ e outro estudo, baseado em uma população chinesa, correlacionou a presença 
de mutação BRAF em melanoma com pior sobrevida geral (Devitt, Liu et al. 2011; Safaee Ardekani, Jafarnejad et al. 2012; Si, Kong et al. 2012).

Estudos recentes têm correlacionado aspectos morfológicos do melanoma com o seu estado mutacional. De acordo com esses autores, melanomas com mutação no gene BRAF apresentam as seguintes características histológicas: disseminação pagetoide de melanócitos, formação de ninhos intraepidérmicos, nítida delimitação da neoplasia e espessamento da epiderme (Viros, Fridlyand et al. 2008; Broekaert, Roy et al. 2010). Em resumo, mutações em BRAF são mais comumente encontradas em melanoma do tipo extensivo superficial $(51 \%)$, seguido do tipo nodular (43\%), melanoma acral (15\%) e lentigo maligno melanoma (14\%), em que o padrão de crescimento é predominantemente lentiginoso, com pouca delimitação lateral da neoplasia e ausência de disseminação pagetoide (Curtin, Fridlyand et al. 2005; Liu, Kelly et al. 2007; Platz, Egyhazi et al. 2008).

Há relatos de associação significativa entre melanoma $B R A F$ mutado e nevo melanocítico, apesar de este não estar presente em todos melanomas mutados (Edlundh-Rose, Egyhazi et al. 2006; Poynter, Elder et al. 2006).

Em relação aos parâmetros histopatológicos prognósticos, não houve, na maioria dos estudos, correlação entre espessura tumoral (Breslow) e atividade mitótica com o estado mutacional do gene BRAF (Omholt, Platz et al. 2003; Deichmann, Thome et al. 2004; Shinozaki, Fujimoto et al. 2004; Akslen, Angelini et al. 2005). Por outro lado, poucos estudos demonstraram associação entre melanoma com mutação em $B R A F$, menor espessura tumoral $(<2,0 \mathrm{~mm})$ e baixa atividade mitótica (Goel, Lazar et al. 2006; Liu, Kelly et al. 2007; Devitt, Liu et al. 2011). Correlação entre ulceração e $B R A F$ mutado também foi sugerida por 
alguns autores (Edlundh-Rose, Egyhazi et al. 2006; Ellerhorst, Greene et al. 2011; Si, Kong et al. 2012). Edlundh-Rose et al. (2006) associaram infiltrado linfocitário tumoral moderado a intenso com mutação no gene $B R A F$, sendo que 87\% destas mutações foram $B R A F^{\mathrm{V} 600 \mathrm{E}}$ (Edlundh-Rose, Egyhazi et al. 2006).

\subsection{Mutações do gene KIT em melanoma cutâneo}

Quinases são membros de uma grande família de proteínas que desempenham importante papel no processo de sinalização e controle do crescimento celular (Hanks, Quinn et al. 1988). A proteína KIT (CD117) é uma tirosina quinase transmembrana que atua como receptor para o fator de crescimento de mastócitos, chamado também de fator célula tronco. Ela pertence à família de receptor de quinases tipo III, sendo encontrada em vários tipos de células normais, incluindo células hematopoiéticas, células germinativas, células intersticiais de Cajal, epitélio ductal da mama, mastócitos e melanócitos (Matsuda, Takahashi et al. 1993; Lammie, Drobnjak et al. 1994).

Vários tipos de neoplasias malignas, em humanos, contêm mutações específicas em genes que codificam proteínas quinases e essas mutações, provavelmente, são responsáveis por eventos oncogênicos primários (Corless, Fletcher et al. 2004; Dibb, Dilworth et al. 2004). Mutações nesses genes resultam na produção de uma proteína quinase ativada que não é sensível aos sinais inibitórios habituais. A sinalização constante por essas proteínas estimula a proliferação celular, ativa cascata antiapoptótica e a oncogênese (Houben, Becker et al. 2004; Sordella, Bell et al. 2004; Wan, Garnett et al. 2004). A proteína KIT é comumente ativada por mutações em tumores estromais gastrintestinais (GIST), com a maioria das mutações ocorrendo no éxon 11 do 
gene KIT. A expressão de KIT em neoplasias malignas tem sido de grande interesse por ser um dos alvos de drogas inibidoras de tirosina quinase, como, por exemplo, o imatinibe (STI571, Glivec).

O gene KIT foi descrito pela primeira vez em 1987 por Yarden et al. (1987) (Yarden, Kuang et al. 1987). Estruturalmente, esse gene apresenta cinco domínios: um domínio extracelular de ligação, contendo cinco estruturas imunoglobulina-símiles repetidas, codificado pelos éxons 1 a 9, o domínio transmembrana hidrofóbico, codificado pelo éxon 10, e um segmento intracelular que consiste em um domínio justamembrana, codificado pelo éxon 11 e dois domínios intracelulares de tirosino-quinase, separados por uma região de inserção da quinase, codificadas pelos éxons 12 a 21 (Figura 2) (Woodman and Davies 2010; Postow and Carvajal 2012).

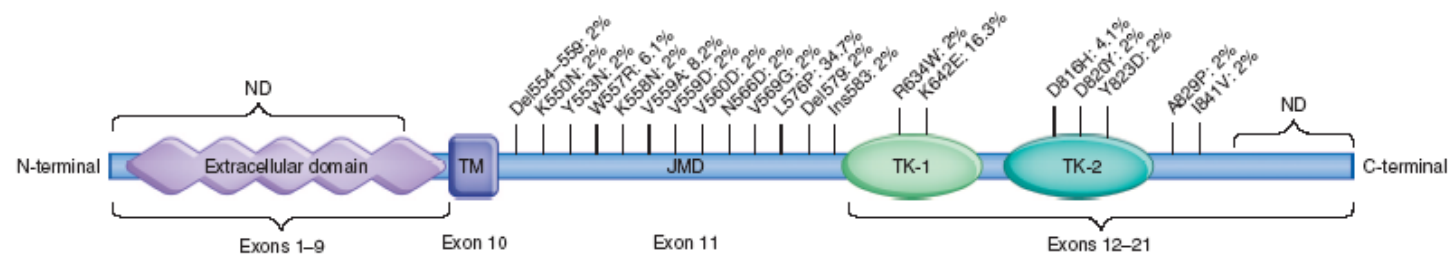

Fonte: Garrido and Bastian 2010.

Figura 2 - Representação esquemática do receptor KIT e as frequências das mutações descritas em melanoma

Cada domínio apresenta uma função distinta. O domínio justamembrana é responsável pela autoinibição do receptor KIT, quando não acoplado ao seu ligante. A ativação ocorre quando há ligação do ligante do KIT ao domínio extracelular do receptor $K I T$, resultando em dimerização. A dimerização resulta na autofosforilação do domínio intracelular de tirosino-quinase (Woodman and Davies 2010; Postow and Carvajal 2012). Com o receptor KIT ativado, iniciam-se 
as sinalizações por várias vias, incluindo as vias $R A F / M E K / E R K, P / 3 K / A K T$ e JAK/STAT (Figura 1).

Em melanomas, as mutações em KIT são mais frequentemente encontradas em mucosa, pele glabra, aparato ungueal e pele associada a dano solar crônico (Curtin, Busam et al. 2006; Beadling, Jacobson-Dunlop et al. 2008; Torres-Cabala, Wang et al. 2009). A prevalência da mutação no gene KIT, em melanomas, varia de acordo com o domínio. Dentre as mutações que envolvem o gene $K I T$, as mutações no éxon 11 ocorrem em maior número (46\%), sendo a mutação L576P a mais frequentemente descrita. Contudo, é importante salientar mutação em KIT é rara dentre os melanomas, presente em menos de $2 \%$ dos casos (Went, Dirnhofer et al. 2004; Willmore-Payne, Holden et al. 2005). O éxon 13 está mutado em, aproximadamente, 19\% dos melanomas com mutação em KIT. Os éxons 17 e 18 estão mutados em 10 e 19\%, respectivamente. Por fim, o éxon 9 é mutado em 6\% dos casos (Figura 2) (Carvajal, Antonescu et al. 2011; Bello, Ariyan et al. 2013).

O primeiro caso de melanoma com mutação em KIT foi descrito por Went et al., (2004), relatando a mutação L576P (éxon 11) em um de dois melanomas sequenciados (Went, Dirnhofer et al. 2004). Em dois estudos relacionados, um total de 3/153 melanomas (primários e metastáticos) apresentaram mutação em KIT, todas no éxon 11, mais especificamente a mutação L576P (Willmore-Payne, Holden et al. 2005; Willmore-Payne, Holden et al. 2006). Nenhum dos casos apresentou mutação no gene $B R A F$, sugerindo que o $K I T$ pode funcionar como um raro e independente oncogene em melanomas.

Curtin et al. (2006), em estudo analisando 102 casos de melanoma, encontraram predomínio de mutações KIT em melanomas de mucosa (39\%), 
melanomas acrais (36\%) e melanomas cutâneos associado à exposição solar crônica (28\%). Observou-se, ainda, maior frequência de padrão lentiginoso entre as neoplasias mutadas. Mutações no éxon 11 (domínio justamembrana) foram as mais frequentemente observadas (Curtin, Busam et al. 2006). Beadling et al., (2008) detectaram mutações KIT em $23 \%$ dos melanomas acrais, $15,6 \%$ dos melanomas de mucosa, $7,7 \%$ dos melanomas conjuntivais, $1,7 \%$ dos melanomas cutâneos e em 0\% dos melanomas de coroide (Beadling, JacobsonDunlop et al. 2008). Handolias et al. (2010) detectaram mutação KIT em 2\% (5/261) dos casos estudados e também relataram predomínio dessa mutação em melanomas acrais, de mucosa e relacionados ao dano solar crônico. Terada (2010) encontrou mutação KIT em um de 12 casos (8\%) de melanoma em uma população japonesa, sendo este um melanoma acral (Terada 2010).

Kong et al. (2011), em uma coorte de população chinesa, avaliaram 502 amostras de melanoma, encontrando frequência de 10,8\% (54) de mutação no gene KIT. Melanomas relacionados ao dano solar crônico foram os que apresentaram maior frequência de mutações $(20,7 \%)$. Em melanomas acrais e melanomas de mucosa, as frequências foram 11,9\% (23/193) e 9,6\% (16/167), respectivamente. Esses autores não encontraram relação entre mutações KIT e idade, sexo, espessura e ulceração, em melanomas cutâneos. Contudo, a sobrevida global dos pacientes com melanomas com mutação KIT foi significativamente menor do que a de pacientes sem alterações genéticas neste gene (Kong, Si et al. 2011).

Na maioria dos estudos avaliando o gene KIT, em melanomas, não houve correlação entre a presença da mutação e a positividade para a proteína KIT (CD117), pelo estudo imuno-histoquímico (Went, Dirnhofer et al. 2004; Willmore- 
Payne, Holden et al. 2005; Beadling, Jacobson-Dunlop et al. 2008; TorresCabala, Wang et al. 2009).

Tumores estromais gastrintestinais (GIST) que possuem mutação no éxon 11 do gene KIT são sensíveis ao tratamento com mesilato de imatinibe. Dessa forma, o KIT tornou-se um oncogene importante em melanoma, principalmente devido a possibilidade de benefício com terapia-alvo em casos que apresentam mutação no éxon 11 (Curtin, Busam et al. 2006).

Embora rara, a incidência do melanoma cutâneo em pacientes jovens tem aumentado. A literatura carece de informações sobre melanomas que ocorrem nessa faixa etária (18-30 anos), incluindo os aspectos etiológico, molecular, comportamento biológico e apresentação clínica. Alguns raros estudos sugerem que pacientes jovens podem apresentar pior evolução clínica, com recorrências precoces em comparação aos idosos. Esse eventual comportamento clínico mais agressivo levanta a hipótese de que o melanoma pode não ser uma entidade biologicamente homogênea.

A recente identificação de alterações genéticas relacionadas ao desenvolvimento e progressão do melanoma, dentre elas as mutações nos genes BRAF, NRAS e KIT, apoiam o conceito de tipos biologiamente distintos dessa neoplasia. A escassez de estudos moleculares e sua correlação clínica em melanomas cutâneos na população jovem é o principal fator de motivação deste estudo. 
2. Clijetivas 


\subsection{Objetivo geral}

Avaliar as características clínicas, morfológicas e moleculares, em relação aos genes $B R A F$, NRAS e KIT, em espécimes cirúrgicos de melanomas cutâneos primários em pacientes adultos jovens, com idade entre 18 e 30 anos.

\subsection{Objetivos específicos}

1. Estabelecer a frequência de mutações dos genes $B R A F, N R A S$ e KIT em melanomas cutâneos em população de adultos jovens;

2. Correlacionar a presença dessas mutações com fatores clínicos (localização anatômica, sexo e sobrevida);

3. Correlacionar a presença dessas mutações com achados anatomopatológicos e fatores prognósticos histológicos (tipo histológico, nível de Clark, índice de Breslow, presença de mitose no componente intradérmico, ulceração, regressão, satelitose, invasão angiolinfática, invasão perineural, elastose solar, infiltrado inflamatório peri e intratumoral e nevo melanocítico associado). 
3. Material e Métada 


\subsection{Aprovação institucional da pesquisa}

O presente estudo foi aprovado pelo Comitê Científico do Departamento de Patologia da Faculdade de Medicina da Universidade de São Paulo (São Paulo-SP) e pela Comissão de Ética para Análise de Projetos de Pesquisa (CAPPesq) de Diretoria Clínica do Hospital das Clínicas e da Faculdade de Medicina da Universidade de São Paulo (São Paulo-SP), sob o Protocolo de Pesquisa número 149/12 (vide Anexo).

\subsection{Seleção da amostra}

\subsubsection{Critérios de inclusão}

A amostra estudada foi composta por 132 espécimes cirúrgicos de lesões primárias de pacientes de ambos os sexos, na faixa etária entre 18 e 30 anos, diagnosticados com melanoma cutâneo entre o período 1995 a 2012 (17 anos), provenientes de dois laboratórios de patologia distintos: Laboratório Bacchi/Consultoria em Patologia (68 casos), de Botucatu-SP, e Instituto de Patologia (64 casos), de Passo Fundo-RS.

\subsubsection{Critérios de exclusão}

Foram excluídos do estudo os casos que apresentavam apenas lesões metastáticas, pacientes com idade inferior a 18 anos ou superior a 30 anos na época do diagnóstico e casos com anatomopatológico incompatível ou duvidoso para o diagnóstico de melanoma, após a revisão histopatológica. 


\subsection{Coleta das variáveis clínicas e anatomopatológicas}

Neste trabalho, foram avaliadas as seguintes variáveis clínicas e anatomopatológicas.

\subsubsection{Variáveis clínicas}

Por meio da revisão dos pedidos clínicos ou contato por telefone/email foram tabulados os seguintes dados clínicos:

- Idade;

- Sexo;

- Localização anatômica da lesão;

- Evolução clínica;

- Data do último contato ou data do óbito.

Em relação à localização anatômica, os casos foram classificados em: cabeça/pescoço, tronco, membros superiores e membros inferiores.

Em relação à evolução clínica, os casos foram divididos em:

- Evolução favorável: paciente vivo, sem evidência de melanoma ou óbito por outras causas;

- Evolução desfavorável: paciente vivo com evidência de melanoma (recidiva local, regional ou metástases à distância) ou óbito pela doença.

O período de seguimento dos pacientes variou de três a 222 meses. 


\subsubsection{Variáveis anatomopatológicas}

As lâminas dos casos selecionados foram revisadas por pelo menos um patologista (Dra. Bruna Estrozi, Dr. Carlos E. Bacchi e Dr. Rubens Rodriguez) para a confirmação diagnóstica de melanoma, baseado nos critérios descritos pela Organização Mundial de Saúde (LeBoit 2006). Para os casos com interpretações discordantes, em relação ao relatório original, um consenso foi determinado pela análise simultânea sob um microscópio de duas cabeças (Dra. Bruna Estrozi e Dr. Carlos E. Bacchi). Novos cortes histológicos foram obtidos a partir de blocos de parafina e corados com hematoxilina e eosina (H\&E), quando necessário.

Foram revistas as seguintes características histológicas:

- Tipo histológico (extensivo superficial, nodular, lentiginoso acral, lentigo maligno e inclassificável);

- Nível de Clark (I a V);

- Índice de Breslow (espessura máxima da lesão em mm);

- Fase de crescimento tumoral (radial ou vertical);

- Figuras de mitose no componente intradérmico (presente ou ausente);

- Regressão;

- Satelitose;

- Invasão angiolinfática;

- Infiltração perineural; 
-Infiltrado inflamatório peritumoral (ausente, discreto, moderado e intenso);

-Infiltrado inflamatório intratumoral (ausente, presente e inativo, presente e ativo);

- Elastose solar;

- Nevo melanocítico associado.

\subsection{Análise molecular}

\subsubsection{Isolamento do DNA e viabilidade do material genético}

O DNA foi extraído a partir de amostras fixadas em formalina e incluídas em parafina. A partir dos blocos de parafina, cortes foram corados por hematoxilina-eosina (HE). As lâminas coradas foram analisadas por um patologista e uma região representativa do tumor (> $40 \%$ de células tumorais) foi demarcada com caneta de retroprojeção. A lâmina com a área marcada foi utilizada para delimitar a área tumoral no bloco de parafina, o qual foi macrodissecado manualmente e submetido à extração de DNA. O material foi submetido à digestão enzimática com Proteinase $\mathrm{K}^{\circledast}$ em solução tamponada a $10 \%$ a $54^{\circ} \mathrm{C}$ em incubação overnight. Após a inativação da enzima ( $94^{\circ} \mathrm{C}$ durante 12 minutos), as amostras de DNA foram quantificadas em 260/280 nm e diluídas para uma concentração padronizada de 50ng/ $\mathrm{LL}$.

Para a avaliação da qualidade e integridade do material extraído foi realizada a amplificação por PCR de sequências-referências definidas pelo 
protocolo BIOMED-2 (van Dongen, Langerak et al. 2003), contendo oligonucleotídeos (iniciadores) para os genes TBXAS1 (gene da tromboxano sintetase humana), RAG1 (gene de ativação de recombinação humana), PLZF (gene do "dedo de zinco" da leucemia promielocítica) e dois éxons do gene $A F 4$, que amplificam 100,200,300, 400 e 600 pb respectivamente. Aqueles casos que apresentaram DNA adequadamente preservado prosseguiram com os estudos moleculares.

\subsubsection{Detecção de mutação BRAF ${ }^{\mathrm{V} 600 \mathrm{E}}$}

O DNA obtido foi amplificado com iniciadores específicos para a mutação-alvo V600E do gene $B R A F\left(B R A F^{V 600 E}\right)$ utilizando ensaios TaqMan $^{\circledR}$ (Applied Biosystem, Foster City, EUA) para análise por discriminação alélica no equipamento de PCR em tempo real (7500 fast PCR System, Applied Biosystems). TaqMan ${ }^{\circledR}$ é um sistema composto por sondas (fragmento de DNA marcado que hibridiza com outra molécula de DNA) e iniciadores utilizados para detectar sequências específicas nos fragmentos de DNA. Essa sonda apresenta em uma extremidade um fluoróforo e, em outra, um quencher (molécula que absorve a energia do fluoróforo). Os produtos da reação são detectados pela fluorescência gerada após a atividade exonuclease da enzima Taq polimerase. Durante a amplificação, a sonda $\operatorname{TaqMan}^{\circledR}$ hibridiza com a sequência da fita simples de DNA complementar e durante a extensão a sonda é degradada separando o quencher. A separação do fluoróforo do quencher resulta em um aumento da intensidade da fluorescência. Durante o processo de amplificação a emissão 
de luz aumenta de forma exponencial. Esse aumento da fluorescência ocorre apenas quando a sonda hibridiza e quando a amplificação da sequência-alvo é estabelecida.

As amostras de DNA foram amplificadas em reações com volume final igual a $15 \mu \mathrm{L}$, utilizando $\operatorname{TaqMan}^{\circledR}$ Universal PCR Master Mix (Applied Biosystems) e Custom TaqMan $^{\circledR}$ SNP Genotyping Assay (Applied Biosystems), que inclui sondas e iniciadores marcados com as fluorescências VIC e FAM, utilizadas para a detecção do alelo selvagem e alelo mutante, respectivamente (Tabela 1). A amplificação foi realizada por 40 ciclos, sendo $93^{\circ} \mathrm{C}$ por 15 segundos para a desnaturação, seguido de $60^{\circ} \mathrm{C}$ por um minuto para o anelamento dos pares de bases em suas sequências complementares e extensão. 
Tabela 1 - Descrição das sequências dos iniciadores e das sondas utilizadas na deteç̧ão da mutação V600E no gene $B R A F$

\begin{tabular}{ccc}
\hline Sondas e iniciadores & Sequência & Amplificação \\
\hline Sondas & & \\
BRAF_Wild-type & VIC-5'-CTAGCTACAGTGAAATC-3'-NQF & $71 \mathrm{pb}$ \\
BRAF_V600E_mutation & FAM-5'-TAGCTACAGAGAAATC-3'-NQF & \\
Iniciadores & & \\
BRAF_éxon15_Foward & 5'-CATGAAGACCTCACAGTAAAAATAGGTGAT-3' \\
BRAF_éxon15_Reverse & 5'-TGGGACCCACTCCATCGA-3' & $71 \mathrm{pb}$
\end{tabular}




\subsubsection{Detecção das mutações no gene NRAS}

Para a pesquisa de mutações no gene NRAS foram utilizados os ensaios de mutação-alvo $\operatorname{TaqMan}^{\circledR}$ Mutation Detection Assay. A reação é baseada em PCR competitiva alelo-específica (competitive allele-specific $\operatorname{TaqMan}^{\circledR} \mathrm{PCR}$ - cast $\left.\mathrm{PCR}{ }^{\mathrm{TM}}\right)$. A reação é altamente específica, pois a detecção do alelo mutante é baseada em uma sequência de primer alelo específica, enquanto o alelo selvagem é suprimido por um oligonucleotídeo bloqueador. Foram avaliadas as seguintes mutações do gene NRAS, Q61K, Q61L e Q61R, utilizando os ensaios identificados como NRAS_580_mu, NRAS 583 mu e NRAS 584 mu, respectivamente, comercializados pela empresa Applied Biosystems (Applied Biosystem, Foster City, EUA). As amostras de DNA foram amplificadas em reações com volume final igual a $15 \mu \mathrm{L}$, utilizando TaqMan ${ }^{\circledR}$ Universal PCR Master Mix (Applied Biosystems) e TaqMan® Mutation Detection Assay (Applied Biosystems) em termociclador 7500 fast PCR System, Applied Biosystems. A amplificação foi realizada por 40 ciclos, sendo $93^{\circ} \mathrm{C}$ por 15 segundos para a desnaturação, seguido de 60 ${ }^{\circ} \mathrm{C}$ por um minuto para $\mathrm{o}$ anelamento dos pares de bases em suas sequências complementares e extensão.

\subsubsection{Detecção de mutações KIT}

As amostras foram submetidas à PCR para a amplificação dos éxons 9,11 , 13 e 17 do gene KIT. As amostras de DNA foram amplificadas em reações com volume final igual a $25 \mu \mathrm{L}$. A DNA polimerase utilizada foi U Platinum Taq polimerase e a reação foi realizada em termociclador MJ Research PTC-200 (Global Medical Instrumentation, Ramsey, EUA), com 
desnaturação inicial a $94{ }^{\circ} \mathrm{C}$ por três minutos, seguida por 44 ciclos de desnaturação a $94 \stackrel{\circ}{\mathrm{C}}$ por 30 segundos, anelamento dos oligonucleotídeos a $54 \stackrel{\circ}{\circ}$ por 20 segundos e extensão a $72 \stackrel{\circ}{\circ}$ por 30 segundos. A amplificação dos éxons foi realizada utilizando as sequências de oligonucleotídeos descritas por Corless et al. (2002) (Tabela 2).

Tabela 2 - Descrição das sequências dos iniciadores utilizados na amplificação dos éxons $9,11,13$ e 17 do gene $K I T$

\begin{tabular}{lcc}
\hline \multicolumn{1}{c}{ Éxons do gene KIT } & Sequência & Amplificação \\
\hline KIT_éxon 9_Foward & 5'-ATGCTCTGCTTCTGTACTGCC-3' & 238pb \\
KIT_éxon 9_Reverse & 5'-CAGAGCCTAAACATCCCCTTA-3' & \\
KIT_éxon 11_Foward & 5'-CCAGAGTGCTCTAATGACTG-3' & 236pb \\
KIT_éxon 11_Reverse & 5'-ACCCAAAAAGGTGACATGGA-3' & \\
KIT_éxon 13_Foward & 5'-CATCAGTTTGCCAGTTGTGC-3' & 174pb \\
KIT_éxon 13_Reverse & 5'-ACACGGCTTTACCTCCAATG-3' & \\
KIT_éxon 17_Foward & 5'-TGTATTCACAGAGACTTGGC-3' & 218pb \\
KIT_éxon 17_Reverse & 5'-GGATTTACATTATGAAAGTCACAGG-3' & \\
\hline
\end{tabular}

O DNA amplificado foi submetido à eletroforese em gel de poliacrilamida a 7\%. Com base no sucesso da amplificação das amostrascontroles e tamanho dos produtos, os casos em estudo foram submetidos ao sequenciamento direto. Os produtos foram sequenciados em ambas as direções utilizando-se BigDye ${ }^{\circledR}$ Terminator v3.1 (Applied Biosystems, Foster City, EUA). O sequenciamento foi realizado no equipamento ABI PRISM ${ }^{\circledR}$ 3130 (Applied Biosystem, Foster City, EUA) e a análise das sequências obtidas foi efetuada por inspeção visual e com o software Mutation Surveyor v.2.2 (SoftGenetics, State College, EUA). 


\subsection{Análise estatística}

Foi realizada a análise descritiva de todas as variáveis pesquisadas. Para as variáveis discretas foi levantada a distribuição de frequências e para as quantitativas (idade e medida de Breslow), as médias e desvios.

$\mathrm{Na}$ avaliação de nível de espessura (medida de Breslow), empregamos a técnica de análise de variância - ANOVA -, com emprego da estatística F-Fischer. A mesma técnica foi empregada na comparação das médias das idades por sexo.

Para avaliação do efeito do sexo em relação à localização do melanoma e a mutação do gene $B R A F$ foram elaboradas tabelas de contingência (dupla entrada) e a associação foi avaliada por meio da estatística Qui-quadrado de Pearson.

A avaliação da sobrevida para subgrupos definidos foi feita por meio da criação de tábuas de vida e determinação das curvas de sobrevida. O teste comparativo das curvas foi elaborado através da metodologia de Kaplan \& Meier, usando a estatística de Breslow.

O nível de significância adotado em todos os testes foi de $5 \%$, sendo que, para todas as estatísticas observadas, o valor do nível descritivo-p foi calculado e apresentado no texto. 
4. Resultados 


\subsection{Descrição geral dos resultados das variáveis clínicas, anatomopatológicas e moleculares}

A amostra deste estudo foi constituída por 132 pacientes com melanoma cutâneo primário na faixa etária entre 18 e 30 anos (média de 25,9 anos). Em 15 (11,3\%) pacientes, houve relato de alteração de cor e/ou simetria da lesão. Em um caso, houve alteração no crescimento em nevo pré-existente durante o período gestacional. Em 20 casos com histórico familiar, quatro pacientes relataram melanoma em parentes (dois em avós e dois em tios). Houve um caso de melanoma que se originou em nevo melanocítico gigante.

\subsubsection{Distribuição quanto ao sexo e idade}

A amostra dividiu-se em 81 (61,4\%) pacientes do sexo feminino e 51 $(38,6 \%)$ do sexo masculino, numa proporção de 1,5 mulheres para cada homem. A idade média dos pacientes do sexo feminino foi de 26,36 (mediana 28) e de 25,31 (mediana 26) no sexo masculino (Tabela 3). 
Tabela 3 - Distribuição de 132 casos de melanoma cutâneo, em pacientes com idade entre 18 e 30 anos, em relação ao sexo

\begin{tabular}{cccc}
\hline Sexo & N & $\%$ & Idade média (mediana) \\
\hline Feminino & 81 & 61,4 & $26,36(28)$ \\
Masculino & 51 & 38,6 & $25,31(26)$ \\
Total & 132 & 100,0 & $25,9(27)$ \\
\hline
\end{tabular}

4.1.2. Distribuição quanto à localização anatômica da lesão primária

Informação sobre o sítio primário foi obtida em 120 dos 132 casos. O tronco foi a localização mais comum, ocorrendo em 53 casos $(44,3 \%)$, seguido de membros inferiores (34 casos; $28,3 \%$ ). No sexo masculino, a neoplasia foi encontrada mais frequentemente no tronco $(45,8 \%)$, seguido de cabeça/pescoço $(27,1 \%)$, enquanto que no sexo feminino, tronco $(43,1 \%)$ e membros inferiores $(36,1 \%)$, nesta ordem, foram os sítios anatômicos mais comuns. A distribuição da localização anatômica, geral, ou seja, em ambos os sexos, dos 120 casos está representada na Tabela 4.

Tabela 4 - Distribuição de 120 casos de melanoma cutâneo, em pacientes com idade entre 18 e 30 anos, em relação à localização anatômica em ambos os sexos

\begin{tabular}{ccc}
\hline Localização & N & $\%$ \\
\hline Tronco & $\mathbf{5 3}$ & $\mathbf{4 4 , 2}$ \\
\hline Membros inferiores & 34 & 28,3 \\
\hline Membros superiores & 17 & 14,2 \\
Cabeça/pescoço & 16 & 13,3 \\
\hline Total & 120 & 100,0 \\
\hline
\end{tabular}




\subsection{Descrição das variáveis histopatológicas}

\subsubsection{Tipos histológicos}

Melanoma extensivo superficial foi o tipo histológico mais comum, encontrado em 105 casos (79,5\%), incluindo 11 casos de melanoma in situ. Melanoma nodular foi observado em 23 casos (17,5\%), melanoma lentiginoso acral em dois casos $(1,5 \%)$ e dois casos $(1,5 \%)$ foram inclassificáveis (Tabela 5). Não houve caso de lentigo maligno melanoma.

Tabela 5 - Distribuição de 132 casos de melanoma cutâneo, em pacientes com idade entre 18 e 30 anos, em relação ao tipo histológico

\begin{tabular}{ccc}
\hline Tipo Histológico & N & $\%$ \\
\hline Extensivo superficial & 105 & 79,5 \\
Nodular & 23 & 17,5 \\
\hline Lentiginoso acral & 2 & 1,5 \\
\hline Não classificável & 2 & 1,5 \\
Total & 132 & 100,0 \\
\hline
\end{tabular}

\subsubsection{Distribuição quanto aos níveis de Clark}

A maioria dos casos apresentou nível II de Clark (48,5\%), seguido do nível III (31,1\%). A distribuição quanto aos níveis de Clark se encontra na Tabela 6. 
Tabela 6 - Distribuição de 132 casos de melanoma cutâneo, em pacientes com idade entre 18 e 30 anos, em relação aos níveis de Clark

\begin{tabular}{ccc}
\hline Nível de Clark & N & $\%$ \\
\hline I & 11 & 8,3 \\
II & 64 & 48,5 \\
III & 41 & 31,1 \\
IV & 13 & 9,8 \\
V & 3 & 2,3 \\
Total & 132 & 100,0 \\
\hline
\end{tabular}

\subsubsection{Distribuição quanto à espessura tumoral (Breslow)}

A espessura nos melanomas invasivos variou de 0,2 a $11,5 \mathrm{~mm}$ (média de 1,65 $\pm 1,31 \mathrm{~mm}$ ). A média da espessura de Breslow foi maior no sexo masculino $(2,06 \mathrm{~mm})$ em relação ao sexo feminino $(1,17 \mathrm{~mm})$. A distribuição dos casos, em relação à medida de Breslow, preconizada pela AJCC (American Joint Committee on Cancer, 2009), está demonstrada na Tabela 7.

Tabela 7 - Distribuição de 132 casos de melanoma cutâneo, em pacientes com idade entre 18 e 30 anos, em relação à espessura de Breslow

\begin{tabular}{ccc}
\hline Espessura de Breslow & $\mathbf{N}$ & $\%$ \\
\hline In situ & 11 & 8,3 \\
$\mathbf{0 , 1 - 1 , 0 ~} \mathbf{~ m m}$ & 68 & 51,5 \\
$\mathbf{1 , 0 1 - 2 , 0 ~} \mathbf{m m}$ & 23 & 17,4 \\
$\mathbf{2 , 0 1}$ a 4,0 $\mathbf{~ m m}$ & 22 & 16,7 \\
$\mathbf{>} 4,0 \mathbf{m m}$ & 8 & 6,1 \\
Total & 132 & 100,0 \\
\hline
\end{tabular}




\subsubsection{Distribuição quanto à fase de crescimento}

A maioria dos pacientes apresentou-se em fase de crescimento vertical. A Tabela 8 apresenta a distribuição em relação à fase de crescimento tumoral.

Tabela 8 - Distribuição de 132 casos de melanoma cutâneo, em pacientes com idade entre 18 e 30 anos, em relação à fase de crescimento

\begin{tabular}{ccc}
\hline Fase de crescimento & N & $\%$ \\
\hline Vertical & 78 & 59,1 \\
Radial & 54 & 40,9 \\
Total & 132 & 100,0 \\
\hline
\end{tabular}

\subsubsection{Distribuição quanto à presença de ulceração}

A maioria dos casos não apresentou sinais de ulceração. A distribuição dos casos, em relação à presença ou não de ulceração, pode ser observada na Tabela 9.

Tabela 9 - Distribuição de 132 casos de melanoma cutâneo, em pacientes com idade entre 18 e 30 anos, em relação à presença de ulceração

\begin{tabular}{ccc}
\hline Ulceração & $\mathbf{N}$ & $\%$ \\
\hline Não & 104 & 78,8 \\
Sim & 28 & 21,2 \\
Total & 132 & 100,0 \\
\hline
\end{tabular}


4.2.6. Distribuição quanto à presença de figura de mitose no componente intradérmico nos casos de melanoma cutâneo invasivo

A presença de pelo menos uma figura de mitose no componente intradérmico foi encontrada em $56,2 \%$ dos casos (Tabela 10).

Tabela 10 - Distribuição de 121 casos de melanoma cutâneo invasivo, em pacientes com idade entre 18 e 30 anos, em relação à presença de figuras de mitose no componente intradérmico

\begin{tabular}{ccc}
\hline $\begin{array}{c}\text { Figura de mitose no } \\
\text { componente } \\
\text { intradérmico }\end{array}$ & N & $\%$ \\
\hline Presente & 68 & 56,2 \\
Ausente & 53 & 43,8 \\
Total & 121 & 100,0 \\
\hline
\end{tabular}

4.2.7. Distribuição quanto à presença de invasão angiolinfática

A distribuição dos casos em relação à presença de invasão angiolinfática apresenta-se na Tabela 11.

Tabela 11 - Distribuição de 132 casos de melanoma cutâneo, em pacientes com idade entre 18 e 30 anos, em relação à presença de invasão angiolinfática

\begin{tabular}{ccc}
\hline Invasão angiolinfática & N & $\%$ \\
\hline Ausente & 129 & 97,7 \\
Presente & 3 & 2,3 \\
Total & 132 & 100,0 \\
\hline
\end{tabular}


4.2.8. Distribuição quanto à presença de infiltração perineural

A distribuição dos casos em relação à presença de infiltração perineural apresenta-se na Tabela 12

Tabela 12 - Distribuição de 132 casos de melanoma cutâneo, em pacientes com idade entre 18 e 30 anos, em relação à presença de infiltração perineural

\begin{tabular}{ccc}
\hline Infiltração perineural & $\mathbf{N}$ & $\%$ \\
\hline Ausente & 129 & 97,7 \\
Presente & 3 & 2,3 \\
Total & 132 & 100,0 \\
\hline
\end{tabular}

4.2.9. Distribuição quanto à presença de elastose solar

A presença de elastose solar foi observada em apenas três casos (Tabela 13).

Tabela 13 - Distribuição de 132 casos de melanoma cutâneo, em pacientes com idade entre 18 e 30 anos, em relação à presença de elastose solar

\begin{tabular}{ccc}
\hline Elastose solar & N & $\%$ \\
\hline Presente & 3 & 2,3 \\
Ausente & 129 & 97,7 \\
Total & 132 & 100,0 \\
\hline
\end{tabular}


4.2.10. Distribuição quanto à presença de satelitose

A maioria dos casos não apresentou satelitose (Tabela 14).

Tabela 14 - Distribuição de 132 casos de melanoma cutâneo, em pacientes com idade entre 18 e 30 anos, em relação à presença de satelitose

\begin{tabular}{ccr}
\hline Satelitose & N & $\%$ \\
\hline Ausente & 130 & 98,5 \\
Presente & 2 & 1,5 \\
Total & 132 & 100,0 \\
\hline
\end{tabular}

4.2.11. Distribuição quanto à intensidade do infiltrado inflamatório peritumoral

A maioria dos casos (56\%) apresentou infiltrado inflamatório peritumoral discreto, como consta na Tabela 15.

Tabela 15 - Distribuição de 132 casos de melanoma cutâneo, em pacientes com idade entre 18 e 30 anos, em relação à intensidade do infiltrado inflamatório peritumoral

\begin{tabular}{ccc}
\hline Infiltrado inflamatório peritumoral & $\mathbf{N}$ & $\%$ \\
\hline Ausente & 7 & 5,3 \\
Discreto & 74 & 56 \\
Moderado & 44 & 33,4 \\
Intenso & 7 & 5,3 \\
Total & 132 & 100,0 \\
\hline
\end{tabular}


4.2.12. Distribuição quanto à intensidade do infiltrado inflamatório intratumoral

Em relação aos 121 casos de melanoma invasivo, a frequência quanto ao infiltrado inflamatório intratumoral está relatada na tabela abaixo.

Tabela 16 - Distribuição de 121 casos de melanoma cutâneo, em pacientes com idade entre 18 e 30 anos, em relação à intensidade do infiltrado inflamatório intratumoral

\begin{tabular}{ccc}
\hline $\begin{array}{c}\text { Infiltrado inflamatório } \\
\text { intratumoral }\end{array}$ & N & $\%$ \\
\hline Ausente & 48 & 39,7 \\
Presente e inativo & 52 & 43 \\
Presente e ativo & 21 & 17,3 \\
Total & 121 & 100,0 \\
\hline
\end{tabular}

4.2.13. Distribuição quanto à presença de nevo melanocítico associado

$25(18,9 \%)$ casos de melanoma apresentaram nevo melanocítico associado (Tabela 17).

Tabela 17 - Distribuição de 132 casos de melanoma cutâneo, em pacientes com idade entre 18 e 30 anos, em relação à presença de nevo melanocítico

\begin{tabular}{ccc}
\hline Nevo melanocítico & $\mathbf{N}$ & $\%$ \\
\hline Ausente & 107 & 81,1 \\
Presente & 25 & 18,9 \\
Total & 132 & 100,0 \\
\hline
\end{tabular}




\subsubsection{Mutações em NRAS}

Blocos de parafina de 102 casos foram disponíveis para a avaliação das mutações Q61R, Q61L, Q61K no gene NRAS, códon 2, éxon 61. A amplificação falhou em 26 desses casos, devido à má qualidade do DNA. Do material amplificado com sucesso (76 casos), foram observados três casos com mutação no gene NRAS. As três mutações encontradas foram do tipo Q61K (Tabela 18). Os três pacientes eram do sexo masculino, em região de cabeça e pescoço. Dois casos apresentaram ulceração. As espessuras tumorais foram $0,6,4,0$ e 5,5 mm. Todos esses três casos apresentaram $B R A F^{\mathrm{V} 600 \mathrm{E}}$ selvagem (Tabela 19).

Tabela 18 - Distribuição de 76 casos de melanoma cutâneo, em pacientes com idade entre 18 e 30 anos, em relação à presença de mutação no gene NRAS

\begin{tabular}{cccc}
\hline Mutação NRAS & Positivo (N) & Negativo (N) & Total $(\mathbf{N})$ \\
\hline Q61R & 0 & 76 & 76 \\
Q61L & 0 & 76 & 76 \\
Q61K & 3 & 76 & 76 \\
\hline
\end{tabular}


Tabela 19 - Mutações do gene NRAS em três casos de melanomas em pacientes jovens

\begin{tabular}{|c|c|c|c|c|c|c|c|c|c|c|c|}
\hline Referência & Idade & Sexo & Local & $\begin{array}{c}\text { Breslow } \\
(\mathrm{mm})\end{array}$ & $\begin{array}{c}\text { E. } \\
\text { solar }\end{array}$ & Clark & $\begin{array}{c}\text { Tipo } \\
\text { histológico }\end{array}$ & Ulceração & $\underset{\text { V600E }}{\text { BRAF }}$ & NRAS & $K I T$ \\
\hline CB 3468/09 & 18 & M & $\mathrm{CP}$ & 0,6 & Não & II & ES & Sim & Selvagem & Mut. $61 \mathrm{~K}$ & Mut. V489I \\
\hline
\end{tabular}

E. solar: Elastose solar, F. crescimento: Fase de crescimento, M: masculino, CP: cabeça e pescoço, NC: não classificável, ES: extensivo superficial, NR: não realizado, Mut.: mutação. 


\subsubsection{Mutação BRAF ${ }^{\mathrm{V} 600 \mathrm{E}}$}

Blocos de parafina estavam disponíveis para a análise molecular em 112 casos. A amplificação do DNA foi obtida, com sucesso, em 93 casos (86 melanomas invasivos e sete melanomas in situ). A mutação V600E no éxon 15 do gene $B R A F\left(B R A F^{\mathrm{V} 600 \mathrm{E}}\right)$ foi encontrada em 36 casos $(38,7 \%): 24$ de $59(40,7 \%)$ pacientes do sexo feminino e 12 de 34 (35,3\%) do sexo masculino. A tabela 20 mostra a distribuição dos casos em relação à presença da mutação $B R A F^{\mathrm{V} 600 \mathrm{E}}$.

Tabela 20 - Distribuição de 93 casos de melanoma cutâneo, em pacientes com idade entre 18 e 30 anos, em relação à presença da mutação $B R^{-\mathrm{V} 600 \mathrm{E}}$

\begin{tabular}{ccc}
\hline Mutação $^{B_{R A} \boldsymbol{F}^{\mathrm{VG00E}}}$ & $\mathbf{N}$ & $\%$ \\
\hline Selvagem & 57 & 61,3 \\
Mutado & 36 & 38,7 \\
Total & 93 & 100,0 \\
\hline
\end{tabular}

\subsubsection{Mutações em KIT}

102 blocos de parafina foram disponíveis para a análise molecular do gene KIT. A amplificação do DNA foi obtida com sucesso em 27 casos. A Tabela 21 descreve a avaliação das mutações do KIT nos éxons 9, 11, 13 e 17. Saliente-se, conforme demonstrado, que em alguns casos não foi possível realizar avaliação mutacional em todos os quatro éxons. A mutação KIT foi detectada em três casos, sendo dos seguintes tipos: G498S, G510D e V489I, todas localizadas no éxon 9. Dois casos eram do sexo feminino, ambos com 28 anos de idade, localizados em membro inferior e tronco. $\mathrm{O}$ terceiro caso foi encontrado em homem, 18 anos, em região de cabeça e pescoço. Em um caso houve mutação concomitante com gene NRAS e outro com BRAF (Tabela 22). 
Tabela 21 - Distribuição dos casos 32 de melanoma cutâneo, em pacientes com idade entre 18 e 30 anos, em relação à presença da mutação no gene KIT

\begin{tabular}{|c|c|c|c|c|}
\hline Referência & Éxon 9 & Éxon 11 & Éxon 13 & Éxon 17 \\
\hline CB 23823/09 & Selv. & Selv. & Selv. & Selv. \\
\hline CB 27892/10 & Mutado G498S & Selv. & Selv. & Selv. \\
\hline CB 172/11 & Selv. & Selv. & Selv. & Selv. \\
\hline CB 8029/12 & Selv. & Selv. & Selv. & Selv. \\
\hline CB $8683 / 12$ & Selv. & Selv. & Selv. & Selv. \\
\hline CB 13355/12 & Selv. & Selv. & Selv. & Selv. \\
\hline CB 20108/12 & Selv. & Selv. & Selv. & Selv. \\
\hline RR 26731/09 & Selv. & Selv. & Selv. & Selv. \\
\hline RR 16540/08 & Selv. & Selv. & Selv. & Selv. \\
\hline CB 8978/12 & Selv. & Selv. & Selv. & Selv. \\
\hline SP 5835/10 & Selv. & Selv. & Selv. & Selv. \\
\hline CB 19321/12 & Selv. & Selv. & Selv. & Selv. \\
\hline CB 18525/12 & Selv. & Selv. & Selv. & Selv. \\
\hline RR 1441/12 & Selv. & Selv. & Selv. & Selv. \\
\hline RR 26016/08 & Selv. & NA & Selv. & Selv. \\
\hline RR 6137/11 & Selv. & NA & Selv. & Selv. \\
\hline RR 17231/11 & Selv. & NA & Selv. & Selv. \\
\hline RR 16347/11 & Selv. & NA & Selv. & Selv. \\
\hline RR 6235/09 & Mutado G510D & NA & Selv. & Selv. \\
\hline CB 9080/01 & Selv. & NA & Selv. & NA \\
\hline CB 3468/09 & Mutado V489I & NA & Selv. & NA \\
\hline CB 29607/10 & Selv. & NA & Selv. & NA \\
\hline RR 1399/12 & Selv. & Selv. & NA & Selv. \\
\hline RR 6624/10 & Selv. & NA & NA & NA \\
\hline RR $3211 / 10$ & Selv. & NA & NA & NA \\
\hline RR 19016/10 & Selv. & NA & NA & NA \\
\hline RR 2664/12 & Selv. & NA & NA & NA \\
\hline
\end{tabular}

Selv: selvagem, NA: não amplificado. 
Tabela 22 - Mutações do gene KIT em três casos de melanomas em pacientes jovens

\begin{tabular}{|c|c|c|c|c|c|c|c|c|c|c|}
\hline Referência & Idade & Sexo & Local & $\begin{array}{c}\text { Breslow } \\
(\mathrm{mm})\end{array}$ & $\begin{array}{l}\text { Elastose } \\
\text { solar }\end{array}$ & Clark & $\begin{array}{c}\text { Tipo } \\
\text { histológico }\end{array}$ & KIT & $\underset{V 600 E}{B R A F}$ & NRAS \\
\hline CB 3468/09 & 18 & $M$ & $\mathrm{CP}$ & 0,6 & Não & II & ES & $\begin{array}{c}\text { Mutado } \\
\text { V489l }\end{array}$ & Selvagem & $\begin{array}{l}\text { Mutado } \\
61 \mathrm{~K}\end{array}$ \\
\hline CB 27892/10 & 28 & $\mathrm{~F}$ & Tronco & 1,65 & Não & III & ES & $\begin{array}{l}\text { Mutado } \\
\text { G498S }\end{array}$ & Selvagem & Selvagem \\
\hline RR09-6235 & 28 & $\mathrm{~F}$ & MMII & 0,5 & Não & II & ES & $\begin{array}{l}\text { Mutado } \\
\text { G510D }\end{array}$ & Mutado & Selvagem \\
\hline
\end{tabular}

M: masculino, F: Feminino, CP: cabeça e pescoço, MMII: membros inferiores, ES: extensivo superficial. 
4.3. Correlação entre as variáveis clínicas, histopatológicas e moleculares

\subsubsection{Sexo e idade}

O teste comparativo das médias de idade teve estatística $F=2,284$, com $p=0,133$, indicando que não houve diferença significativa entre os sexos (Tabela 23).

Tabela 23 - Distribuição de 132 casos de melanoma cutâneo quanto ao sexo em relação à idade

\begin{tabular}{cccc}
\hline Sexo & Idade média & Desvio & N \\
\hline Masculino & 25,31 & 3,61 & 51 \\
Feminino & 26,26 & 3,43 & 81 \\
Total & 25,89 & 3,51 & 132 \\
\hline
\end{tabular}

$p=0,133$

\subsubsection{Sexo e localização anatômica}

O teste de associação teve estatística igual a $\chi^{2}=16,445$ com $p<$ 0,001, evidenciando associação significativa entre a localização anatômica dos melanomas e o sexo dos pacientes. Pode-se notar maior frequência de melanoma cutâneo da região de cabeça e pescoço no sexo masculino $(27,1 \%)$ em comparação ao sexo feminino (4,2\%). (Tabela 24 e Gráfico 1). 
Tabela 24 - Distribuição de 120 casos de melanoma cutâneo quanto ao sexo em relação à localização anatômica

\begin{tabular}{ccccccc}
\hline Localização & \multicolumn{2}{c}{ Feminino } & \multicolumn{2}{c}{ Masculino } & \multicolumn{2}{c}{ Total } \\
\hline Cabeça/pescoço & $\mathrm{N}$ & $\%$ & $\mathrm{~N}$ & $\%$ & $\mathrm{~N}$ & $\%$ \\
MMSS & 3 & 4,2 & 13 & 27,1 & 16 & 13,3 \\
MMII & 12 & 16,6 & 5 & 10,4 & 17 & 14,2 \\
Tronco & 26 & 36,1 & 8 & 16,7 & 34 & 28,3 \\
Total & 31 & 43,1 & 22 & 45,8 & 53 & 44,2 \\
\hline
\end{tabular}

$p<0,001$

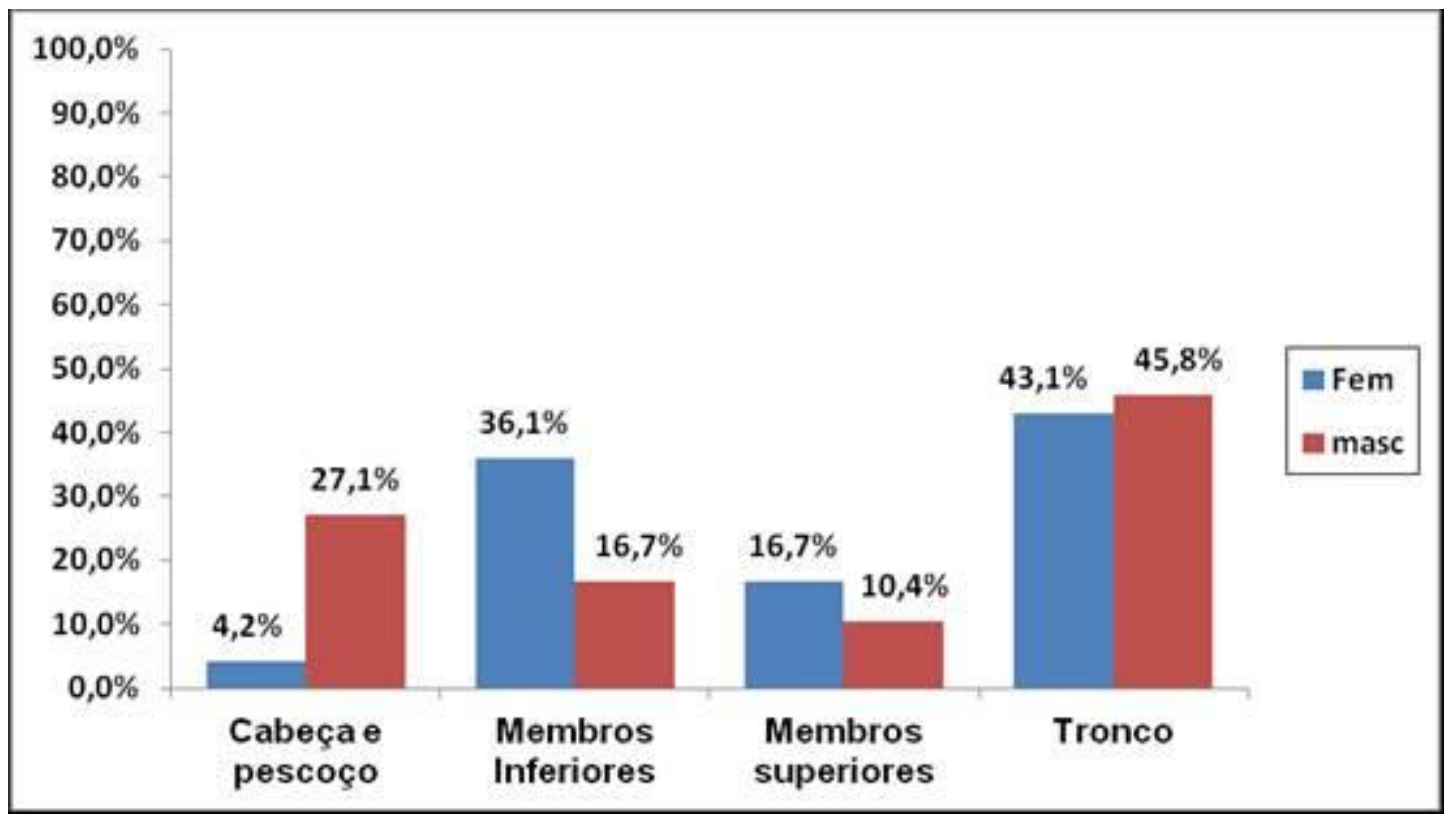

Gráfico 1 - Distribuição de 120 casos de melanoma cutâneo, em pacientes com idade entre 18 e 30 anos, em relação à localização anatômica e sexo

\subsubsection{Sexo e espessura tumoral (Breslow)}

Não houve diferença entre as classes da medida da espessura tumoral e o sexo. Contudo, quando avaliada a média da espessura tumoral, pacientes do sexo masculino apresentaram espessura média significativamente maior do que pacientes do sexo feminino $(p=0,018)$. As distribuições dos sexos em relação à espessura tumoral (Breslow) e espessura média estão relacionadas nas Tabelas 25 e 26. 
Tabela 25 - Distribuição de 132 casos de melanoma cutâneo quanto ao sexo em relação à espessura tumoral (Breslow)

\begin{tabular}{ccccc}
\hline Breslow & \multicolumn{2}{c}{ Feminino } & \multicolumn{2}{c}{ Masculino } \\
\hline in situ & $\mathrm{N}$ & $\%$ & $\mathrm{~N}$ & $\%$ \\
até $\mathbf{1 , 0} \mathbf{~ m m}$ & 7 & 8,65 & 4 & 7,85 \\
$\mathbf{1 , 0 1 - 2 , 0 ~} \mathbf{~ m m}$ & 48 & 59,25 & 20 & 39,22 \\
$\mathbf{2 , 0 1 - 4 , 0 ~} \mathbf{~ m m}$ & 13 & 16,05 & 10 & 19,60 \\
$>\mathbf{4 , 0} \mathbf{~ m m}$ & 3 & 12,35 & 12 & 23,53 \\
Total & 81 & 3,70 & 5 & 9,80 \\
\hline
\end{tabular}

$p=0,141$

Tabela 26 - Distribuição de 132 casos de melanoma cutâneo quanto ao sexo em relação à espessura média

\begin{tabular}{cccc}
\hline Sexo & Espessura média & Desvio & $\begin{array}{c}\text { Número de } \\
\text { casos }\end{array}$ \\
\hline Masculino & 2,06 & 2,408 & 51 \\
Feminino & 1,17 & 1,246 & 81 \\
Total & 1,51 & 1,83 & 132 \\
\hline
\end{tabular}

$p=0,018$

\subsubsection{Sexo e nível de Clark}

O teste de associação teve estatística igual a $\chi^{2}=4,812$ com $p=$ 0,307, ou seja, não foi evidenciada associação significativa entre o nível de Clark e o sexo dos pacientes. A comparação entre sexo e nível de Clark está detalhada na Tabela 27. 
Tabela 27 - Distribuição de 132 casos de melanoma cutâneo quanto ao sexo em relação ao nível de Clark

\begin{tabular}{crrrrrr}
\hline Nível de Clark & \multicolumn{2}{c}{ Feminino } & \multicolumn{2}{c}{ Masculino } & \multicolumn{2}{c}{ Total } \\
\hline & $\mathrm{N}$ & $\%$ & $\mathrm{~N}$ & $\%$ & $\mathrm{~N}$ & $\%$ \\
I & 7 & 8,6 & 4 & 7,8 & 11 & 8,3 \\
II & 43 & 53,1 & 21 & 41,2 & 64 & 48,5 \\
III & 25 & 30,9 & 16 & 31,4 & 41 & 31,1 \\
IV & 5 & 6,2 & 8 & 15,7 & 13 & 9,8 \\
V & 1 & 1,2 & 2 & 3,9 & 3 & 2,3 \\
Total & 81 & 100,0 & 51 & 100,0 & 132 & 100,0 \\
\hline
\end{tabular}

$p=0,307$

\subsection{Relação entre mutação $B R A F^{V 600 E} e$ as variáveis clínico-patológicas}

4.4.1. $\mathrm{BRAF}^{\mathrm{V} 600 \mathrm{E}}$ e seXO

Em relação ao sexo, a mutação $B R A F^{V 600 E}$ esteve presente em $35,3 \%$ dos pacientes do sexo masculino e em $40,7 \%$, no sexo feminino. $O$ teste de associação teve estatística igual a $\chi^{2}=0,085$, com $p=0,770$, indicando que a distribuição da mutação $B R A F^{\sqrt{600}}$ pode ser considerada independente do sexo (Tabela 28).

Tabela 28 - Distribuição de 93 casos de melanoma cutâneo quanto ao sexo em relação à mutação $B R A F^{V 600 E}$

\begin{tabular}{crrrr}
\hline Sexo & \multicolumn{2}{c}{$\boldsymbol{B R A F}^{\text {V600E }}$} & Total \\
\hline & & Mutado & Selvagem & \\
Feminino & $\mathrm{N}$ & 24 & 35 & 59 \\
& $\%$ & 66,7 & 61,4 & 63,4 \\
\hline Masculino & $\mathrm{N}$ & 12 & 22 & 34 \\
& $\%$ & 33,3 & 38,6 & 36,6 \\
\hline Total & $\mathrm{N}$ & 36 & 57 & 93 \\
& $\%$ & 100,0 & 100,0 & 100,0 \\
\hline
\end{tabular}

$p=0,770$ 


\subsection{2. $\mathrm{BRAF}^{\mathrm{V} 600 \mathrm{E}}$ e sítio anatômico}

Em relação aos sítios anatômicos, houve uma tendência dos melanomas de cabeça e pescoço a não apresentarem a mutação $B R A F^{V 600 E}$ (Tabela 29).

Tabela 29 - Distribuição de 84 casos de melanoma cutâneo quanto à localização anatômica em relação à mutação $B R A F^{V 600 E}$

\begin{tabular}{crrrr}
\hline Sítio anatômico & \multicolumn{3}{c}{ BRAF $^{\text {V600E }}$} & Total \\
\hline Cabeça/pescoço & $\mathrm{N}$ & 2 & 12 & \\
& $\%$ & 6,5 & 22,6 & 14 \\
\hline Membros inferiores & $\mathrm{N}$ & 11 & 13 & 24 \\
& $\%$ & 35,5 & 24,5 & 28,6 \\
\hline Membros superiores & $\mathrm{N}$ & 5 & 4 & 9 \\
\hline Tronco & $\%$ & 16,1 & 7,5 & 10,7 \\
& $\mathrm{~N}$ & 13 & 24 & 37 \\
\hline Total & $\%$ & 41,9 & 45,3 & 44,0 \\
& $\mathrm{~N}$ & 31 & 53 & 84 \\
& $\%$ & 100,0 & 100,0 & 100,0 \\
\hline
\end{tabular}

$p=0,128$

\subsection{3. $\mathrm{BRAF}^{\mathrm{V} 600 \mathrm{E}}$ e tipo histológico}

De 74 casos de melanoma extensivo superficial, a mutação foi detectada em 26 (35,1\%). Em relação ao tipo nodular, dez (58,8\%) de 17 casos apresentaram a mutação. O teste de associação teve estatística igual a $\chi^{2}=4,561$, com $p=0,207$. Não foi evidenciada associação significativa entre a mutação $B R A F^{V 600 E}$ e o tipo histológico (Tabela 30). 
Tabela 30 - Distribuição de 93 casos de melanoma cutâneo quanto o tipo histológico em relação à mutação $B R A F^{V 600 E}$

\begin{tabular}{crrrr}
\hline Tipo histológico & \multicolumn{2}{c}{ BRAF $^{\text {V600E }}$} & Total \\
\hline \multirow{2}{*}{ Extensivo superficial } & $\mathrm{N}$ & Mutado & Selvagem & \\
& $\%$ & 72,2 & 48 & 74 \\
\hline Nodular & $\mathrm{N}$ & 10 & 84,2 & 79,6 \\
\hline Acral & $\%$ & 27,8 & 12,3 & 17 \\
& $\mathrm{~N}$ & 0 & 1 & 18,3 \\
\hline Não classificável & $\%$ & 0,0 & 1,8 & 1,1 \\
\hline & $\mathrm{N}$ & 0 & 1 & 1 \\
\hline Total & $\%$ & 0,0 & 1,8 & 1,1 \\
& $\mathrm{~N}$ & 36 & 57 & 93 \\
\hline & $\%$ & 100,0 & 100,0 & 100,0 \\
\hline
\end{tabular}

$p=0,207$

4.4.4. $\mathrm{BRAF}^{\mathrm{V} 600 \mathrm{E}}$ e nível de Clark

O teste de associação entre $B R A F^{V 600 E}$ e nível de Clark teve estatística igual a $\chi^{2}=3,041$, com $p=0,551$, não havendo associação significativa entre as duas variáveis (Tabela 31). 
Tabela 31 - Distribuição de 93 casos de melanoma cutâneo quanto ao nível de Clark em relação à mutação $B R A F^{V 600 E}$

\begin{tabular}{|c|c|c|c|c|}
\hline \multirow[t]{2}{*}{ Nível de Clark } & & \multicolumn{2}{|c|}{$B R A F^{V 600 E}$} & \multirow[t]{2}{*}{ Total } \\
\hline & & Mutado & Selvagem & \\
\hline \multirow[t]{2}{*}{ I } & $\mathrm{N}$ & 1 & 6 & 7 \\
\hline & $\%$ & 2,8 & 10,5 & 7,5 \\
\hline \multirow[t]{2}{*}{ II } & $\mathrm{N}$ & 19 & 29 & 48 \\
\hline & $\%$ & 52,8 & 50,9 & 51,6 \\
\hline \multirow[t]{2}{*}{ III } & $\mathrm{N}$ & 12 & 13 & 25 \\
\hline & $\%$ & 33,3 & 22,8 & 26,9 \\
\hline \multirow[t]{2}{*}{ IV } & $N$ & 3 & 7 & 10 \\
\hline & $\%$ & 8,3 & 12,3 & 10,8 \\
\hline \multirow[t]{2}{*}{ v } & $\mathrm{N}$ & 1 & 2 & 3 \\
\hline & $\%$ & 2,8 & 3,5 & 3,2 \\
\hline \multirow[t]{2}{*}{ Total } & $\mathrm{N}$ & 36 & 57 & 93 \\
\hline & $\%$ & 100,0 & 100,0 & 100,0 \\
\hline
\end{tabular}

$p=0,551$

\subsection{5. $\mathrm{BRAF}^{\mathrm{V} 600 \mathrm{E}} e$ índice de Breslow}

Em relação à espessura tumoral, dos 36 casos mutados, 19 (52,8\%) apresentaram medida $\leq 1,0 \mathrm{~mm}$. $O$ teste de associação teve estatística $\chi^{2}=$ 2,838 , com $p=0,417$, ou seja, não foi evidenciada associação significativa entre a mutação $B R A F^{V G 00 E}$ e o índice de Breslow (Tabela 32). Quando os casos foram divididos em melanomas finos $(\leq 1,0 \mathrm{~mm})$ e melanomas grossos (> 1,01 mm), também não houve associação estatística significante $\left(\chi^{2}=0,897\right.$ com $\left.p=0,344\right)$ (Tabela 33). 
Tabela 32 - Distribuição de 93 casos de melanoma cutâneo quanto à medida de Breslow em relação à mutação $B R A F^{v 600 E}$

\begin{tabular}{|c|c|c|c|c|}
\hline \multirow[t]{2}{*}{ Breslow } & & \multicolumn{2}{|c|}{$B R A F^{V 600 E}$} & \multirow[t]{2}{*}{ Total } \\
\hline & & Mutado & Selvagem & \\
\hline \multirow[t]{2}{*}{$\leq 1,0$} & $N$ & 19 & 37 & 56 \\
\hline & $\%$ & 52,8 & 64,9 & 60,2 \\
\hline \multirow[t]{2}{*}{$1,01-2,0$} & $\mathrm{~N}$ & 5 & 9 & 14 \\
\hline & $\%$ & 13,9 & 15,8 & 15,1 \\
\hline \multirow[t]{2}{*}{$2,01-4,0$} & $N$ & 7 & 8 & 15 \\
\hline & $\%$ & 19,4 & 14,0 & 16,1 \\
\hline \multirow[t]{2}{*}{$>4,0$} & $\mathrm{~N}$ & 5 & 3 & 8 \\
\hline & $\%$ & 13,9 & 5,3 & 8,6 \\
\hline \multirow[t]{2}{*}{ Total } & $\mathrm{N}$ & 36 & 57 & 93 \\
\hline & $\%$ & 100,0 & 100,0 & 100,0 \\
\hline
\end{tabular}

$\mathrm{p}=0,417$

Tabela 33 - Distribuição de 93 casos de melanoma cutâneo quanto à espessura em relação à mutação $B R A F^{V 600 E}$

\begin{tabular}{|c|c|c|c|c|}
\hline \multicolumn{2}{|l|}{ Breslow } & \multicolumn{2}{|c|}{$B_{R A F^{V 600 E}}$} & \multirow[t]{2}{*}{ Total } \\
\hline & & Mutado & Selvagem & \\
\hline \multirow[t]{2}{*}{$\leq 1,0 \mathrm{~mm}$ (fino) } & $\mathrm{N}$ & 19 & 37 & 56 \\
\hline & $\%$ & 52,8 & 64,9 & 60,2 \\
\hline \multirow{2}{*}{$>1,0 \mathrm{~mm}$ (grosso) } & $\mathrm{N}$ & 17 & 20 & 37 \\
\hline & $\%$ & 47,2 & 35,1 & 39,8 \\
\hline \multirow[t]{2}{*}{ Total } & $\mathrm{N}$ & 36 & 57 & 93 \\
\hline & $\%$ & 100,0 & 100,0 & 100,0 \\
\hline
\end{tabular}

$p=0,344$ 


\subsection{6. $\mathrm{BRAF}^{\mathrm{V} 600 \mathrm{E}}$ e fase de crescimento}

$75 \%$ dos casos mutados apresentaram-se em fase vertical de crescimento. $O$ teste de associação teve estatística igual a $\chi^{2}=6,919$, com $p$ $=0,009$, indicando haver associação significativa entre a mutação $B R A F^{V 600 E}$ e a fase de crescimento vertical (Tabela 34).

Tabela 34 - Distribuição de 93 casos de melanoma cutâneo quanto à fase de crescimento em relação à mutação $B R A F^{V G 00 E}$

\begin{tabular}{crrrr}
\hline Fase de crescimento & \multicolumn{2}{c}{ BRAF $^{\text {V600E }}$} & Total \\
\hline \multirow{2}{*}{ Radial } & $\mathrm{N}$ & Mutado & Selvagem & \\
& $\%$ & 9 & 30 & 39 \\
Vertical & $\mathrm{N}$ & 25,0 & 52,6 & 41,9 \\
& $\%$ & 75,0 & 27 & 54 \\
Total & $\mathrm{N}$ & 36 & 47,4 & 58,1 \\
& $\%$ & 100,0 & 57 & 93 \\
& & & 100,0 & 100,0 \\
\hline
\end{tabular}

$p=0,009$

\subsection{7. $\mathrm{BRAF}^{\mathrm{V} 600 \mathrm{E}}$ e infiltrado inflamatório peritumoral}

A distribuição do infiltrado inflamatório peritumoral está relatada na Tabela 35. Houve diferença estatisticamente significante entre os tipos de infiltrado inflamatório e a mutação $B R A F^{V 600 E}$ apresentando o infiltrado discreto maior número de casos mutados. 
Tabela 35 - Distribuição de 93 casos de melanoma cutâneo quanto ao infiltrado inflamatório peritumoral em relação à mutação BRAF ${ }^{V 600 E}$

\begin{tabular}{crrrr}
\hline $\begin{array}{c}\text { Infiltrado inflamatório } \\
\text { peritumoral }\end{array}$ & & \multicolumn{2}{c}{$\boldsymbol{B R A F}^{\mathbf{V 6 0 0 E}}$} & Total \\
\hline Ausente & $\mathrm{N}$ & Mutado & Selvagem & \\
\hline & $\%$ & 0,0 & 4 & 4 \\
Discreto & $\mathrm{N}$ & 27 & 7,0 & 4,3 \\
& $\%$ & 75,0 & 49,1 & 55 \\
Moderado & $\mathrm{N}$ & 8 & 20 & 59,1 \\
& $\%$ & 22,2 & 35,1 & 30,1 \\
Intenso & $\mathrm{N}$ & 1 & 5 & 6 \\
& $\%$ & 2,8 & 8,8 & 6,5 \\
Total & $\mathrm{N}$ & 36 & 57 & 93 \\
& $\%$ & 100,0 & 100,0 & 100,0 \\
\hline
\end{tabular}

$p=0,029$

4.4.8. $\mathrm{BRAF}^{\mathrm{V} 600 \mathrm{E}}$ e infiltrado inflamatório intratumoral

A distribuição do infiltrado inflamatório intratumoral está relatada na Tabela 36. Não houve associação significativa entre essas duas variáveis. 
Tabela 36 - Distribuição de 86 casos de melanoma cutâneo quanto ao infiltrado inflamatório intratumoral em relação à mutação BRAF ${ }^{V 600 E}$

\begin{tabular}{|c|c|c|c|c|}
\hline \multirow[t]{2}{*}{$\begin{array}{c}\text { Infiltrado inflamatório } \\
\text { intratumoral }\end{array}$} & & \multicolumn{2}{|c|}{$B R A F^{V 600 E}$} & \multirow[t]{2}{*}{ Total } \\
\hline & & Mutado & Selvagem & \\
\hline \multirow[t]{2}{*}{ Ausente } & $\mathrm{N}$ & 13 & 17 & 30 \\
\hline & $\%$ & 37,1 & 33,3 & 34,9 \\
\hline \multirow[t]{2}{*}{ Presente/inativo (nonbrisk) } & $\mathrm{N}$ & 15 & 23 & 38 \\
\hline & $\%$ & 42,9 & 45,1 & 44,2 \\
\hline \multirow[t]{2}{*}{ Presente/ativo (brisk) } & $\mathrm{N}$ & 7 & 11 & 18 \\
\hline & $\%$ & 20,0 & 21,6 & 20,9 \\
\hline \multirow[t]{2}{*}{ Total } & $\mathrm{N}$ & 35 & 51 & 86 \\
\hline & $\%$ & 100,0 & 100,0 & 100,0 \\
\hline
\end{tabular}

$p=0,935$

\subsection{9. $\mathrm{BRAF}^{\mathrm{V} 600 \mathrm{E}}$ e elastose solar}

Os três casos de melanoma associado a elastose solar de moderada a intensa, submetidos a análise molecular, não apresentaram a mutação. $\mathrm{O}$ teste de associação teve estatística igual a $\chi^{2}=0,635$ com $p=0,426$, ou seja, não foi evidenciada associação significativa entre a elastose solar e a mutação $B R A F^{V 600 E}$ (Tabela 37). 
Tabela 37 - Distribuição de 93 casos de melanoma cutâneo quanto à presença de elastose solar em relação à mutação BRAF $F^{V G O 0 E}$

\begin{tabular}{crrrr}
\hline Elastose solar & \multicolumn{2}{c}{ BRAF $^{\text {V600E }}$} & Total \\
\hline \multirow{2}{*}{ Ausente } & $\mathrm{N}$ & Mutado & Selvagem & \\
& $\%$ & 36 & 54 & 90 \\
Presente & $\mathrm{N}$ & 100,0 & 94,7 & 96,8 \\
& $\%$ & 0,0 & 3 & 3 \\
Total & $\mathrm{N}$ & 36 & 5,3 & 3,2 \\
& $\%$ & 100,0 & 57 & 93 \\
& & & 100,0 & 100,0 \\
\hline
\end{tabular}

$p=0,426$

\subsubsection{0. $\mathrm{BRAF}^{\mathrm{V} 600 \mathrm{E}}$ e ulceração}

A associação entre mutação $B R A F^{V 600 E}$ e ulceração está descrita na Tabela 38. $O$ teste de associação teve estatística igual a $\chi^{2}=3,704 \operatorname{com} p=$ 0,054. Ou seja, há forte indício de associação entre a mutação $B R A F^{V 600 E} \mathrm{e}$ a presença de ulceração.

Tabela 38 - Distribuição de 93 casos de melanoma cutâneo quanto à presença de ulceração em relação à mutação $B R A F^{V 600 E}$

\begin{tabular}{crrrr}
\hline Ulceração & \multicolumn{2}{c}{ BRAF $^{\text {V600E }}$} & \multicolumn{1}{c}{ Total } \\
\hline \multirow{2}{*}{ Ausente } & $\mathrm{N}$ & Mutado & Selvagem & \\
& $\%$ & 25 & 49 & 74 \\
\hline \multirow{2}{*}{ Presente } & $\mathrm{N}$ & 69,4 & 86,0 & 79,6 \\
& $\%$ & 30,6 & 8 & 19 \\
Total & $\mathrm{N}$ & 36 & 14,0 & 20,4 \\
& $\%$ & 100,0 & 57 & 93 \\
\hline
\end{tabular}

$p=0,054$ 


\subsubsection{1. $\mathrm{BRAF}^{\mathrm{V} 600 \mathrm{E}}$ e regressão}

O teste de associação entre as variáveis acima teve estatística igual a $\chi^{2}=12,146$, com $p<0,001$, apontando a existência de associação significativa entre a $B R A F^{V G 00 E}$ selvagem e o fenômeno de regressão. Enquanto não foi observada regressão nos casos mutados, ela ocorreu em $31,6 \%$ dos pacientes do grupo $B R A F^{V 600 E}$ selvagem (Tabela 39).

Tabela 39 - Distribuição de 93 casos de melanoma cutâneo quanto à presença de regressão em relação à mutação $B R A F^{V 600 E}$

\begin{tabular}{crrrr}
\hline Regressão & \multicolumn{2}{c}{ BRAF $^{\text {V600E }}$} & \multicolumn{1}{c}{ Total } \\
\hline \multirow{2}{*}{ Ausente } & $\mathrm{N}$ & Mutado & Selvagem & \\
& $\%$ & 36 & 39 & 75 \\
Presente & $\mathrm{N}$ & 100,0 & 68,4 & 80,6 \\
& $\%$ & 0 & 18 & 18 \\
Total & $\mathrm{N}$ & 36 & 31,6 & 19,4 \\
& $\%$ & 100,0 & 57 & 93 \\
& & & 100,0 & 100,0 \\
\hline
\end{tabular}

$p<0,001$

\subsubsection{2. $\mathrm{BRAF}^{\mathrm{V} 600}$ e satelitose}

Não houve associação entre satelitose e a mutação $B R A F^{V 600 E}$, ou seja, essas variáveis podem ser consideradas independentes. O teste de associação teve estatística igual a $\chi^{2}=0,107, \operatorname{com} p=0,774$ (Tabela 40). 
Tabela 40 - Distribuição de 93 casos de melanoma cutâneo quanto à presença de satelitose em relação à mutação $B R A F^{V 600 E}$

\begin{tabular}{|c|c|c|c|c|}
\hline \multirow[t]{2}{*}{ Satelitose } & & \multicolumn{2}{|c|}{$B R A F^{V 600 E}$} & \multirow[t]{2}{*}{ Total } \\
\hline & & Mutado & Selvagem & \\
\hline \multirow[t]{2}{*}{ Ausente } & $\mathrm{N}$ & 35 & 56 & 91 \\
\hline & $\%$ & 97,2 & 98,2 & 97,8 \\
\hline \multirow[t]{2}{*}{ Presente } & $\mathrm{N}$ & 1 & 1 & 2 \\
\hline & $\%$ & 2,8 & 1,8 & 2,2 \\
\hline \multirow[t]{2}{*}{ Total } & $\mathrm{N}$ & 36 & 57 & 93 \\
\hline & $\%$ & 100,0 & 100,0 & 100,0 \\
\hline
\end{tabular}

$p=0,774$

\subsubsection{3. $\mathrm{BRAF}^{\mathrm{V}}{ }^{\mathrm{G}} \mathrm{E}$ e invasão angiolinfática}

Com base nos dados disponíveis, não foi possível evidenciar associação entre a invasão angiolinfática e a presença de mutação $B R A F^{V 600 E}$. O teste de associação teve estatística igual a $\chi^{2}=0,638$, com $p=$ 0,424 (Tabela 41).

Tabela 41 - Distribuição de 93 casos de melanoma cutâneo quanto à presença de invasão angiolinfática em relação à mutação BRAF $F^{V 600 E}$

\begin{tabular}{crrrr}
\hline Invasão angiolinfática & \multicolumn{2}{c}{$\boldsymbol{B R A F}^{\text {V600E }}$} & \multicolumn{1}{c}{ Total } \\
\hline & & Mutado & Selvagem & \\
Ausente & $\mathrm{N}$ & 36 & 56 & 92 \\
& $\%$ & 100,0 & 98,2 & 98,9 \\
Presente & $\mathrm{N}$ & 0 & 1 & 1 \\
& $\%$ & 0,0 & 1,8 & 1,1 \\
Total & $\mathrm{N}$ & 36 & 57 & 93 \\
& $\%$ & 100,0 & 100,0 & 100,0 \\
\hline
\end{tabular}

$p=0,424$ 


\subsubsection{4. $\mathrm{BRAF}^{\mathrm{V}}{ }^{\mathrm{G}} \mathrm{e}$ infiltração perineural}

O teste de associação teve estatística igual a $\chi^{2}=0,635$, com $p=$ 0,426. Não foi evidenciada associação significativa entre a mutação $B R A F^{V 600 E}$ e infiltração perineural (Tabela 42).

Tabela 42 - Distribuição de 93 casos de melanoma cutâneo quanto à presença de infiltração perineural em relação à mutação BRAF ${ }^{V 600 E}$

\begin{tabular}{crrrr}
\hline Infiltração perineural & \multicolumn{2}{c}{$\boldsymbol{B R A F}^{\text {V600E }}$} & Total \\
\hline \multirow{2}{*}{ Ausente } & $\mathrm{N}$ & Mutado & Selvagem & \\
& $\%$ & 100,0 & 54 & 90 \\
Presente & $\mathrm{N}$ & 0 & 94,7 & 96,8 \\
& $\%$ & 0,0 & 3 & 3 \\
Total & $\mathrm{N}$ & 36 & 5,3 & 3,2 \\
& $\%$ & 100,0 & 100,0 & 100,0 \\
\hline
\end{tabular}

$p=0,426$

4.4.15. $\mathrm{BRAF}^{\mathrm{V} 600 \mathrm{E}}$ e presença de mitose no componente intradérmico

O teste de associação teve estatística igual a $\chi^{2}=9,990$, com $p=$ 0,004 , ou seja, foi evidenciada associação significativa entre a presença da mutação $B R A F^{\mathrm{V} 600 \mathrm{E}}$ e figuras de mitose no componente intradérmico (Tabela 43). 
Tabela 43 - Distribuição de 86 casos de melanoma cutâneo invasivo quanto à presença de figuras de mitose no componente intradérmico em relação à mutação $B R A F^{\mathrm{V} 600 \mathrm{E}}$

\begin{tabular}{crrrr}
\hline $\begin{array}{c}\text { Figuras de mitose } \\
\text { intradérmica }\end{array}$ & \multicolumn{2}{c}{$\boldsymbol{B R A F}^{\text {V600E }}$} & Total \\
\hline Ausente & $\mathrm{N}$ & Mutado & Selvagem & \\
& $\%$ & 9 & 29 & 38 \\
Presente & $\mathrm{N}$ & 25,7 & 56,9 & 44,2 \\
& $\%$ & 74,3 & 22 & 48 \\
Total & $\mathrm{N}$ & 35 & 43,1 & 55,8 \\
& $\%$ & 100,0 & 51 & 86 \\
\hline & & & 100,0 & 100,0 \\
\hline
\end{tabular}

$p=0,004$

4.4.16. $\mathrm{BRAF}^{\mathrm{V} 600 \mathrm{E}}$ e nevo melanocítico associado

A maioria dos casos mutados (29 casos; 80,6\%) não apresentou associação com nevo melanocítico. O teste de associação teve estatística igual a $\chi^{2}=0,002$, com $p=0,986$, ou seja, essas variáveis podem ser consideradas independentes (Tabela 44).

Tabela 44 - Distribuição de 93 casos de melanoma cutâneo quanto à presença de nevo melanocítico associado em relação à mutação $B R A F^{V 600 E}$.

\begin{tabular}{crrrr}
\hline $\begin{array}{c}\text { Nevo melanocítico } \\
\text { associado }\end{array}$ & \multicolumn{2}{c}{$\boldsymbol{B R A F}^{\text {V600E }}$} & \multicolumn{1}{c}{ Total } \\
\hline Ausente & $\mathrm{N}$ & Mutado & Selvagem & \\
& $\%$ & 80,6 & 46 & 75 \\
\hline Presente & $\mathrm{N}$ & 7 & 80,7 & 80,6 \\
\hline & $\%$ & 19,4 & 11 & 18 \\
\hline Total & $\mathrm{N}$ & 36 & 19,3 & 19,4 \\
\hline & $\%$ & 100,0 & 57 & 93 \\
\hline & & & 100,0 & 100,0 \\
\hline
\end{tabular}

$p=0,986$ 


\subsubsection{BRAF ${ }^{\mathrm{V} 600 \mathrm{E}}$ e evolução clínica}

A Tabela 45 mostra a associação entre a mutação $B R A F^{V 600 E}$ e a evolução clínica (prognóstico favorável/desfavorável), a qual não foi significante.

Tabela 45 - Distribuição de 50 casos de melanoma cutâneo invasivo quanto ao prognóstico em relação à mutação $B R A F^{V 600 E}$

\begin{tabular}{crrrr}
\hline Prognóstico & \multicolumn{2}{c}{$\boldsymbol{B R A F}^{\text {V600E }}$} & \multicolumn{1}{c}{ Total } \\
\hline & & Mutado & Selvagem & \\
Favorável & $\mathrm{N}$ & 13 & 26 & 39 \\
& $\%$ & 72,2 & 81,3 & 78,0 \\
Desfavorável & $\mathrm{N}$ & 5 & 6 & 11 \\
& $\%$ & 27,8 & 18,8 & 22,0 \\
Total & $\mathrm{N}$ & 18 & 32 & 50 \\
& $\%$ & 100,0 & 100,0 & 100,0 \\
\hline
\end{tabular}

$p=0,464$

\subsection{Curvas de sobrevida}

O Gráfico 2 ilustra a curva de sobrevida geral, considerando todos os pacientes estudados que apresentaram melanoma invasivo. $O$ tempo de sobrevida está representado em meses. 


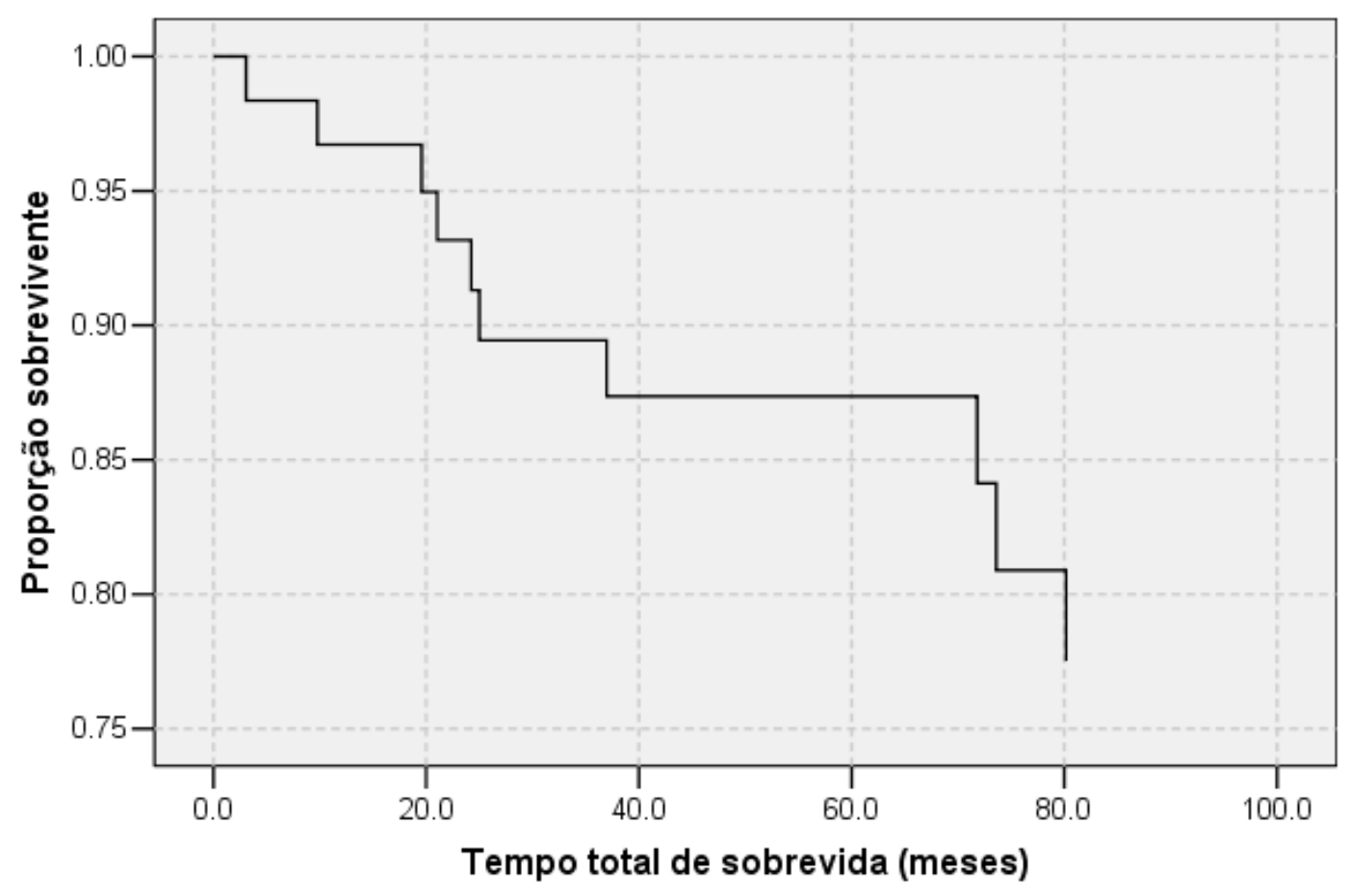

Gráfico 2 - Curva de sobrevida geral dos pacientes com melanoma cutâneo invasivo com idade entre 18 e 30 anos $(N=61)$

O Gráfico 3 ilustra a curva de sobrevida dos casos de melanoma cutâneo invasivo, considerando a presença ou não da mutação $B R A F^{V 600 E}$. O tempo está tabulado em meses. 


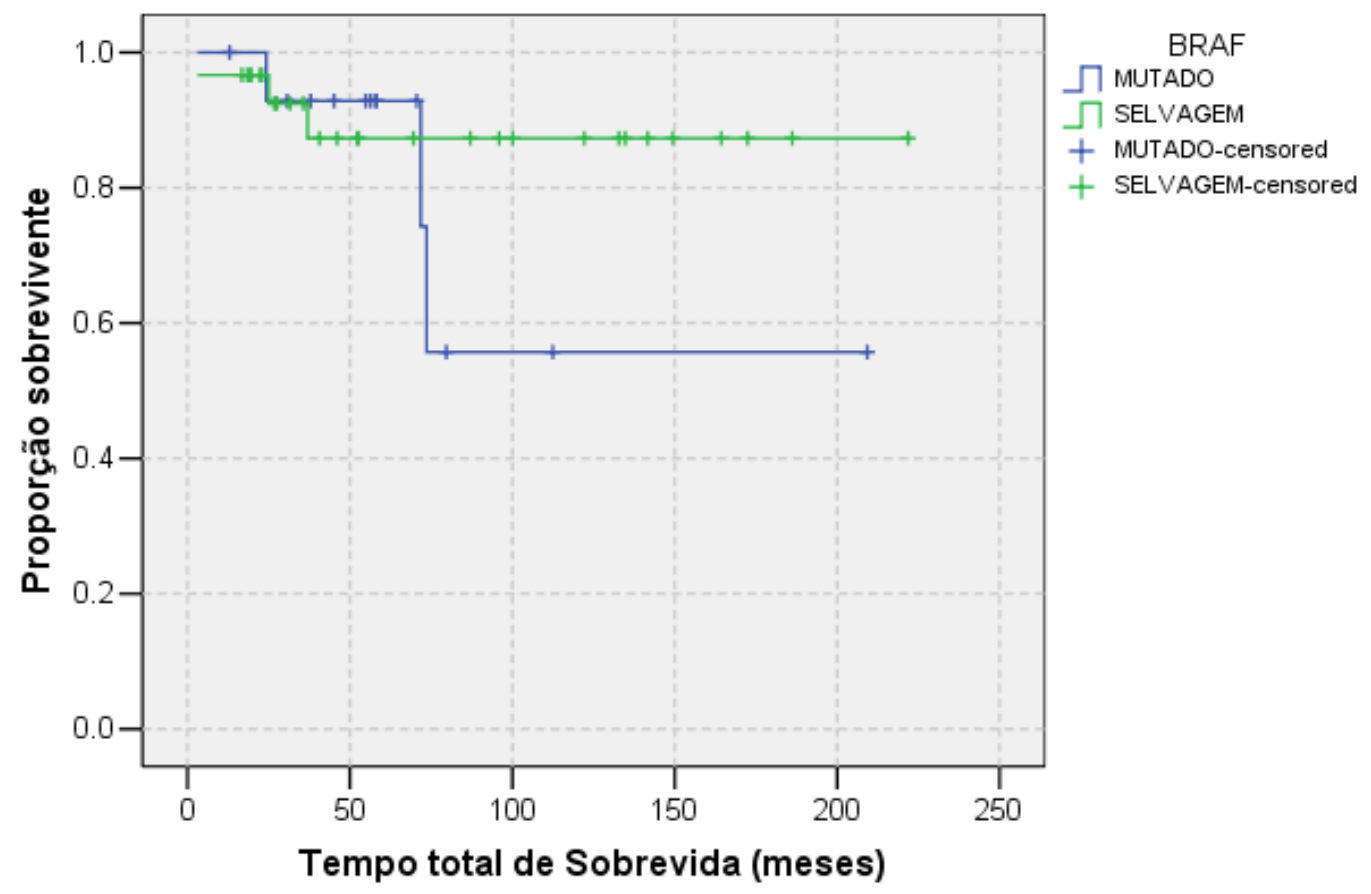

Gráfico 3 - Curva de sobrevida de pacientes com melanoma cutâneo invasivo com idade entre 18 e 30 anos, em relação à presença ou não de mutação $B R A F^{V 600 E}(\mathrm{~N}=45)$

Não há diferença significativa quando se compara a sobrevida de pacientes com melanoma $B R A F^{\mathrm{V} 600 \mathrm{E}}$ mutado ou selvagem, ou seja, as sobrevidas são semelhantes. 


\section{Discussãa}


Melanoma cutâneo é o tipo mais letal de câncer de pele e o segundo câncer mais comumente diagnosticado entre adolescentes e adultos jovens, com idade abaixo de 30 anos, precedido apenas pelos linfomas (Bleyer, Viny et al. 2006). Embora raro, a incidência de melanoma cutâneo, em jovens, tem aumentado em várias partes do mundo (Marrett, Frood et al. 2002; Alston, Rowan et al. 2007; Purdue, Freeman et al. 2008). Contudo, pouco ainda se sabe sobre o comportamento biológico e as alterações moleculares do melanoma cutâneo nessa faixa etária. Diante dessa realidade, estudaram-se, no presente trabalho, 132 casos de melanoma cutâneo em pacientes na faixa etária entre 18 e 30 anos, analisando os aspectos clínicopatológicos e moleculares, incluindo a avaliação de mutações nos genes NRAS, BRAF e KIT.

Neste estudo, observou-se predomínio da população feminina $(61,4 \%)$. Tal achado está em conformidade com estudos prévios que avaliaram melanoma cutâneo em população jovem (Pratt, Palmer et al. 1981; Mackie, Watt et al. 1991; de Sa, Rezze et al. 2004; Bleyer, Viny et al. 2006; Jemal, Saraiya et al. 2011; Weir, Marrett et al. 2011), porém difere do padrão encontrado nos pacientes idosos, em que o predomínio é do sexo masculino (Jemal, Saraiya et al. 2011). A inversão de incidência entre os sexos nessa faixa etária sugere que diferenças na etiologia do melanoma podem ser influenciadas pelo sexo (Weir, Marrett et al. 2011). Além disso, comportamentos sexo-específicos podem levar a diferenças na exposição à radiação ultravioleta. Mulheres jovens, por exemplo, são mais propensas a participarem de atividades que aumentam o risco de melanoma, como é o caso da exposição à radiação ultravioleta pelo bronzeamento artificial (Choi, 
Lazovich et al. 2010; Coelho and Hearing 2010). Em estudo prévio, Robinson et al. (1997) constataram que, apesar do aumento da consciência pública em relação aos danos da exposição à radiação ultravioleta, tem havido aumento na frequência de queimaduras graves e no uso de bronzeamento artificial, principalmente entre as mulheres (Robinson, Rigel et al. 1997). Embora controverso, outro fator que pode estar relacionado a esse padrão idade-específico é o hormônio sexual feminino, incluindo uso de contraceptivos orais e terapia de reposição hormonal, os quais podem estar associados ao aumento do risco de melanoma (Holly, Cress et al. 1994; Feskanich, Hunter et al. 1999). Genótipos específicos, como o MDM2 SNP309, têm sido relacionados com aumento da incidência de melanoma entre mulheres jovens e podem ter um papel crucial no desenvolvimento dessa neoplasia no referido grupo (Firoz, Warycha et al. 2009). No presente estudo, quando correlacionado o sexo com a presença da mutação $B R A F^{V 600 E}$, não se observou associação significativa. Saliente-se, contudo, que diferentes estudos na literatura, baseados na população geral, têm demonstrado resultados conflitantes, ou seja, maior incidência da mutação tanto no sexo feminino (Shinozaki, Fujimoto et al. 2004) quanto no sexo masculino (Thomas, Alexander et al. 2004) são descritas.

Em relação à localização anatômica, no presente estudo tronco foi o sítio mais frequentemente envolvido em ambos os sexos, achado semelhante a outros estudos sobre melanoma cutâneo nessa faixa etária (Robinson, Rigel et al. 1997; de Sa, Rezze et al. 2004; Weir, Marrett et al. 2011; Reed, Brewer et al. 2012). No sexo masculino, cabeça/pescoço foi a segunda localização mais comum e, no sexo feminino, os membros 
inferiores. É possível que a elevada frequência de melanomas em região de cabeça e pescoço, nos pacientes do sexo masculino, esteja relacionada aos hábitos ocupacionais, visto que praticamente metade dos casos dessa casuística é de população da Região Sul do país, onde é frequente a atividade agrícola e consequente exposição solar nesta região anatômica.

Melanoma extensivo superficial foi o tipo histológico mais frequente no presente estudo $(79,6 \%)$, assim como em outras publicações prévias estudando melanomas em jovens (Rhodes, Wood et al. 1981; Ceballos, Ruiz-Maldonado et al. 1995; Robinson, Rigel et al. 1997; Sander, Karlsson et al. 1999; Livestro, Kaine et al. 2007; Paradela, Fonseca et al. 2011; Weir, Marrett et al. 2011; Reed, Brewer et al. 2012). Contrariamente, outras séries demonstraram que o melanoma nodular foi o tipo mais comum entre adolescentes e adultos jovens (Davidoff, Cirrincione et al. 1994; Bittencourt, Marghoob et al. 2000; de Sa, Rezze et al. 2004; Reed, Brewer et al. 2012). Melanoma lentiginoso acral é raro nessa faixa etária, dado confirmado neste estudo. Em relação ao lentigo maligno melanoma, não é surpreendente a sua raridade entre os pacientes jovens, pois esse tipo de melanoma encontra-se intimamente relacionado à exposição solar crônica, achado que corrobora essa interpretação é a infrequente presença de elastose solar nos casos de melanomas estudados nos pacientes jovens.

Dados de estudos prévios revelaram que melanomas em crianças apresentam tumores iniciais mais espessos $(>1,5 \mathrm{~mm})$ comparados aos adultos (Ceballos, Ruiz-Maldonado et al. 1995; Spatz, Ruiter et al. 1996). A espessura média dos melanomas invasivos, neste estudo, foi de 1,65 mm. A maioria dos casos $(59,1 \%)$ apresentou-se em fase vertical de crescimento. A 
razão para a elevada frequência de lesões espessas, em pacientes jovens, pode ser explicada pela falta de suspeita clínica em lesões iniciais, devido à raridade do melanoma nessa faixa etária e consequente atraso no diagnóstico. Observou-se, ainda, que a média de espessura tumoral foi maior nos pacientes do sexo masculino. A consciência estética da mulher deve influenciar no diagnóstico mais precoce de melanomas, podendo explicar, em parte, essa diferença nas espessuras tumorais.

Até o presente momento, não há, na literatura, estudos relatando a frequência de mutação $B R A F$ especificamente em pacientes com melanoma na faixa etária entre 18 e 30 anos. Neste estudo, 36 de 93 casos avaliados apresentaram mutação $B R A F^{V 600 E}$ (Estrozi, Machado et al. 2014). A frequência observada $(38,7 \%)$ foi semelhante em dois estudos que avaliaram a população geral (Deichmann, Thome et al. 2004; Saldanha, Potter et al. 2006), respectivamente, porém, menor que em outros estudos (Davies, Bignell et al. 2002; Omholt, Platz et al. 2003; Pollock, Harper et al. 2003; Thomas, Alexander et al. 2004; Goydos, Mann et al. 2005; Goel, Lazar et al. 2006; Liu, Kelly et al. 2007; Viros, Fridlyand et al. 2008). Frequências menores também já foram descritas (Dong, Phelps et al. 2003; Maldonado, Fridlyand et al. 2003; Deichmann, Thome et al. 2004; Sasaki, Niu et al. 2004; Shinozaki, Fujimoto et al. 2004; Lang and MacKie 2005; Poynter, Elder et al. 2006; Saldanha, Potter et al. 2006; Si, Kong et al. 2012). A Tabela 46 aponta os principais estudos avaliando o gene $B R A F$ e as frequências encontradas. 
Tabela 46 - Principais estudos avaliando o gene BRAFe as frequências de mutações

\begin{tabular}{lrrl}
\hline \multicolumn{1}{c}{ Autores } & $\begin{array}{r}\text { N total de } \\
\text { casos }\end{array}$ & $\begin{array}{r}\text { N de casos } \\
\text { mutados (\%) }\end{array}$ & Tipo de mutação \\
\hline Deichman et al. (2004) & 50 & $19(38)$ & Éxon 15 \\
Saldanha et al. (2006) & 59 & $22(37,3)$ & Éxon 15 \\
Davies et al. (2002) & 9 & $6(66,6)$ & Éxon 15 \\
Omholt et al. (2003) & 71 & $42(59)$ & Éxons 15 e 11 \\
Pollock et al. (2003) & 5 & $4(80)$ & Éxon 15 (V600E) \\
Thomas et al. (2004) & 37 & $17(46)$ & Éxon 15 \\
Goydos et al. (2005) & 36 & $25(69,4)$ & Éxon 15 (V600E) \\
Goel et al. (2006) & 58 & $33(57)$ & Éxon 15 (V600E) \\
Liu et al. (2007) & 251 & $112(45)$ & Éxon 15 (V600E) \\
Viros et al. (2008) & 286 & $135(47,2)$ & Éxon 15 \\
Dong et al. (2003) & 28 & $7(25)$ & Éxon 15 \\
Maldonado et al. (2003) & 115 & $32(27,8)$ & Éxon 15 (V600E) \\
Sasaki et al. (2004) & 35 & $9(26)$ & Éxon 15 (V600E) \\
Shinozaki et al. (2004) & 59 & $18(30)$ & Éxon 15 e 11 \\
Lang et al. (2005) & 52 & $13(25)$ & Éxon 15 (V600E) \\
Poynter et al. (2006) & 81 & $19(23,4)$ & Éxon 15 \\
Si et al. (2012) & 432 & $110(25,5)$ & Éxon 15 e 11 \\
Estrozi et al. (2013) & 93 & $36(37,8)$ & Éxon 15 (V600E) \\
\hline
\end{tabular}

A ampla variação na frequência de mutações no gene $B R A F$, encontrada na literatura, pode ser explicada, em partes, devido a diferenças na seleção das amostras (número de casos analisados, tipos histológicos selecionados, sítios anatômicos, características da população) e pelos tipos de mutações analisadas envolvendo o gene BRAF, assim como as metodologias aplicadas. De forma geral, a maioria dos estudos não mostra elevada frequência de mutação do gene BRAF em melanomas cutâneos, sugerindo que essas mutações possam não ser um fator determinante na 
tumorigênese do melanoma e que deve haver múltiplas vias genéticas alternativas relacionadas a esta neoplasia. Ou seja, mutações específicas no gene BRAF devem representar apenas uma das alterações genéticas que contribuem para o desenvolvimento do melanoma cutâneo.

A maioria dos artigos avaliando a população geral, não mostra correlação significativa entre mutações no gene $B R A F$ e parâmetros clínicos e histológicos (Omholt, Platz et al. 2003; Shinozaki, Fujimoto et al. 2004; Thomas, Alexander et al. 2004; Libra, Malaponte et al. 2005; Saldanha, Potter et al. 2006). Neste estudo, não foi observada relação entre mutação $B R A F^{V 600 E}$ e sexo $(p=0,770)$, tipo histológico $(p=0,207)$, nível de Clark $(p=$ $0,551)$, medida de Breslow $(p=0,417)$, invasão angiolinfática $(p=0,424)$, infiltração perineural $(p=0,426)$, satelitose $(p=0,774)$, infiltrado inflamatório intratumoral $(p=0,935)$, nevo melanocítico associado $(p=0,986)$ e presença de elastose solar $(p=0,426)$.

Nos três casos em que houve, histologicamente, a presença de elastose solar moderada ou intensa, indicando dano solar crônico, a mutação $B R A F^{V 600 E}$ não foi identificada. A frequência da mutação $B R A F^{V 600 E}$ foi baixa nos melanomas de cabeça e pescoço $(p=0,128)$, regiões constantemente expostas à radiação solar. Essa associação inversa entre mutação no gene $B R A F$, áreas de exposição solar crônica e elastose solar já foi descrita em estudos prévios relacionados à população geral (Maldonado, Fridlyand et al. 2003; Curtin, Fridlyand et al. 2005), demonstrando que mutações BRAF são mais frequentes em regiões anatômicas onde o melanoma sugere, epidemiologicamente, papel patogenético de exposição 
solar intermitente (Holman, Armstrong et al. 1986; Bulliard 2000). Além disso, o códon 600 (GTG) do gene BRAF não é hotspot óbvio de radiação ultravioleta, mas é um sítio específico para ativações mutacionais com a forma oncogência do gene, o que explica a presença de mutações nesse gene em neoplasias não relacionadas à exposição solar, como o carcinoma papilífero de tireoide, carcinoma de pâncreas, carcinoma colorretal e tumores ovarianos borderlines. Processos inflamatórios e danos oxidativos, resultantes da inflamação, foram fatores sugeridos por Saldanha et al. (2006) como responsáveis pelas mutações BRAF em outros sítios não cutâneos e que o dano causado pela radiação ultravioleta seria apenas um dos diversos meios que originam uma resposta inflamatória (Saldanha, Potter et al. 2006). Embora, neste estudo, o número de casos com dano solar importante seja baixo, o fato de não haver mutação $B R A F^{V 600 E}$ levanta a consideração de que a exposição solar crônica possa não ter um papel importante em relação à frequência de mutações $B R A F$ em melanomas cutâneos em pacientes jovens, assim como já descrito na população em geral. Estudos adicionais com maior número de casos são necessários para confirmar este achado.

Alguns autores observaram elevada frequência de mutação $B R A F$ em nevos melanocíticos (Dong, Phelps et al. 2003; Pollock, Harper et al. 2003; Uribe, Wistuba et al. 2003; Kumar, Angelini et al. 2004). Neste estudo, a mutação $B R A F^{V 600 E}$ não foi avaliada nos nevos melanocíticos, isoladamente. Não se observou aumento na frequência de mutações $B R A F^{V 600 E} \mathrm{em}$ melanomas associados a nevos melanocíticos $(p=0,98)$. Ao contrário, 
apenas sete de 18 (39\%) casos de melanoma com nevo melanocítico coexistente apresentaram a mutação. Esses dados estão em concordância com o estudo de Maldonado et al. (2003), o qual concluiu que nem todos os casos de melanoma associado a nevo melanocítico apresentam mutação no gene BRAF (Maldonado, Fridlyand et al. 2003), apoiando a evidência de que a cascata MAPK está ativada em grande proporção de lesões melanocíticas, porém, essas mutações, isoladamente, não seriam suficientes para a transformação maligna (Poynter, Elder et al. 2006) (Figura 3).

Normal Skin

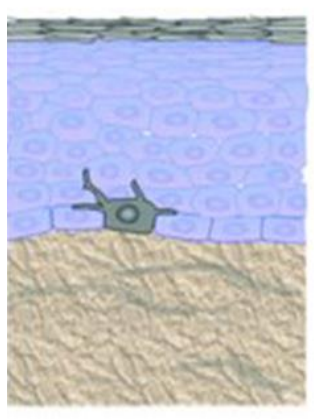

Nevus

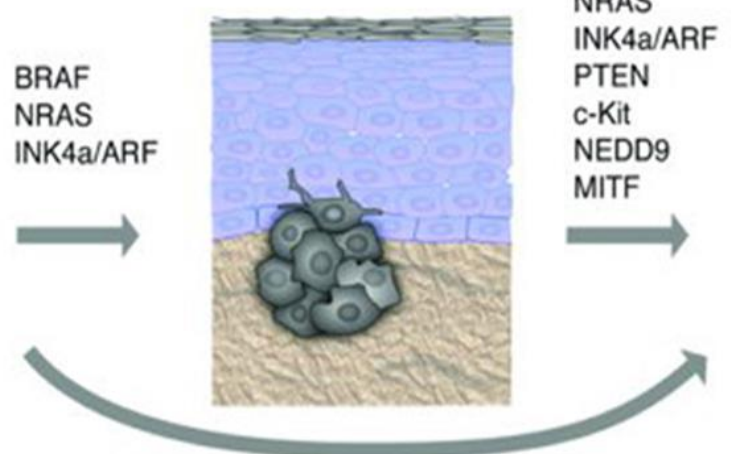

Melanoma

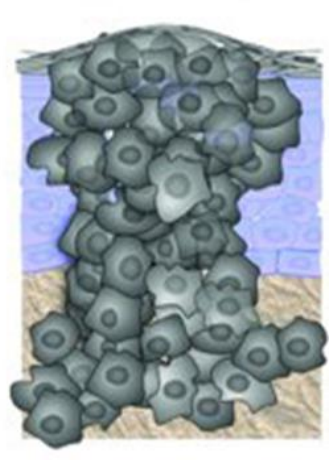

Fonte: DeVita VT, Lawrence TS, Rosenberg AS: DeVita, Hellman and Rosenberg's Cancer: Principles \& Practice of Oncology, $9^{\text {th }}$ Edition.

Figura 3 - Eventos genéticos associados à progressão de melanócitos normais para melanoma, como processo linear, embora a maioria dos melanomas não se originem a partir de nevo preexistente

A mutação $B R A F^{\mathrm{V} 600 \mathrm{E}}$ foi significantemente associada à fase vertical de crescimento $(p=0,01)$. Esse achado também foi observado em estudos de pacientes na população geral, sugerindo que mutações no gene BRAF poderiam não estar correlacionadas, na maioria dos casos, com a iniciação 
da neoplasia, mas refletir um evento genético progressivo, podendo ter implicações prognósticas importantes e até representar um biomarcador de progressão desta neoplasia (Dong, Phelps et al. 2003; Greene, Johnson et al. 2009). Todavia, quando avaliada a espessura tumoral (melanomas finos e grossos), não se observou relação dela com a presença da mutação $B_{R A F^{V 600 E}}(p=0,344)$. Ou seja, a mutação ocorreu tanto em melanomas finos $(\leq 1,0 \mathrm{~mm})$, quanto em melanomas grossos $(>1,0 \mathrm{~mm})$, indicando que essas mutações também ocorrem em estágios iniciais da doença e questiona o papel prognóstico da mutação do BRAF. Essa ausência de relação entre espessura e mutação $B R A F$ também foi observada em estudo realizado por Thomas et al., (2004), avaliando a população geral (Thomas, Alexander et al. 2004).

Liu et al. (2007) citam a associação entre mutação $B R A F^{V 600 E}$ e o índice mitótico. Esses autores observaram que tumores com poucas mitoses no componente intradérmico $\left(<1 / \mathrm{mm}^{2}\right)$ apresentaram maior porcentagem de mutações $(53,9 \%)$ do que aqueles com índice mitótico $\geq 10 / \mathrm{mm}^{2}(35,5 \%)$. No presente estudo, analisou-se ainda a associação entre mutação $B R A F^{V 600 E} \mathrm{e}$ presença/ausência de figuras de mitose no componente intradérmico, notando-se associação significativa entre melanoma $B R A F^{V 600 E}$ mutado e a presença de figuras de mitose intradérmica $(p=0,002)$. Esse achado corrobora a associação encontrada entre a mutação $B R A F^{V 600 E}$ e a fase vertical de crescimento, visto que a presença de mitose no componente intradérmico é um dos critérios utilizados na definição da fase vertical de crescimento, podendo também ter implicância prognóstica. 
Houve associação significativa entre a presença de infiltrado inflamatório peritumoral discreto e a mutação $B R A F^{V 600 E}(p=0,029)$. Contudo, quando avaliado o infiltrado inflamatório intratumoral, não se observou associação significativa com o estado mutacional ( $p=0,935)$. A mutação $B R A F^{V 600 E}$ não foi identificada nos casos que apresentaram fenômeno de regressão $(p=0,001)$ e foi discretamente mais prevalente nos casos que apresentavam ulceração $(p=0,05)$.

Não houve diferença significativa nas curvas de sobrevida entre os pacientes com melanoma $B R A F^{V 600 E}$ mutado e selvagem. Esse achado também foi observado na maioria dos estudos avaliando a população em geral, sugerindo que mutações no gene $B R A F$ não apresentam papel relevante em relação à sobrevida, pelo menos em melanomas cutâneos (Maldonado, Fridlyand et al. 2003; Omholt, Platz et al. 2003; Deichmann, Thome et al. 2004; Shinozaki, Fujimoto et al. 2004; Akslen, Angelini et al. 2005; Edlundh-Rose, Egyhazi et al. 2006; Ellerhorst, Greene et al. 2011).

Alterações no códon 600 do gene BRAF e no códon 61 do gene NRAS são as mutações pontuais mais frequentes em melanomas cutâneos. Em geral, essas mutações são mutuamente exclusivas (Omholt, Platz et al. 2003; Poynter, Elder et al. 2006), embora, raramente, possam ser concomitantes (Edlundh-Rose, Egyhazi et al. 2006; Goel, Lazar et al. 2006). O presente estudo não evidenciou mutações BRAF e NRAS concomitantes, sugerindo que, embora esses genes sejam complementares na via de ativação MAPK, provavelmente apresentam diferentes ativações oncogênicas entre as formas mutantes. 
Enquanto mutações no gene $B R A F$ são mais frequentes em sítios anatômicos que sugerem exposição solar intermitente, mutações no gene NRAS acometem áreas de exposição solar crônica, em especial a região de cabeça e pescoço e membros superiores (van 't Veer, Burgering et al. 1989; Ball, Yohn et al. 1994; van Elsas, Zerp et al. 1995; Platz, Egyhazi et al. 2008; Ellerhorst, Greene et al. 2011; Lee, Choi et al. 2011). No presente estudo, encontrou-se mutação NRAS em três de 76 (3,95\%) melanomas analisados. Nos três casos detectou-se a mutação $61 K$, acometendo homens com melanoma em região de cabeça e pescoço, porém sem evidências histológicas de dano solar crônico. Apesar de o número de casos no presente estudo com mutação do NRAS ser pequeno, saliente-se que há outros autores que também não encontraram relação significativa entre mutação NRAS e exposição solar crônica (Carr and Mackie 1994; Devitt, Liu et al. 2011).

KIT é um gene essencial para a sobrevivência e o desenvolvimento dos melanócitos. Embora normalmente expresso por melanócitos, mutações em KIT não são frequentemente observadas em melanomas cutâneos (Willmore-Payne, Holden et al. 2005; Curtin, Busam et al. 2006; WillmorePayne, Holden et al. 2006). Neste estudo, a avaliação de 27 casos identificou três $(11,1 \%)$ melanomas cutâneos com mutação em KIT, todas localizadas no éxon 9 (G498S, G510D e V489I). Essa frequência de mutações KIT encontrada é relativamente alta, levando-se em consideração que mutações nesse gene são mais frequentes em melanomas de mucosas, melanomas acrais e melanomas associados ao dano solar crônico, tipos 
raros em pacientes jovens, objeto deste estudo (Curtin, Busam et al. 2006; Beadling, Jacobson-Dunlop et al. 2008).

Os dois casos de melanoma acral e os quatro que apresentaram elastose solar (indicativo de dano solar crônico), incluídos nesta casuística, não foram sequenciados para a pesquisa de mutações $K I T$ devido à amostra inadequada ou a indisponibilidade de bloco de parafina. A mutação KIT mais frequentemente relatada nos melanomas encontra-se no éxon 11 (L576P). Essa mutação não foi encontrada no presente estudo, muito provavelmente devido aos tipos de melanomas avaliados.

A frequência relatada de mutações no éxon 9 , em melanomas, é baixa, de aproximadamente 6\% (Carvajal, Antonescu et al. 2011; Bello, Ariyan et al. 2013). Até o presente momento, não há, na literatura, descrição das mutações G510D e G498S. Já a mutação V489I foi recentemente descrita por Kong et al. (2011) em um paciente asiático portador de melanoma acral (Kong, Si et al. 2011). O único caso, no presente estudo, com a mutação (V489I) ocorreu em paciente do sexo masculino, com melanoma em região de cabeça e pescoço, porém, sem evidências histológicas de dano solar crônico. Curiosamente, este caso apresentou mutação NRAS $61 \mathrm{~K}$ concomitante, achado incomum na literatura. Os outros dois casos com KIT mutado dessa série ocorreram em membro inferior e tronco, ambos também sem evidências de dano solar crônico à histologia. Wu et al. (2009) foram os pioneiros a descrever um caso de melanoma em tronco com mutação L576P (éxon 11) do gene KIT, sem relação com a exposição solar crônica. Esses achados sugerem que, em melanomas 
cutâneos, a presença de mutação no gene KIT não esteja diretamente relacionada ao dano actínico. Essa relação entre dano solar crônico e probabilidade de mutação em KIT merece mais investigações.

A maioria dos estudos avaliando mutações BRAF e KIT, em melanomas, indica que a presença dessas mutações é mutuamente exclusiva (Willmore-Payne, Holden et al. 2005; Beadling, Jacobson-Dunlop et al. 2008; Wu, Alvarez et al. 2009). Por outro lado, Curtin et al. (2006), ao analisarem melanomas com mutações KIT, encontraram um caso de melanoma acral com mutação BRAF concomitante. A mutação KIT (K642E), encontrada por esses autores, é rara e questiona-se o seu papel oncogênico independente (Curtin, Busam et al. 2006). No presente estudo, encontrou-se um caso com mutação em ambos os genes BRAF e KIT (G510D). Não há informações, na literatura, a respeito do papel oncogênico das três mutações KIT encontradas no presente estudo.

Estudos analisando o perfil genético de melanoma em pacientes jovens são raros na literatura. Daniotti et al. (2009) pesquisaram alterações em nível somático dos genes KIT, BRAF e NRAS em uma coorte de 21 casos de melanomas em crianças e adolescentes (faixa etária entre dois e 19 anos). Esses autores encontraram alterações de sequenciamento do gene $K I T$, assim como perda da proteína $K I T$, porém, não observaram mutações no gene KIT e no gene NRAS. Ainda nesse estudo, a ocorrência de mutações $\operatorname{BRAF}^{V 600 E}(5 / 10 ; 50 \%)$ foi semelhante àquela descrita na população adulta. 
Em um estudo avaliando melanomas em uma população chinesa, Kong et al. (2011) identificaram sobrevida global significativamente menor em pacientes com mutações KIT do que naqueles com o gene selvagem. Além disso, as mutações do KIT não apresentaram relacão com a idade, sexo, estágio, espessura e ulceração dos melanomas primários.

Embora vários autores tenham investigado mutações KIT em melanomas, o pequeno número de casos com mutação nesse genes, no presente estudo, não permite correlação de mutações do KIT com fatores prognósticos clínicos ou histológicos. 
6. Canclusães 
Os resultados apresentados neste estudo levaram às seguintes conclusões:

1. Em relação aos parâmetros clínicos e morfológicos, houve predomínio de pacientes do sexo feminino, sendo o tronco a região anatômica mais acometida em ambos os sexos. Melanoma extensivo superficial foi o tipo histológico mais frequente, com a maioria dos casos em fase vertical de crescimento;

2. A frequência da mutação $B R A F^{V 600 E}$ foi de $38,7 \%$;

3. Não houve correlação entre a mutação $B R A F^{V 600 E}$ e sexo, tipo histológico, nível de Clark, medida de Breslow, invasão angiolinfática, infiltração perineural, satelitose, infiltrado inflamatório peritumoral, nevo melanocítico associado e presença de elastose solar;

4. Houve relação inversa entre a presença de mutação $B R A F^{V 600 E} \mathrm{e}$ região anatômica de cabeça e pescoço;

5. Melanomas com fenômeno de regressão não apresentaram mutações em BRAF ${ }^{V 600 E}$;

6. Houve associação significativa entre mutação $B R A F^{V 600 E}$ e fase vertical de crescimento, presença de figura de mitose no componente intradérmico, infiltrado inflamatório peritumoral discreto e presença de ulceração, todos achados histopatológicos que indicam pior prognóstico; 
7. Em relação à sobrevida, não houve diferença significativa entre os pacientes com melanoma $B R A F^{V 600 E}$ mutado e selvagem;

8. A frequência de mutações $N R A S$ foi de $3,95 \%$. As três mutações encontradas foram do tipo $61 \mathrm{~K}$ ocorreram em pacientes do sexo masculino e em região de cabeça e pescoço;

9. Quando presentes, as mutações $B R A F^{V 600 E}$ e $N R A S$ foram mutuamente exclusivas;

10. A frequência de mutações $K I T$ foi de $11,1 \%$, todas localizadas no éxon 9;

11. Houve concomitância de mutação KIT tanto com NRAS, como com BRAF ${ }^{V 600 E}$;

12. Este estudo é o primeiro a descrever as mutações G510D e G498S no gene KIT em melanomas cutâneos. 
7. Bileliagrafia 
Akslen LA, Angelini S, et al. "BRAF and NRAS mutations are frequent in nodular melanoma but are not associated with tumor cell proliferation or patient survival." J Invest Dermatol. 2005;125(2):312-317.

Albino AP, Strange $R L$, et al. "Transforming ras genes from human melanoma: a manifestation of tumour heterogeneity?" Nature. 1984;308(5954):69-72.

Albino AP, Nanus DM, et al. "Analysis of ras oncogenes in malignant melanoma and precursor lesions: correlation of point mutations with differentiation phenotype." Oncogene. 1989;4(11):1363-1374.

Alston R.D, Rowan S, et al. "Cancer incidence patterns by region and socioeconomic deprivation in teenagers and young adults in England." $\mathrm{Br} \mathrm{J}$ Cancer. 2007;96(11):1760-1766.

Armstrong BK, Kricker A. "How much melanoma is caused by sun exposure?" Melanoma Res. 1993;3(6):395-401.

Ascierto PA, Kirkwood JM, et al. "The role of BRAF V600 mutation in melanoma." J Transl Med. 2012;10:85.

Austin PF, Cruse CW, et al. "Age as a prognostic factor in the malignant melanoma population." Ann surg oncol. 1994;1(6):487-494.

Balch CM, Buzaid AC, et al. "Final version of the American Joint Committee on Cancer staging system for cutaneous melanoma." $J$ Clin Oncol. 2001;19(16): 3635-3648.

Balch CM, Gershenwald JE, et al. "Final version of 2009 AJCC melanoma staging and classification." J Clin Oncol. 2009;27(36): 6199-6206.

Balch CM, Soong SJ, et al. "Prognostic factors analysis of 17,600 melanoma patients: validation of the American Joint Committee on Cancer melanoma staging system." J Clin Oncol. 2001;19(16): 3622-3634. 
Ball NJ, Yohn JJ, et al. "Ras mutations in human melanoma: a marker of malignant progression." J Invest Dermatol. 1994;102(3): 285-290.

Barnhill RL, Mihm Jr MC. "The histopathology of cutaneous malignant melanoma." Semin Diagn Pathol. 1993;10(1): 47-75.

Barnier JV, Papin C, et al. "The mouse B-raf gene encodes multiple protein isoforms with tissue-specific expression." J Biol Chem. 1995;270(40): 2338123389.

Bauer J, Buttner $\mathrm{P}$, et al. "BRAF mutations in cutaneous melanoma are independently associated with age, anatomic site of the primary tumor, and the degree of solar elastosis at the primary tumor site." Pigment Cell Melanoma Res. 2011;24(2): 345-351.

Bauer J, Curtin JA, et al. "Congenital melanocytic nevi frequently harbor NRAS mutations but no BRAF mutations." J Invest Dermatol. 2007;127(1): 179-182.

Beadling C, Jacobson-Dunlop E, et al. "KIT gene mutations and copy number in melanoma subtypes." Clin Cancer Res. 2008;14(21): 6821-6828.

Bello DM, Ariyan CE, et al. "Melanoma mutagenesis and aberrant cell signaling." Cancer Control. 2013;20(4): 261-281.

Berk DR, LaBuz E, et al. "Melanoma and melanocytic tumors of uncertain malignant potential in children, adolescents and young adults--the Stanford experience 1995-2008." Pediatr Dermatol. 2010;27(3): 244-254.

Bittencourt FV, Marghoob AA, et al. "Large congenital melanocytic nevi and the risk for development of malignant melanoma and neurocutaneous melanocytosis." Pediatrics. 2000;106(4): 736-741.

Blessing K, McLaren KM. "Histological regression in primary cutaneous melanoma: recognition, prevalence and significance." Histopathology. 1992;20(4): 315-322. 
Bleyer A, Viny A, et al. "Cancer in 15- to 29-year-olds by primary site." Oncologist. 2006;11(6): 590-601.

Boddie AW, Smith Jr JL., et al. "Malignant melanoma in children and young adults: effect of diagnostic criteria on staging and end results." South Med J. 1978;71(9): 1074-1078.

Bokoch GM, Der CJ. "Emerging concepts in the Ras superfamily of GTPbinding proteins." FASEB J. 1993;7(9): 750-759.

Borbola K, Banfalvi T, et al. "Etiologic factors of malignant melanoma in young adults." Orv Hetil. 2005;146(28): 1481-1487.

Bos JL. "Ras oncogenes in human cancer: a review." Cancer Res. 1989;49(17): 4682-4689.

Broekaert SM, Roy R, et al. "Genetic and morphologic features for melanoma classification." Pigment Cell Melanoma Res. 2010;23(6): 763-770.

Bulliard JL. "Site-specific risk of cutaneous malignant melanoma and pattern of sun exposure in New Zealand." Int J Cancer. 2000;85(5): 627-632.

Buzaid AC, Ross MI, et al. "Critical analysis of the current American Joint Committee on Cancer staging system for cutaneous melanoma and proposal of a new staging system." J Clin Oncol. 1997;15(3): 1039-1051.

Carr J, Mackie RM. "Point mutations in the $\mathrm{N}$-ras oncogene in malignant melanoma and congenital naevi." Br J Dermatol. 1994;131(1): 72-77.

Carvajal RD, Antonescu CR, et al. "KIT as a therapeutic target in metastatic melanoma." JAMA. 2011;305(22): 2327-2334.

Ceballos PI, Ruiz-Maldonado R, et al. "Melanoma in children." N Engl J Med. 1995;332(10): 656-662. 
Choi K, Lazovich D, et al. "Prevalence and characteristics of indoor tanning use among men and women in the United States". Arch Dermatol. 2010;146(12): 1356-1361.

Clark WH, Elder Jr DE, et al. "Model predicting survival in stage I melanoma based on tumor progression." J Natl Cancer Inst. 1989;81(24): 1893-1904.

Clark WH, Evans JR HL, et al. "Early melanoma. Histologic terms." Am J Dermatopathol. 1991;13(6): 579-582.

Cochran AJ, Roberts AA, et al. "The place of lymphatic mapping and sentinel node biopsy in oncology." Int J Clin Oncol. 2003;8(3): 139-150.

Coelho SG, Hearing VJ. "UVA tanning is involved in the increased incidence of skin cancers in fair-skinned young women". Pigment Cell Melanoma Res. 2010;23(1): 57-63.

Corless CL, Fletcher JA, et al. "Biology of gastrointestinal stromal tumors." J Clin Oncol. 2004;22(18): 3813-3825.

Curtin JA, Busam K, et al. "Somatic activation of KIT in distinct subtypes of melanoma." J Clin Oncol. 2006;24(26): 4340-4346.

Curtin JA, Fridlyand $\mathrm{J}$, et al. "Distinct sets of genetic alterations in melanoma." N Engl J Med. 2005;353(20): 2135-2147.

Davidoff AM, Cirrincione C, et al. "Malignant melanoma in children." Ann Surg Oncol. 1994;1(4): 278-282.

Davies $\mathrm{H}$, Bignell GR, et al. "Mutations of the BRAF gene in human cancer." Nature. 2002;417(6892): 949-954.

Day CL, Harrist Jr TJ, et al. "Malignant melanoma. Prognostic significance of "microscopic satellites" in the reticular dermis and subcutaneous fat." Ann Surg. 1981;194(1): 108-112. 
Sa BC, Rezze GG, et al. "Cutaneous melanoma in childhood and adolescence: retrospective study of 32 patients." Melanoma Res. 2004;14(6): 487-492.

Deichmann M, Thome M, et al. "B-raf exon 15 mutations are common in primary melanoma resection specimens but not associated with clinical outcome." Oncology. 2004;66(5): 411-419.

Denkler K, Johnson J. "A lost piece of melanoma history." Plast Reconstr Surg. 1999;104(7): 2149-2153.

Devitt B, Liu W, et al. "Clinical outcome and pathological features associated with NRAS mutation in cutaneous melanoma." Pigment Cell Melanoma Res. 2011;24(4): 666-672.

Dibb NJ, Dilworth SM, et al. "Switching on kinases: oncogenic activation of BRAF and the PDGFR family." Nat Rev Cancer. 2004;4(9): 718-727.

Dong J, Phelps RG, et al. "BRAF oncogenic mutations correlate with progression rather than initiation of human melanoma." Cancer Res. 2003;63(14): 3883-3885.

Downward J. "Targeting RAS signalling pathways in cancer therapy." Nat Rev Cancer. 2003;3(1): 11-22.

Edlundh-Rose E, Egyhazi S, et al. "NRAS and BRAF mutations in melanoma tumours in relation to clinical characteristics: a study based on mutation screening by pyrosequencing." Melanoma Res. 2006;16(6): 471-478.

Ellerhorst JA, Greene VR, et al. "Clinical correlates of NRAS and BRAF mutations in primary human melanoma." Clin Cancer Res. 2011;17(2): 229235.

Estrozi B, Machado J, et al. "Clinicopathologic findings and BRAF mutation in cutaneous melanoma in young adults." Appl Immunohistochem Mol Morphol. 2014;22(1): 57-64. 
Fedorenko IV, Gibney GT, et al. "NRAS mutant melanoma: biological behavior and future strategies for therapeutic management." Oncogene. 2013;32(25): 3009-3018.

Ferrari A, Bono A, et al. "Does melanoma behave differently in younger children than in adults? A retrospective study of 33 cases of childhood melanoma from a single institution." Pediatrics. 2005;115(3): 649-654.

Feskanich D, Hunter DJ, et al. "Oral contraceptive use and risk of melanoma in premenopausal women." Br J Cancer. 1999;81(5): 918-923.

Firoz EF, Warycha M, et al. "Association of MDM2 SNP309, age of onset, and gender in cutaneous melanoma." Clin Cancer Res. 2009;15(7): 25732580.

Franceschi S, Levi F, et al. "Site distribution of different types of skin cancer: new aetiological clues." Int J Cancer. 1996;67(1): 24-28.

Garrido MC, Bastian BC. "KIT as a therapeutic target in melanoma." J Invest Dermatol. 2010;130(1): 20-27.

Gershenwald JE, Thompson W, et al. "Multi-institutional melanoma lymphatic mapping experience: the prognostic value of sentinel lymph node status in 612 stage I or II melanoma patients." J Clin Oncol. 1999;17(3): 976-983.

Giblin AV, Thomas JM. "Incidence, mortality and survival in cutaneous melanoma." J Plast Reconstr Aesthet Surg. 2007;60(1): 32-40.

Goel VK, Lazar AJ, et al. "Examination of mutations in BRAF, NRAS, and PTEN in primary cutaneous melanoma." J Invest Dermatol. 2006;126(1): 154-160.

Goydos JS, Mann B, et al. "Detection of B-RAF and N-RAS mutations in human melanoma." J Am Coll Surg. 2005;200(3): 362-370. 
Green A, McCredie M, et al. "A case-control study of melanomas of the soles and palms (Australia and Scotland)." Cancer Causes Control. 1999;10(1): 21-25.

Greene VR, Johnson MM, et al. "Frequencies of NRAS and BRAF mutations increase from the radial to the vertical growth phase in cutaneous melanoma." J Invest Dermatol. 2009;129(6): 1483-1488.

Haluska $F$, Pemberton $T$, et al. "The RTK/RAS/BRAF/PI3K pathways in melanoma: biology, small molecule inhibitors, and potential applications." Semin Oncol. 2007;34(6): 546-554.

Hanks SK, Quinn AM, et al. "The protein kinase family: conserved features and deduced phylogeny of the catalytic domains." Science. 1988;241(4861): $42-52$.

Holly EA, Cress RD, et al. "Cutaneous melanoma in women: ovulatory life, menopause, and use of exogenous estrogens." Cancer Epidemiol Biomarkers Prev. 1994;3(8): 661-668.

Holman CD, Armstrong BK, et al. "Relationship of cutaneous malignant melanoma to individual sunlight-exposure habits." J Natl Cancer Inst. 1986;76(3): 403-414.

Houben R, Becker JC, et al. "Constitutive activation of the Ras-Raf signaling pathway in metastatic melanoma is associated with poor prognosis." J Carcinog. 2004;3(1): 6.

Jafari M, Papp T, et al. "Analysis of ras mutations in human melanocytic lesions: activation of the ras gene seems to be associated with the nodular type of human malignant melanoma." J Cancer Res Clin Oncol. 1995;121(1): 23-30.

Jakob JA, Bassett Jr RL, et al. "NRAS mutation status is an independent prognostic factor in metastatic melanoma." Cancer. 2012;118(16): 40144023. 
Jemal A, Devesa SS, et al. "Recent trends in cutaneous melanoma incidence among whites in the United States." J Natl Cancer Inst. 2001;93(9): 678-683.

Jemal A, Saraiya M, et al. "Recent trends in cutaneous melanoma incidence and death rates in the United States, 1992-2006." J Am Acad Dermatol. 2011;65(5 Suppl 1): S17-25 e11-13.

Jemal A, Siegel R, et al. "Cancer statistics, 2010." Cancer J Clin. 2010;60(5): 277-300.

Kaddu S, Smolle J, et al. "Melanoma with benign melanocytic naevus components: reappraisal of clinicopathological features and prognosis." Melanoma research. 2002;12(3): 271-278.

Karjalainen JM, Eskelinen MJ, et al. "Mitotic rate and S-phase fraction as prognostic factors in stage I cutaneous malignant melanoma." $\mathrm{Br} \mathrm{J}$ Cancer. 1998;77(11): 1917-1925.

Kashani-Sabet M, Sagebiel RW, et al. "Vascular involvement in the prognosis of primary cutaneous melanoma." Arch Dermatol. 2001;137(9): 1169-1173.

Kelleher FC, McArthur GA. "Targeting NRAS in melanoma." Cancer J. 2012;18(2): 132-136.

King R, Googe PB, et al. "Thin melanomas." Clin Lab Med. 2000;20(4): 713729.

Kong Y, Si L, et al. "Large-scale analysis of KIT aberrations in Chinese patients with melanoma." Clin Cancer Res. 2011;17(7): 1684-1691.

Kumar R, Angelini S, et al. "BRAF mutations are common somatic events in melanocytic nevi." J Invest Dermatol. 2004;122(2): 342-348.

Lammie A, Drobnjak M, et al. "Expression of c-kit and kit ligand proteins in normal human tissues." J Histochem Cytochem. 1994;42(11): 1417-1425. 
Lang J, Mackie RM. "Prevalence of exon 15 BRAF mutations in primary melanoma of the superficial spreading, nodular, acral, and lentigo maligna subtypes." J Invest Dermatol. 2005;125(3): 575-579.

LeBoit PE. Pathology and genetics of skin tumours, WHO. 2006.

Lee JH, Choi JW, et al. "Frequencies of BRAF and NRAS mutations are different in histological types and sites of origin of cutaneous melanoma: a meta-analysis." Br J Dermatol, 2011;164(4): 776-784.

Leon P, Daly JM, et al. "The prognostic implications of microscopic satellites in patients with clinical stage I melanoma." Arch Surg. 1991;126(12): 14611468.

Leong SP. "Selective sentinel lymphadenectomy for malignant melanoma." Surg Clin North Am. 2003;83(1): 157-185, vii.

Libra M, Malaponte $\mathrm{G}$, et al. "Analysis of BRAF mutation in primary and metastatic melanoma." Cell Cycle. 2005;4(10): 1382-1384.

Liu W, Kelly JW, et al. "Distinct clinical and pathological features are associated with the BRAF(T1799A(V600E)) mutation in primary melanoma." J Invest Dermatol. 2004;127(4): 900-905.

Livestro DP, Kaine EM, et al. "Melanoma in the young: differences and similarities with adult melanoma: a case-matched controlled analysis." Cancer. 2007;110(3): 614-624.

Mackie RM, Watt $\mathrm{D}$, et al. "Malignant melanoma occurring in those aged under 30 in the west of Scotland 1979-1986: a study of incidence, clinical features, pathological features and survival." $\mathrm{Br} J$ Dermatol. 1991;124(6): 560-564.

Maldonado JL, Fridlyand $\mathrm{J}$, et al. "Determinants of BRAF mutations in primary melanomas." J Natl Cancer Inst. 2003;95(24): 1878-1890. 
Marrett LD, Frood J, et al. "Cancer incidence in young adults in Canada: preliminary results of a cancer surveillance project." Chronic Dis Can. 2002;23(2): 58-64.

Masback $\mathrm{A}$, Olsson $\mathrm{H}$, et al. "Prognostic factors in invasive cutaneous malignant melanoma: a population-based study and review." Melanoma Res. 2001;11(5): 435-445.

Massi D, Franchi A, et al. "Thin cutaneous malignant melanomas $(<$ or $=1.5$ $\mathrm{mm}$ ): identification of risk factors indicative of progression." Cancer. 1999;85(5): 1067-1076.

Matsuda R, Takahashi T, et al. "Expression of the c-kit protein in human solid tumors and in corresponding fetal and adult normal tissues." Am J Pathol. 1993;142(1): 339-346.

Milton GW, Shaw HM, et al. (1997). "Cutaneous melanoma in childhood: incidence and prognosis."Aust J Dermatol. 1997;38 Suppl 1: S44-48.

Moore-Olufemi S, Herzog C, et al. "Outcomes in pediatric melanoma: comparing prepubertal to adolescent pediatric patients." Ann Surg. $2011 ; 253(6): 1211-1215$.

Morton DL, Wen DR, et al. "Technical details of intraoperative lymphatic mapping for early stage melanoma." Arch Surg. 1992;127(4): 392-399.

Okun MR, Mattia AD, et al. "Malignant melanoma developing from intradermal nevi." Arch Dermatol. 1974;110(4): 599-601.

Omholt $\mathrm{K}$, Karsberg $\mathrm{S}$, et al. "Screening of $\mathrm{N}$-ras codon 61 mutations in paired primary and metastatic cutaneous melanomas: mutations occur early and persist throughout tumor progression." Clin Cancer Res. 2002;8(11): 3468-3474. 
Omholt K, Platz A, et al. "NRAS and BRAF mutations arise early during melanoma pathogenesis and are preserved throughout tumor progression." Clin Cancer Res. 2003;9(17): 6483-6488.

Owen SA, Sanders LL, et al. "Identification of higher risk thin melanomas should be based on Breslow depth not Clark level IV." Cancer. 2001;91(5): 983-991.

Padua RA, Barrass NC, et al. "Activation of $\mathrm{N}$-ras in a human melanoma cell line." Mol Cell Biol. 1985;5(3): 582-585.

Paradela S, Fonseca E, et al. "Melanoma in children." Arch Pathol Lab Med. 2011;135(3): 307-316.

Platz A, Egyhazi S, et al. "Human cutaneous melanoma; a review of NRAS and BRAF mutation frequencies in relation to histogenetic subclass and body site." Mol Oncol. 2008;1(4): 395-405.

Pollock PM, Harper UL, et al. "High frequency of BRAF mutations in nevi." Nat Genet. 2003;33(1): 19-20.

Postow MA, Carvajal, RD. "Therapeutic implications of KIT in melanoma." Cancer J. 2012;18(2): 137-141.

Poynter JN, Elder JT, et al. "BRAF and NRAS mutations in melanoma and melanocytic nevi." Melanoma Res. 2006;16(4): 267-273.

Pratt CB, Palmer MK, et al. "Malignant melanoma in children and adolescents." Cancer. 1981;47(2): 392-397.

Purdue MP, Freeman LE, et al. "Recent trends in incidence of cutaneous melanoma among US Caucasian young adults." J Invest Dermatol. 2008;128(12): 2905-2908. 
Raybaud F, Noguchi T, et al. "Detection of a low frequency of activated ras genes in human melanomas using a tumorigenicity assay." Cancer Res. 1988;48(4): 950-953.

Reed KB, Brewer JD, et al. "Increasing incidence of melanoma among young adults: an epidemiological study in Olmsted County, Minnesota." Mayo Clin Proc. 2012;87(4): 328-334.

Rhodes AR, Wood WC, et al. "Nonepidermal origin of malignant melanoma associated with a giant congenital nevocellular nevus." Plast Reconstr Surg. 1981;67(6): 782-790.

Robinson JK, Rigel DS, et al. "Trends in sun exposure knowledge, attitudes, and behaviors: 1986 to 1996." J Am Acad Dermatol. 1997;37(2 Pt 1): 179186.

Safaee Ardekani G, Jafarnejad SM, et al. "The prognostic value of BRAF mutation in colorectal cancer and melanoma: a systematic review and metaanalysis." PLoS One. 2012;7(10): e47054.

Sagebiel R. "Regression and other factors of prognostic interest in malignant melanoma." Arch Dermatol. 1985;121(9): 1125-1126.

Saldanha G, Potter L, et al. "Cutaneous melanoma subtypes show different BRAF and NRAS mutation frequencies." Clin Cancer Res. 2006;12(15): 4499-4505.

Sander B, Karlsson P, et al. "Cutaneous malignant melanoma in Swedish children and teenagers 1973-1992: a clinico-pathological study of 130 cases." Int J Cancer. 1999;80(5): 646-651.

Sasaki $\mathrm{Y}$, Niu C, et al. "BRAF point mutations in primary melanoma show different prevalences by subtype." J Invest Dermatol. 2004;123(1): 177-183.

Scalzo DA, Hida CA, et al. "Childhood melanoma: a clinicopathological study of 22 cases." Melanoma Res. 1997;7(1): 63-68. 
Schuchter L, Schultz DJ, et al. "A prognostic model for predicting 10-year survival in patients with primary melanoma. The Pigmented Lesion Group." Ann Int Med. 1996;125(5): 369-375.

Shinozaki M, Fujimoto A, et al. "Incidence of BRAF oncogene mutation and clinical relevance for primary cutaneous melanomas." Clin Cancer Res. 2004;10(5): 1753-1757.

Si L, Kong $\mathrm{Y}$, et al. "Prevalence of BRAF V600E mutation in Chinese melanoma patients: large scale analysis of BRAF and NRAS mutations in a 432-case cohort." Eur J Cancer. 2012;48(1): 94-100.

Silvers DN, Gorham JD. "Observations on a melanoma by William Norris, M.D., a country practitioner of the early 19th century." Am J Dermatopathol. 1982;4(5): 421-424.

Slingluff CL, Seigler Jr HF. "Thin" malignant melanoma: risk factors and clinical management." Ann Plast Surg. 1992;28(1): 89-94.

Sordella R, Bell DW, et al. "Gefitinib-sensitizing EGFR mutations in lung cancer activate anti-apoptotic pathways." Science. 2004;305(5687): 11631167.

Spatz A, Ruiter D, et al. "Melanoma in childhood: an EORTC-MCG multicenter study on the clinico-pathological aspects." Int $\mathrm{J}$ Cancer. 1996;68(3): 317-324.

Straume O, Akslen LA. "Independent prognostic importance of vascular invasion in nodular melanomas." Cancer. 1996;78(6): 1211-1219.

Terada T. "Low incidence of KIT gene mutations and no PDGFRA gene mutations in primary cutaneous melanoma: an immunohistochemical and molecular genetic study of Japanese cases." Int J Clin Oncol. 2010;15(5): 453-456. 
Thomas NE, Alexander A, et al. "Tandem BRAF mutations in primary invasive melanomas." J Invest Dermatol. 2004;122(5): 1245-1250.

Thomas NE, Berwick M, et al. "Could BRAF mutations in melanocytic lesions arise from DNA damage induced by ultraviolet radiation?" J Invest Dermatol. 2006;126(8): 1693-1696.

Thorn M, Ponten F, et al. "Clinical and histopathologic predictors of survival in patients with malignant melanoma: a population-based study in Sweden." J Natl Cancer Inst. 1994;86(10): 761-769.

Torres-Cabala CA, Wang WL, et al. "Correlation between KIT expression and KIT mutation in melanoma: a study of 173 cases with emphasis on the acrallentiginous/mucosal type." Mod Pathol. 2009;22(11): 1446-1456.

Ugurel S, Thirumaran RK, et al. "B-RAF and N-RAS mutations are preserved during short time in vitro propagation and differentially impact prognosis." PLoS One. 2007;2(2): e236.

Unger JM, Flaherty LE, et al. "Gender and other survival predictors in patients with metastatic melanoma on Southwest Oncology Group trials." Cancer. 2001;91(6): 1148-1155.

Uribe P, Wistuba II, et al. "BRAF mutation: a frequent event in benign, atypical, and malignant melanocytic lesions of the skin." Am J Dermatopathol, 2003;25(5): 365-370.

Van 't Veer LJ, Burgering BM, et al. "N-ras mutations in human cutaneous melanoma from sun-exposed body sites." Mol Cell Biol. 1989;9(7): 31143116.

Van Dongen JJ, Langerak AW, et al. "Design and standardization of PCR primers and protocols for detection of clonal immunoglobulin and T-cell receptor gene recombinations in suspect lymphoproliferations: report of the BIOMED-2 Concerted Action BMH4-CT98-3936." Leukemia. 2003;17(12): 2257-2317. 
Van Elsas A, Zerp S, et al. "Analysis of N-ras mutations in human cutaneous melanoma: tumor heterogeneity detected by polymerase chain reaction/single-stranded conformation polymorphism analysis." Recent Results Cancer Res. 1995;139: 57-67.

Viros A, Fridlyand J, et al. "Improving melanoma classification by integrating genetic and morphologic features." Plos Med. 2008;5(6): e120.

Wagner SN, Ockenfels HM, et al. "Ras gene mutations: a rare event in nonmetastatic primary malignant melanoma." J Invest Dermatol. 1995;104(5): 868-871.

Wan PT, Garnett MJ, et al. "Mechanism of activation of the RAF-ERK signaling pathway by oncogenic mutations of B-RAF." Cell. 2004;116(6): 855-867.

Weir HK, Marrett LD, et al. "Melanoma in adolescents and young adults (ages 15-39 years): United States, 1999-2006." J Am Acad Dermatol. 2011;65(5 Suppl 1): S38-49.

Went PT, Dirnhofer S, et al. "Prevalence of KIT expression in human tumors." J Clin Oncol. 2004;22(22): 4514-4522.

Whiteman DC, Pavan WJ, et al. "The melanomas: a synthesis of epidemiological, clinical, histopathological, genetic, and biological aspects, supporting distinct subtypes, causal pathways, and cells of origin." Pigment Cell Melanoma Res. 2011;24(5): 879-897.

Whiteman DC, Watt P, et al. (2003). "Melanocytic nevi, solar keratoses, and divergent pathways to cutaneous melanoma." J Natl Cancer Inst. 2003;95(11): 806-812.

Willmore-Payne C, Holden JA, et al. "BRAF and c-kit gene copy number in mutation-positive malignant melanoma." Hum Pathol. 2006;37(5): 520-527. 
Willmore-Payne $\mathrm{C}$, Holden JA, et al. "Human malignant melanoma: detection of BRAF- and c-kit-activating mutations by high-resolution amplicon melting analysis." Hum Pathol. 2005;36(5): 486-493.

Woodman SE, Davies MA. "Targeting KIT in melanoma: a paradigm of molecular medicine and targeted therapeutics." Biochem Pharmacol. 2010;80(5): 568-574.

Wu JM, Alvarez $\mathrm{H}$, et al. "Melanoma hyperpigmentation is strongly associated with KIT alterations." Am J Dermatopathol. 2009;31(7): 619-625.

Wu SJ, Lambert, DR. "Melanoma in children and adolescents." Pediatr Dermatol. 1997;14(2): 87-92.

Yarden Y, Kuang WJ, et al. "Human proto-oncogene c-kit: a new cell surface receptor tyrosine kinase for an unidentified ligand." EMBO J. 1987;6(11): 3341-3351.

Zettersten E, Sagebiel RW, et al. "Prognostic factors in patients with thick cutaneous melanoma (> 4 mm)." Cancer. 2002;94(4): 1049-1056.

Zettersten E, Shaikh L, et al. "Prognostic factors in primary cutaneous melanoma." Surg Clin North Am. 2003;83(1): 61-75. 
Apêndice 
7. Apêndice 1 - Informações gerais dos 139 casos de melanoma cutâneo em pacientes jovens (18-30 anos).

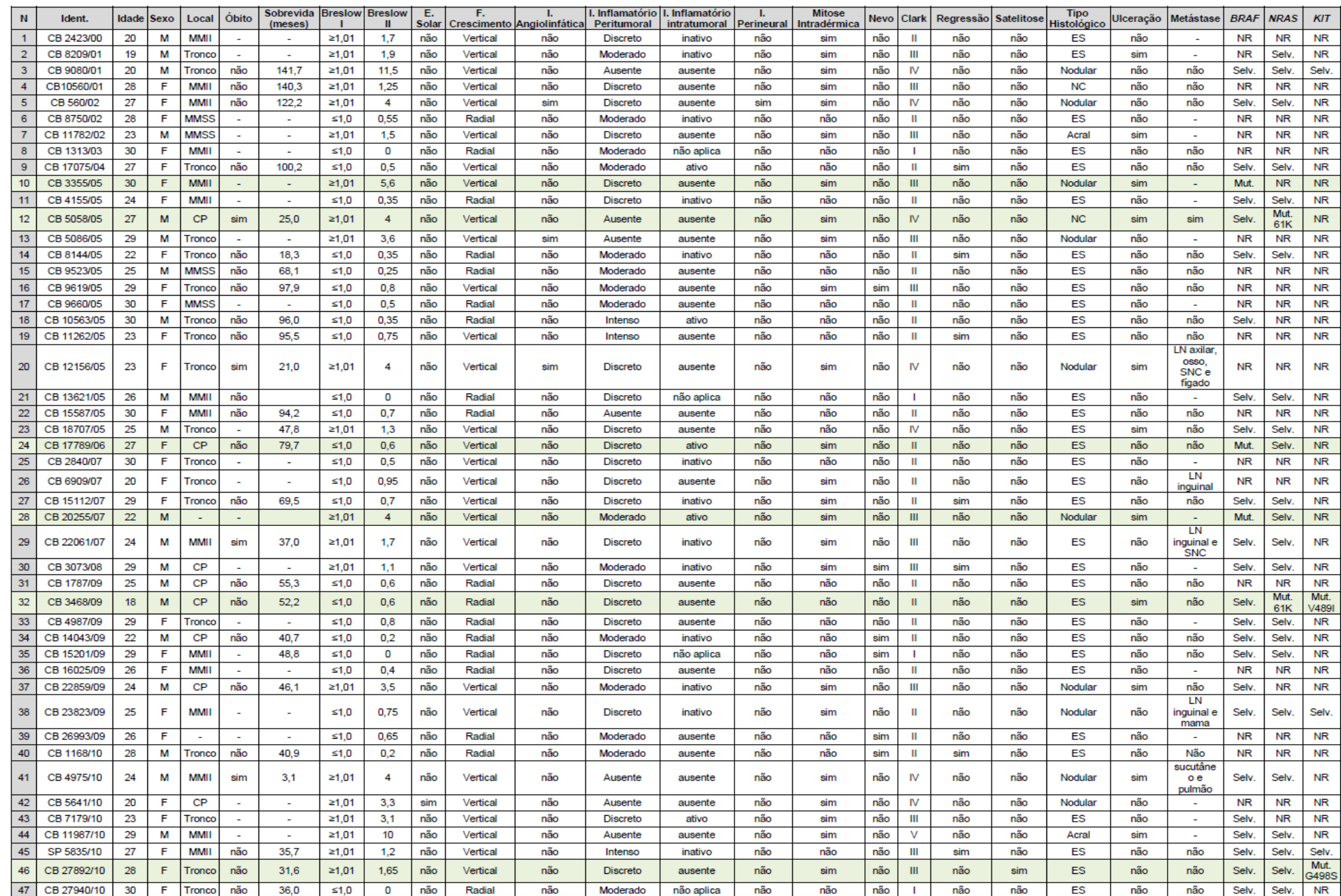




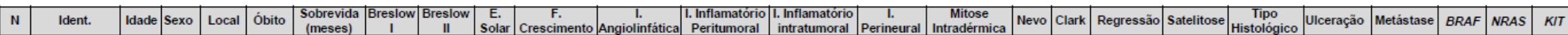

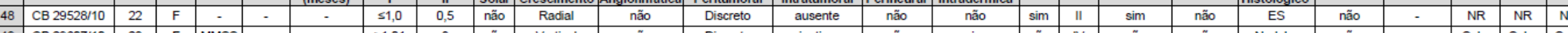

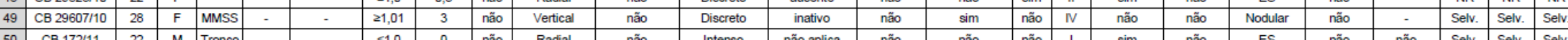

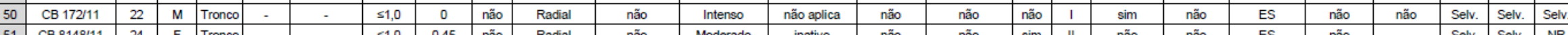

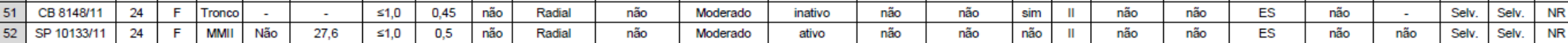

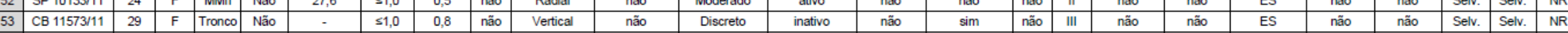

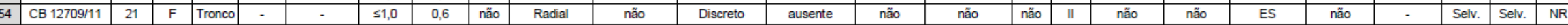

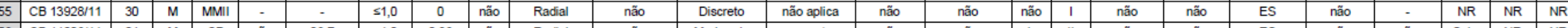

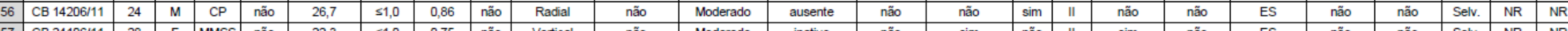

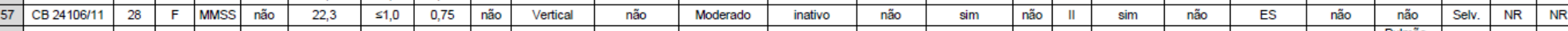

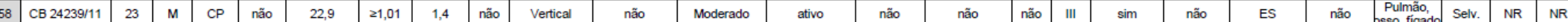

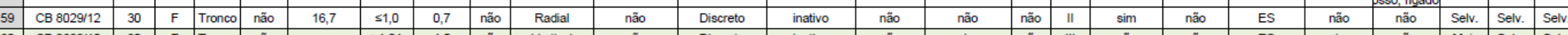

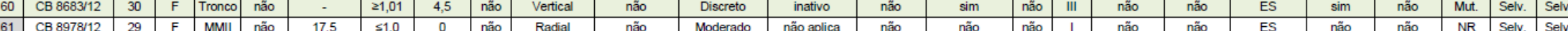

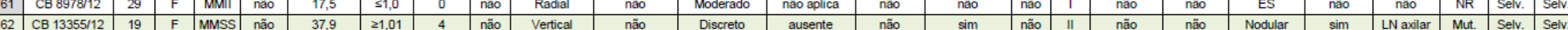

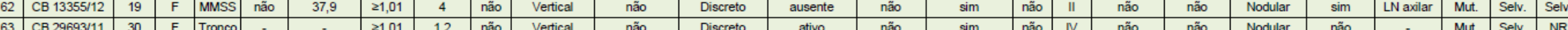

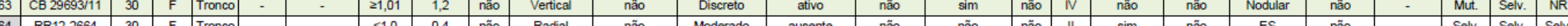

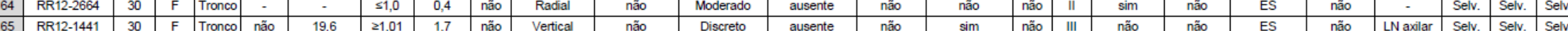

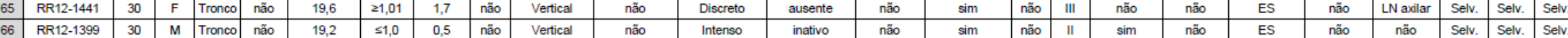

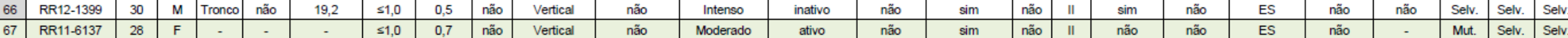

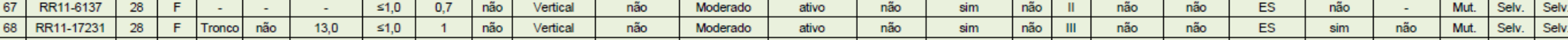

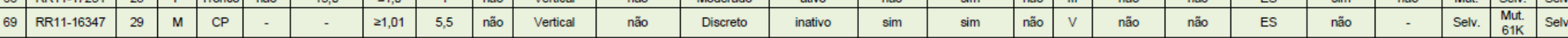

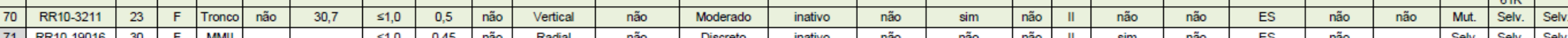

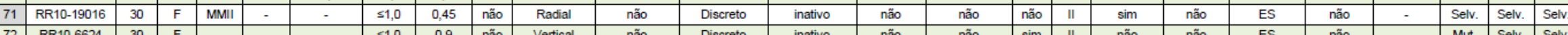

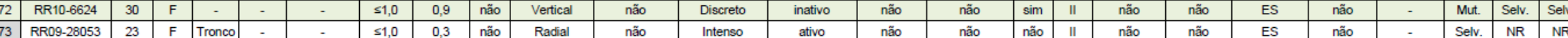

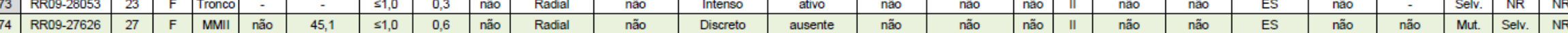

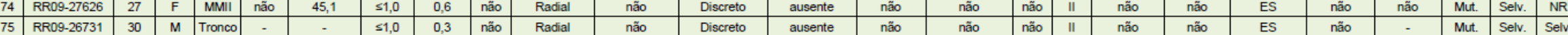

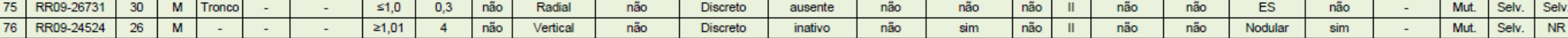

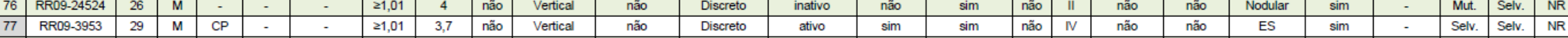

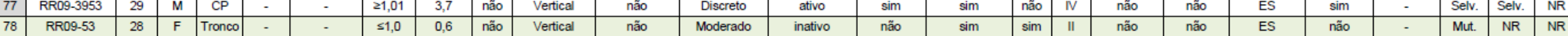

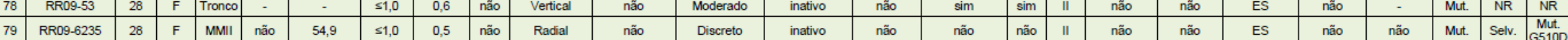

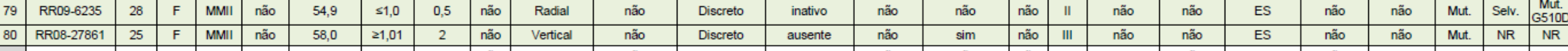

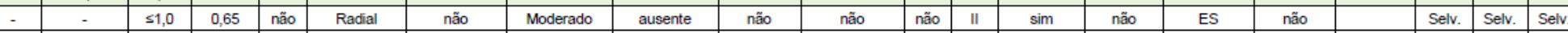

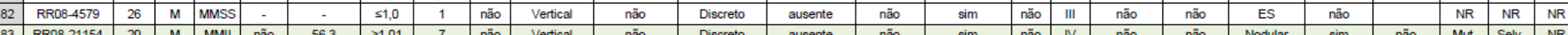

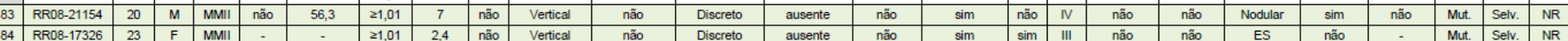

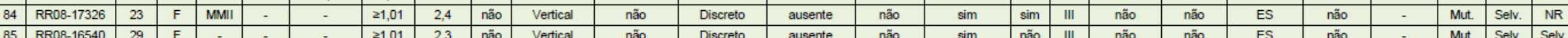

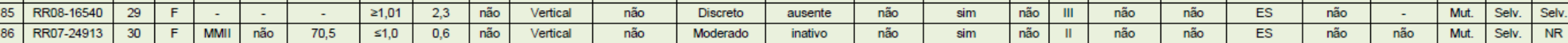

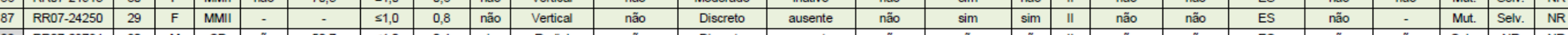

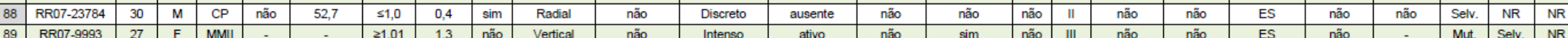

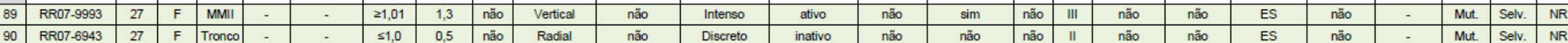

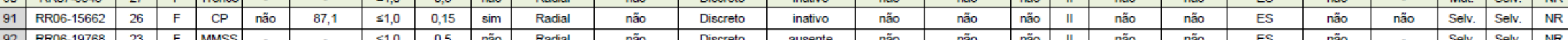

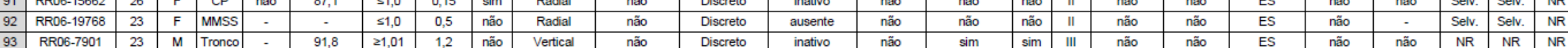

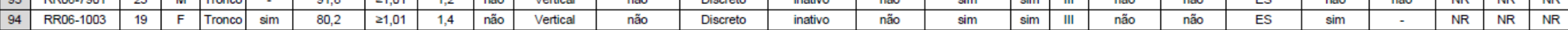




\begin{tabular}{|c|c|c|c|c|c|c|c|c|c|c|c|c|c|c|c|c|c|c|c|c|c|c|c|c|c|}
\hline $\mathrm{N}$ & Ident. & Idade & Sexo & Local & óbito & \begin{tabular}{c|}
$\begin{array}{c}\text { Sobrevida } \\
\text { (meses) }\end{array}$ \\
\end{tabular} & $\begin{array}{c}\text { Breslow } \\
1\end{array}$ & $\begin{array}{l}\text { eslow } \\
\text { II }\end{array}$ & \begin{tabular}{|c|}
$E$. \\
Solar
\end{tabular} & \begin{tabular}{c|} 
F. \\
Crescimento
\end{tabular} & \begin{tabular}{|c|}
1. \\
Angiolinfática
\end{tabular} & \begin{tabular}{|l|} 
1. Inflamatório \\
Peritumoral
\end{tabular} & \begin{tabular}{|c|} 
1. Inflamatório \\
intratumoral
\end{tabular} & \begin{tabular}{|c|}
1. \\
Perineural \\
\end{tabular} & \begin{tabular}{|c|} 
Mitose \\
Intradérmica
\end{tabular} & Nevo & Clark & Regressão & \begin{tabular}{|l|} 
Satelitose \\
\end{tabular} & $\begin{array}{l}\text { Tipo } \\
\text { Histológico }\end{array}$ & UIceraçäo & Metástase & $B R A F$ & NRAS & KIT \\
\hline 95 & RR05-5249 & 29 & $\mathrm{~F}$ & - & - & - & $\leq 1,0$ & 0,7 & não & Radial & não & Moderado & \begin{tabular}{|c|} 
inativo \\
\end{tabular} & năo & näo & \begin{tabular}{|l|} 
não \\
\end{tabular} & II & sim & não & ES & não & - & Selv. & Selv. & NR \\
\hline 96 & \begin{tabular}{|l|} 
RR05-14341 \\
\end{tabular} & 29 & $\mathrm{~F}$ & - & 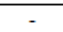 & - & $\leq 1,0$ & 0,5 & não & Radial & não & Discreto & ausente & não & não & \begin{tabular}{|l|} 
não \\
\end{tabular} & II & $\operatorname{sim}$ & não & ES & não & - & Selv. & Selv. & NR \\
\hline 97 & \begin{tabular}{|l|} 
RR04-12775 \\
\end{tabular} & 23 & $\mathrm{~F}$ & \begin{tabular}{|l|} 
MMII \\
\end{tabular} & não & 112,5 & 21,01 & 5,1 & não & Vertical & não & Discreto & ausente & não & $\operatorname{sim}$ & \begin{tabular}{|l|} 
não \\
\end{tabular} & $\mathrm{v}$ & não & não & Nodular & $\operatorname{sim}$ & não & Mut. & Selv. & NR \\
\hline 98 & $\begin{array}{l}\text { RR03-15404 } \\
\end{array}$ & 19 & M & Tronco & - & - & $\leq 1,0$ & 1 & não & Vertical & não & Discreto & ativo & não & $\operatorname{sim}$ & sim & IIII & não & não & ES & não & - & Mut. & Selv. & NR \\
\hline 99 & \begin{tabular}{|l|} 
RR03-21686 \\
\end{tabular} & 28 & $\mathrm{~F}$ & MMSS & - & - & $\leq 1,0$ & 0,5 & não & Radial & não & Moderado & ausente & não & não & \begin{tabular}{|l|} 
não \\
\end{tabular} & II & não & não & ES & não & - & Mut. & NR & NR \\
\hline 100 & RR03-19452 & 20 & M & Tronco & - & - & $\leq 1,0$ & 0,6 & não & Radial & não & Discreto & inativo & não & não & \begin{tabular}{|l|} 
não \\
\end{tabular} & II & näo & näo & ES & não & - & Mut. & NR & NR \\
\hline 101 & RR02-22153 & 26 & M & $\mathrm{CP}$ & não & 134,8 & $\leq 1,0$ & 0,8 & $\sin$ & Vertical & não & Moderado & inativo & não & não & \begin{tabular}{|l|} 
não \\
\end{tabular} & III & não & não & ES & não & não & \begin{tabular}{l|} 
Selv. \\
\end{tabular} & Selv. & NR \\
\hline 102 & \begin{tabular}{|l|} 
RR02-21435 \\
\end{tabular} & 20 & M & Tronco & não & 132,8 & $\leq 1,0$ & 0,45 & não & Radial & não & Discreto & inativo & não & não & \begin{tabular}{|l|} 
não \\
\end{tabular} & II & $\operatorname{sim}$ & não & ES & não & não & Selv. & Selv. & NR \\
\hline 103 & \begin{tabular}{|l|} 
RR01-12746 \\
\end{tabular} & 30 & M & & & & $\leq 1,0$ & 0,5 & não & Radial & não & Moderado & inativo & não & não & \begin{tabular}{|l|} 
não \\
\end{tabular} & II & não & não & ES & não & & NR & NR & NR \\
\hline 104 & $\begin{array}{l}\text { RR01-11855 } \\
\end{array}$ & 18 & $\mathrm{~F}$ & \begin{tabular}{|l|} 
MMII \\
\end{tabular} & não & 149,4 & 21,01 & 1,3 & não & Vertical & กão & Moderado & ativo & não & sim & \begin{tabular}{|l|} 
não \\
\end{tabular} & IIII & não & กão & ES & não & não & Selv. & Selv. & NR \\
\hline 105 & RR01-6642 & 30 & M & Tronco & - & - & 21,01 & 3 & não & Vertical & กão & Discreto & inativo & não & sim & \begin{tabular}{|l|} 
não \\
\end{tabular} & II & sim & não & Nodular & sim & - & NR & $\mathrm{NR}$ & NR \\
\hline 106 & RR00-2044 & 21 & M & \begin{tabular}{|l|} 
Tronco \\
\end{tabular} & sim & 24,2 & 21,01 & 3,2 & näo & Vertical & não & Discreto & inativo & não & sim & \begin{tabular}{|l|} 
não \\
\end{tabular} & N & näo & sim & ES & $\operatorname{sim}$ & SNC & Mut. & Selv. & NR \\
\hline 107 & RR00-7505 & 25 & $\mathrm{~F}$ & \begin{tabular}{|l|} 
Tronco \\
\end{tabular} & não & 164,3 & $s 1,0$ & 0,6 & não & Radial & não & Moderado & ativo & กão & não & sim & III & sim & กão & ES & nåo & não & \begin{tabular}{|l|} 
Sellv. \\
\end{tabular} & Selv. & NR \\
\hline 108 & RR99-5934 & 27 & M & \begin{tabular}{|l|} 
Tronco \\
\end{tabular} & sim & 73,6 & $s 1,0$ & 0,6 & näo & Vertical & não & Discreto & inativo & não & sim & \begin{tabular}{|l|} 
não \\
\end{tabular} & II & nåo & กäo & ES & não & v. biliar & \begin{tabular}{|l|} 
Mut. \\
\end{tabular} & Selv. & NR \\
\hline 109 & RR99-4869 & 28 & $\mathrm{~F}$ & \begin{tabular}{|l|} 
Tronco \\
\end{tabular} & não & 58,2 & 21,01 & 1,8 & não & Vertical & não & Discreto & inativo & não & sim & \begin{tabular}{|l|} 
não \\
\end{tabular} & IIII & não & não & Nodular & não & não & \begin{tabular}{|l|} 
Mut. \\
\end{tabular} & NR & NR \\
\hline 110 & RR99-8576 & 28 & $\mathrm{~F}$ & \begin{tabular}{|l|} 
Tronco \\
\end{tabular} & não & 172,4 & $\leq 1,0$ & 0,3 & não & Radial & não & Moderado & ativo & não & não & sim & II & não & não & ES & não & não & Selv. & Selv. & NR \\
\hline 111 & RR99-4312 & 25 & $\mathrm{~F}$ & MMSS & - & - & $\leq 1,0$ & 0 & não & Radial & não & Moderado & não aplica & não & não & sim & 1 & não & não & ES & não & - & Selv. & Selv. & NR \\
\hline 112 & RR99-1675 & 28 & $\mathrm{~F}$ & - & - & - & 21,01 & 1,1 & não & Vertical & não & Discreto & inativo & não & $\operatorname{sim}$ & \begin{tabular}{|l|} 
não \\
\end{tabular} & IIII & não & กão & ES & não & - & Selv. & NR & NR \\
\hline 113 & \begin{tabular}{l|l} 
RR99-18914 \\
\end{tabular} & 28 & $\mathrm{~F}$ & \begin{tabular}{|l|} 
MMII \\
\end{tabular} & - & - & $s 1,0$ & 0,8 & não & Vertical & não & Moderado & inativo & não & não & \begin{tabular}{|l|} 
não \\
\end{tabular} & IIII & não & não & ES & não & - & NR & $\mathrm{NR}$ & NR \\
\hline 114 & RR99-16805 & 28 & M & \begin{tabular}{|l|} 
Tranco \\
\end{tabular} & $\operatorname{sim}$ & 9,8 & 21,01 & 2,2 & não & Vertical & não & Discreto & inativo & não & sim & não & III & não & não & ES & $\operatorname{sim}$ & $\begin{array}{c}\text { LN axilar, } \\
\text { pele, } \\
\text { figado, } \\
\text { SNC, }\end{array}$ & NR & NR & NR \\
\hline 115 & \begin{tabular}{|l|} 
RR99-16500 \\
\end{tabular} & 23 & $\mathrm{~F}$ & \begin{tabular}{|l|} 
MMSS \\
\end{tabular} & - & 50,4 & 21,01 & 1,2 & näo & Vertical & não & Discreto & ativo & não & sim & \begin{tabular}{|l|} 
não \\
\end{tabular} & IIII & não & não & Nodular & $\operatorname{sim}$ & năo & NR & NR & NR \\
\hline 116 & \begin{tabular}{|l|} 
RR99-16468 \\
\end{tabular} & 29 & $\mathrm{~F}$ & \begin{tabular}{|l|} 
MMII \\
\end{tabular} & não & 170,2 & $s 1,0$ & 0,35 & näo & Radial & não & Moderado & inativo & não & não & \begin{tabular}{|l|} 
não \\
\end{tabular} & II & กล̃o & กão & ES & não & não & NR & NR & NR \\
\hline 117 & $\begin{array}{ll}R R 98-3613 \\
\end{array}$ & 28 & M & \begin{tabular}{|l|} 
MMSS \\
\end{tabular} & - & - & $s 1,0$ & 0 & näo & Radial & não & Discreto & näo aplica & não & não & \begin{tabular}{|l|} 
não \\
\end{tabular} & 1 & não & não & ES & não & - & $N R$ & NR & NR \\
\hline 118 & RR98-2705 & 27 & M & Tronco & - & - & 21,01 & 3,2 & näo & Vertical & não & Discreto & inativo & não & sim & \begin{tabular}{|l|} 
não \\
\end{tabular} & N & não & não & ES & $\operatorname{sim}$ & - & NR & NR & NR \\
\hline 119 & \begin{tabular}{|l|} 
RR98-8779 \\
\end{tabular} & 26 & $\mathrm{~F}$ & Tronco & não & 186,2 & $\leq 1,0$ & 0,25 & não & Radial & não & Moderado & ativo & não & não & sim & II & $\operatorname{sim}$ & não & ES & não & não & Selv. & NR & NR \\
\hline 120 & RR98-118 & 18 & $\mathrm{~F}$ & \begin{tabular}{|l|} 
MMII \\
\end{tabular} & não & 192,7 & 21,01 & 3 & não & Vertical & não & Moderado & ausente & não & sim & \begin{tabular}{|l|} 
não \\
\end{tabular} & IIII & กล̃o & กล̃o & Nodular & não & näo & NR & NR & $\mathrm{NR}$ \\
\hline 121 & RR97-11461 & 30 & M & \begin{tabular}{|l|} 
Tronco \\
\end{tabular} & não & 195,8 & $\leq 1,0$ & 0,65 & não & Vertical & não & Discreto & inativo & não & não & \begin{tabular}{|l|} 
não \\
\end{tabular} & IIII & não & não & ES & não & não & NR & NR & NR \\
\hline 122 & \begin{tabular}{|l|} 
RR97-1478 \\
\end{tabular} & 28 & $\mathrm{~F}$ & \begin{tabular}{|l|} 
MMSS \\
\end{tabular} & não & 203,6 & 21,01 & 1,5 & não & Vertical & não & Moderado & ativo & não & sim & \begin{tabular}{|l|} 
não \\
\end{tabular} & IIII & não & กão & ES & não & não & NR & NR & NR \\
\hline 123 & RR97-1333 & 26 & M & $C P$ & $\operatorname{sim}$ & 71,8 & 21,01 & 4,5 & não & Vertical & não & Moderado & inativo & não & sim & não & IIII & não & não & Nodular & $\operatorname{sim}$ & $\begin{array}{l}\text { LN axilarl } \\
\text { cervicale } \\
\text { seluctataneo }\end{array}$ & Mut. & NR & NR \\
\hline 124 & RR96-5677 & 28 & M & Tronco & sim & 19,6 & 21,01 & 1,2 & não & Vertical & não & Moderado & inativo & não & sim & sim & IIII & não & näo & ES & não & sim & NR & NR & NR \\
\hline 125 & RR96-8693 & 24 & M & \begin{tabular}{|l|} 
MMSS \\
\end{tabular} & não & 209,3 & 21,01 & 1,1 & não & Radial & não & Discreto & ausente & não & não & \begin{tabular}{|l|} 
não \\
\end{tabular} & II & não & não & ES & não & não & Mut. & Selv. & NR \\
\hline 126 & $\begin{array}{l}R R 95-10426 \\
\end{array}$ & 26 & $\mathrm{~F}$ & \begin{tabular}{|l|} 
Tronco \\
\end{tabular} & não & 222,9 & $\leq 1,0$ & 0,9 & nåo & $\begin{array}{l}\text { Vertical } \\
\end{array}$ & não & Moderado & ativo & nẫo & sim & \begin{tabular}{|l|} 
não \\
\end{tabular} & IIII & năo & năo & ES & sim & nẫo & NR & NR & NR \\
\hline 127 & $\begin{array}{l}R R 95-8574 \\
\end{array}$ & 28 & $\mathrm{M}$ & \begin{tabular}{|l|} 
Tronco \\
\end{tabular} & não & 221,9 & 21,01 & 3 & năo & Vertical & Não & Discreto & inativo & năo & sim & \begin{tabular}{|l|} 
sim \\
\end{tabular} & IIII & năo & năo & Nodular & $\operatorname{sim}$ & năo & Selv. & NR & NR \\
\hline 128 & CB 16145/12 & 29 & $\mathrm{~F}$ & \begin{tabular}{|l|} 
MMSS \\
\end{tabular} & & - & $s 1,0$ & 0 & não & Radial & Não & Discreto & não aplica & não & não & \begin{tabular}{|l|} 
não \\
\end{tabular} & $\frac{1}{1}$ & não & não & ES & năo & 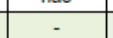 & Mut. & NR & NR \\
\hline 129 & CB 19321/12 & 22 & M & \begin{tabular}{|l|} 
MMII \\
\end{tabular} & não & - & $\leq 1,0$ & 0,3 & não & Radial & Não & Discreto & ausente & não & não & \begin{tabular}{|l|} 
sim \\
\end{tabular} & "I & năo & năo & ES & não & näo & Mut. & NR & Selv. \\
\hline 130 & CB 15139/12 & 19 & $\mathrm{~F}$ & \begin{tabular}{|l|} 
MMII \\
\end{tabular} & - & - & $\leq 1,0$ & 0 & nå̃o & Radial & Não & Discreto & não aplica & não & não & \begin{tabular}{|l|} 
sim \\
\end{tabular} & 1 & năo & não & ES & não & & Selv. & Selv. & NR \\
\hline 131 & CВ 20108/12 & 23 & $\mathrm{~F}$ & MMss & - & - & 21,01 & 3,8 & não & Vertical & Não & Discreto & inativo & não & sim & não & III & não & não & Nodular & sim & $\begin{array}{c}\text { LN axilar } \\
\text { e r. } \\
\text { peitoral }\end{array}$ & Mut. & Selv. & Selv. \\
\hline 132 & CB 18525/12 & 26 & M & \begin{tabular}{|l|} 
Tronco \\
\end{tabular} & - & - & $s 1,0$ & 0,7 & näo & Vertical & Não & Discreto & inativo & não & sim & \begin{tabular}{|l|} 
sim \\
\end{tabular} & II & não & não & ES & não & & Mut. & Selv. & Selv. \\
\hline
\end{tabular}

$\begin{array}{lllll}\text { M - Masculino } & \text { F - Feminino } & \text { CP - Cabeça e pescoço } & \text { MMSS- Membros superiores } & \text { MMII - Membros inferiores } \\ \text { Selv. - Selvagem } & \text { Mut. - Mutado } & \text { NR - Não realizado } & \text { LN - Linfonodo } & \text { ES - Extensivo superficial } \\ & & \text { SNC - Sistema Nervoso Central } & \text { v. biliar - vesícula biliar }\end{array}$


Anesas 
Anexo 1 - Parecer do Comitê de Ética em Pesquisa.

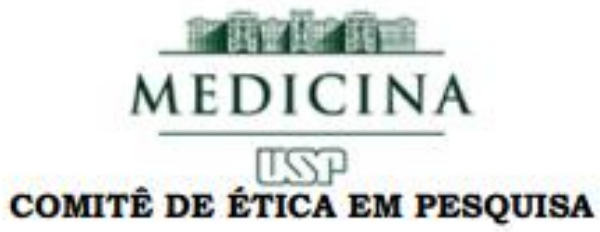

\section{APROVAÇÃO}

o Comitê de Ética em Pesquisa da Faculdade de Medicina da Universidade de São Paulo, em sessão de 11/o7/2012, APROVOU o Protocolo de Pesquisa $\mathrm{n}^{\circ}$ 149/12 intitulado: "AVALIAÇão ANÁTOMO-CLÍNICA E MOLECULAR do MELANOMA CUTÂNEO EM PACIENTES JOVENS (IDADE $\leq 30$ ANOS)" apresentado pelo Departamento de PATOLOGIA

Cabe ao pesquisador elaborar e apresentar ao CEPFMUSP, os relatórios parciais e final sobre a pesquisa (Resolução do Conselho Nacional de Saúde $n^{\circ}$ 196, de 10/10/1996, inciso IX.2, letra "c").

Pesquisador (a) Responsável: Carlos E. Bacchi

Pesquisador (a) Executante: Bruna Estrozi

CEP-FMUSP, 17 de Julho de 2012.

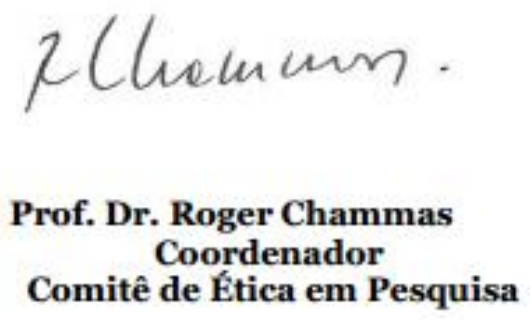


Anexo 2 - Artigo Publicado.

\title{
Clinicopathologic Findings and BRAF Mutation in Cutaneous Melanoma in Young Adults
}

\author{
Bruna Estrozi, MD, ${ }^{*} \dagger$ Juliana Machado, RPh, ${ }^{*}$ Rubens Rodriguez, MD, + \\ and Carlos E. Bacchi, MD, PhD*†
}

\begin{abstract}
Cutaneous melanoma in young patients is rare with increasing incidence. It is not clear whether the etiology and clinical outcome are similar to cutaneous melanoma in the elderly. Mutations in BRAF gene in patients with cutaneous melanoma, in general, range in frequency from $20 \%$ to $80 \%$; however, the status and clinical significance of $B R A F$ mutations in the young population have not been evaluated. We investigated 132 cases of primary cutaneous melanoma in patients aged between 18 and 30 years with emphasis on clinical characteristics, pathologic features, and molecular evaluation of mutation in the $B R A F$ gene $\left(B R A F^{\mathrm{V} 600 \mathrm{E}}\right)$. It was predominantly seen in female individuals $(61.4 \%)$, trunk was the most common site of involvement $(40.4 \%)$, and superifially spreading melanoma was the predominant histologic type $(79.5 \%)$. Mutation in $B R A F^{\mathrm{V} 600 \mathrm{E}}$ was analyzed successfully in 93 cases using an RTPCR. The $B R A F^{\mathrm{V} 600 \mathrm{E}}$ mutation was identified in $38.7 \%(36 / 93)$ and was associated with vertical growth phase $(P=0.01)$ and mild inflammatory infiltrate $(P=0.02)$. No case of melanoma with regression phenomenon presented with $B R A F^{\mathrm{V} 600 \mathrm{E}}$ mutation $(P<0.05)$. There was no significant association between $B R A F^{\mathrm{V} 600 \mathrm{E}}$ mutation and sex, histologic type, the Clark level, the Breslow index, solar elastosis, angiolymphatic and perineural invasion, satellitosis, and coexisting nevus. As in melanomas in older patients, these results probably indicate that $B R A F$ mutation may not be the only key factor in melanoma tumorigenesis, and that there should be multiple alternative genetic pathways related to melanoma.
\end{abstract}

Key Words: melanoma, BRAF, mutation, young adults, skin, molecular biology

(Appl Immunohistochem Mol Morphol 2014;22:57-64)

utaneous melanoma occurs predominantly in adults, with a peak incidence around the sixth decade of life; however, recently, melanoma has been diagnosed increasingly in middle-aged adults and youth with a considerable number of case reports in children and

From the * Consultoria em Patologia, Botucatu; $†$ Department of Pathology of Faculdade de Medicina da Universidade de São Paulo, São Paulo, SP; and $\ddagger$ Instituto de Patologia, Passo Fundo, RS, Brazil The authors declare no conflict of interest.

Reprints: Carlos E. Bacchi, MD, PhD, Consultoria em Patologia, Rua Leônidas Cardoso 739, Botucatu, SP 18602-010, Brazil (e-mail: bacchi@conspat.com.br).

Copyright $(2013$ by Lippincott Williams \& Wilkins adolescents. ${ }^{1}$ The incidence of melanoma in prepubertal patients is very low with estimates of $0.4 \%$ of all melanomas. ${ }^{2}$ In adolescents, the incidence is $2 \%$, and in young adults up to the age of 30 years the incidence is $3.3 \% .^{3,4}$

Although rare, cutaneous melanoma is the second most commonly diagnosed cancer in patients under the age of 30 years in the United States of America, surpassed only by lymphomas. ${ }^{5}$ The main risk factors for melanoma in young people have been attributed to the number of atypical nevi, large congenital nevi, family history of melanoma, xeroderma pigmentosum, immunosuppression, and repeated or severe sunburn in childhood. ${ }^{6}$ Some studies have suggested that young patients may experience worse outcomes with earlier recurrences compared with adults, whereas a more favorable outcome in the young also has been reported. ${ }^{7-9}$ Livestro et al ${ }^{10}$ demonstrated that the survival of young patients with melanoma was similar to the survival of adult thickness-matched control, and prognostic factors in young patients were similar to those identified in adult melanoma. It has been reported that young patients have a higher percentage of thick melanomas, nodular histologic type, and increased risk of lymph node metastasis compared with adult patients. ${ }^{9-11}$ These findings suggest that melanoma may not be a homogenous entity, and young patients may have a disease that differs biologically from that occurring in older patients.

The recent identification of genetic alterations related to the development and progression of melanoma supports the concept of biologically distinct types of this disease. The most common gene mutations described in cutaneous melanomas involve the following genes: $B R A F, N R A S$, and $K I T$. The mitogen-activated protein kinase (MAPK) pathway (RAS/RAF/MEK/ERK) is a critical growth pathway in cutaneous melanoma. ${ }^{12}$ BRAF is a serine threonine protein kinase activated by the Ras-GTP protein. ${ }^{13}$ The gene encodes a BRAF cascade serine/threonine kinase through a RAS/RAF/MAPK pathway involved with the mitogenic signal transduction receptor membrane to the nucleus of cells. ${ }^{13}$ Mutations in the BRAF gene, located on chromosome $7 \mathrm{q}$, are the most frequent mutations $(60 \%$ to $80 \%)$ found in human melanomas. ${ }^{13,14}$ Eighty percent of these mutations are found in exon 15 in a single amino acid residue, usually a substitution of valine for glutamic acid (V600E) $\left(B R A F^{\mathrm{V} 600 \mathrm{E}}\right){ }^{13}$

In this study, we report 132 cases of cutaneous malignant melanoma in patients between 18 and 30 years 
of age with the emphasis on clinical characteristics, pathologic features, and the evaluation of the $B R A F^{\mathrm{V} 600 \mathrm{E}}$ mutation.

\section{MATERIALS AND METHODS}

\section{Patient Selection}

This study was approved by the Department of Pathology Scientific Committee of the Faculdade de Medicina da Universidade de São Paulo and by the Ethical Committee for Research Projects of the Hospital das Clínicas da Faculdade de Medicina da Universidade de São Paulo (CAPPesq, process \#149/12). As the study was retrospective, informed patient consent was waived, and any form of patient identification was abolished. The study involved the analysis of 132 young adult patients (aged between 18 and $30 \mathrm{y}$ ), who were diagnosed with primary cutaneous melanoma between 1995 and 2012 in 2 distinct pathology laboratories: Consultoria em Patologia (68 cases), Botucatu, São Paulo State and Instituto de Patologia (64 cases), Passo Fundo, Rio Grande do Sul State, both in Brazil. Demographic data (age at diagnosis and sex) were recorded. The anatomic locations were divided into 4 groups when the information was available: trunk, head and neck, lower limbs, and upper limbs.

\section{Histopathology}

All slides of the primary lesions were reassessed by at least one of the authors (B.E., C.E.B., and R.R.) and reevaluated according to the criteria described by the World Health Organization (2006). For cases with discordant interpretations with respect to the original report, a consensus was determined by simultaneous examination under a dual-head microscope (B.E. and C.E.B.). New histologic sections were obtained from paraffin blocks and stained with hematoxylin and eosin when necessary. Histologic characteristics were reviewed, that is, histologic type (superficial spreading, nodular, acral lentiginous and lentigo maligna, and unclassifiable when a specific subtype was not possible to be assessed), the Clark level (through levels I to V), the Breslow index (in $\mathrm{mm}$ ), tumor growth phase (radial or vertical), size, ulceration, mitotic index (number of mitoses/10 high-power fields), regression, angiolymphatic invasion, perineura infiltration, microscopic satellitosis, peritumoral and intratumoral inflammatory infiltrate, associated nevus, and solar elastosis.

\section{Molecular Biology}

DNA Extraction and Mutational Analysis of $B R A F$

All tumor specimens underwent microdissection based on hematoxylin and eosin sections obtained from native paraffin block findings before DNA was extracted from formalin-fixed, paraffin-embedded tissues using a saline method. A qualitative size range PCR assay was performed to determine the DNA quality of formalinfixed, paraffin-embedded tissue samples. The assay comprised 5 primers that amplify products of 100 through 600 base pairs and has been used before successfully. ${ }^{15}$ The

58 | www.appliedimmunohist.com cases with adequately preserved DNA were evaluated for $B R A F^{\mathrm{V} 600 \mathrm{E}}$ mutation using real-time PCR allelic discrimination. PCR amplification was performed in $15 \mu \mathrm{L}$ of reaction mixtures comprising $5 \mathrm{ng}$ of template DNA, $1 \times$ TaqMan Universal Master Mix (Applied Biosystems, Foster City, CA), $1 \times$ of each primer and a probe assay (Custom Taqman SNP Genotyping assays), and $\mathrm{H}_{2} \mathrm{O}$ qsp. The thermal cycling was initiated with a denaturation step of 10 minutes at $95^{\circ} \mathrm{C}$, followed by 40 cycles of denaturation at $95^{\circ} \mathrm{C}$ for 15 seconds, and annealing at $60^{\circ} \mathrm{C}$ for 1 minute on a 7500 Fast Real-Time System (Applied Biosystems).

\section{Statistical Methodology}

Descriptive analysis was made for all studied variables. For discrete variables, frequency distribution was raised, and averages and SDs were calculated for the quantitative variables (age and thickness). For the assessment of thickness, we used the analysis of variance technique ANOVA and the F-Fisher statistic. The same technique was used in the comparison of the age averages by sex. To evaluate the effect of sex on the melanoma location and $B R A F^{\mathrm{V} 600 \mathrm{E}}$ mutation, contingency tables were elaborated (double entry), and the association was evaluated by the Pearson $\chi^{2}$ statistic. The significance level adopted in all tests was 0.05 , and, for all observed statistics, the values of descriptive level $P$ were calculated and presented in the text.

\section{RESULTS}

\section{Clinical Findings}

Of the 132 patients surveyed, $81(61.4 \%)$ were female and $51(38.6 \%)$ were male. The average age at diagnosis was 25.9 years (range, 18 to $30 \mathrm{y}$ ). The median male age was 26 (mean 25.31) years, whereas the median female age was 28 (mean 26.36) years. In $15(11.3 \%$ ) patients, there was a history of change of size and alteration of color and/or symmetry of the lesion. Bleeding was reported in 4 cases. In 1 case, there were changes in a preexisting melanocytic lesion during pregnancy. One patient reported a family history of melanoma in a grandfather. A giant congenital melanocytic nevus at the site of the subsequent melanoma was documented in 1 case. The distribution of anatomic location of all 132 cases evaluated is presented in Figure 1A. The most common anatomic primary site of involvement was the trunk in $32 \%$ of patients ( 42 cases), followed by the lower limbs in $25 \%$ ( 33 cases). In $21 \%$ ( 28 cases) of the patients, the site of involvement was not possible to determine. In male patients, melanomas were located most frequently in the trunk, followed by the head and the neck, whereas the lower limbs followed by the trunk were the most common anatomic locations in female patients (Fig. 1B).

\section{Histopathology}

The histologic classification was as follows: 105 $(79.5 \%)$ cases of superficially spreading melanoma, including 11 cases represented by "in situ" melanoma, 23 

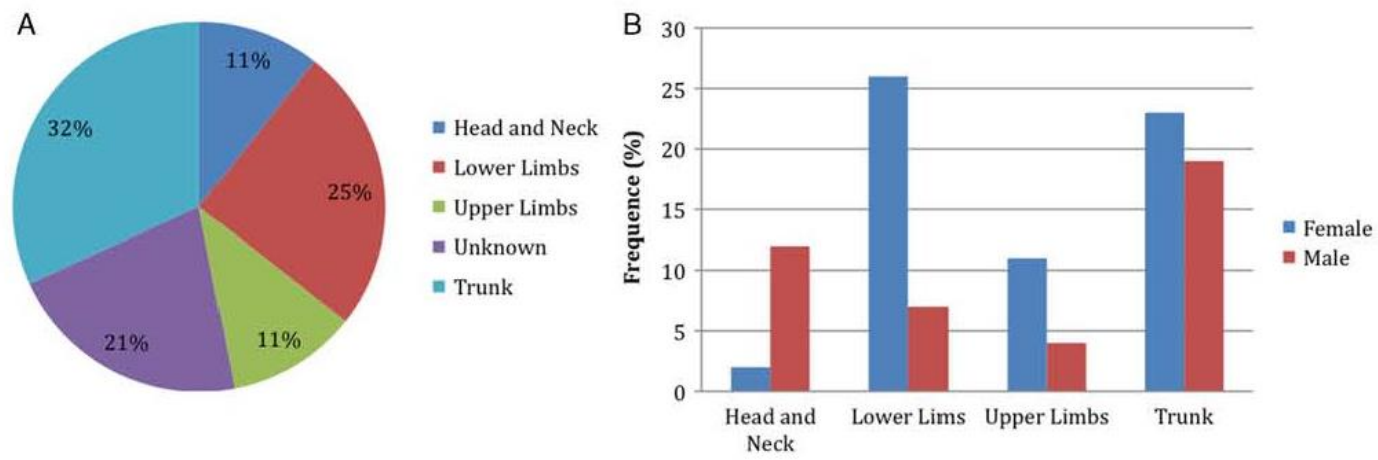

FIGURE 1. A, Distribution by anatomic sites of 132 cases of cutaneous melanoma in patients between 18 and 30 years of age. B, Comparison of anatomic location in 104 cases of cutaneous melanoma in patients between 18 and 30 years of age by sex.

$(17.5 \%)$ nodular melanomas, $2(1.5 \%)$ acral lentiginous melanomas, and $2(1.5 \%)$ unclassifiable. There were no cases of lentigo maligna melanoma. Most cases presented with the Clark level II $(48.5 \%)$, followed by level III $(31.1 \%)$. Tumor thickness in invasive lesions ranged from 0.2 to $11.5 \mathrm{~mm}$ (average $1.65 \pm 1.31 \mathrm{~mm}$ ). With respect to thickness evaluation, the results were: $79(59.84 \%)$ cases had 0 to $1.0 \mathrm{~mm}$-thick tumors (thin melanoma), 23 $(17.42 \%)$ cases had 1.01 to $2.0 \mathrm{~mm}$-thick tumors, 22 $(16.66 \%)$ cases had 2.01 to $4.0 \mathrm{~mm}$-thick tumors, and 8 $(6.06 \%)$ cases had $>4.0 \mathrm{~mm}$-thick tumors. The mean Breslow thickness was greater in male patients $(2.06 \mathrm{~mm})$ than in female patients $(1.17 \mathrm{~mm})$. The medium size of the lesions was $7.85 \mathrm{~mm}( \pm 3.36 \mathrm{~mm})$. Ulceration was detected in $28(21.2 \%)$ cases. Radial growth phase was found in 54 of $132(40.9 \%)$ patients, whereas majority $(59.1 \%)$ of them presented with vertical growth. Mitotic figures (at least 1) in the dermal component were found in $51.5 \%$ of the cases. Only $22(16.7 \%)$ patients presented with regression phenomenon. Angiolymphatic invasion was detected in only $3(2.3 \%)$, and perineural infiltration also was detected in only $3(2.3 \%)$ patients. Satellitosis was seen in $2(1.5 \%)$ patients. Most cases ( 74 cases; $56 \%)$ had mild inflammatory infiltrate. Solar elastosis was identified in 4 patients ( $3 \%$ ). The presence of melanocytic nevus was observed in $18.9 \%$ of the patients (25/132).

Clinicopathologic information in all patients is detailed in Table 1.

\section{Molecular Biology Findings}

Figure 2 summarizes the algorithm used in this study according to the availability of adequate DNA for the evaluation of $B R A F^{\mathrm{V} 600 \mathrm{E}}$ mutation. In 112 cases, paraffin blocks were available for molecular genetic analysis, and DNA amplification were obtained successfully in 93 cases ( 86 cases of invasive melanomas and 7 cases of in situ melanomas). $B R A F^{\mathrm{V} 600 \mathrm{E}}$ mutation was found in 36 cases $(38.7 \%$ ). Figure 3 illustrates a case of melanoma with mutation. The $B R A F^{\mathrm{V} 600 \mathrm{E}}$ mutation was detected in $26(35.1 \%)$ of a total of 74 superficially spreading melanomas and in $10(58.8 \%)$ of 17 nodular melanomas. Only 1 of 7 cases of in situ melanoma revealed $B R A F^{\mathrm{V} 600 \mathrm{E}}$ mutation. The majority of the cases with $B R A F^{\mathrm{V} 600 \mathrm{E}}$ mutation ( 29 cases, $80.6 \%$ ) were not associated with melanocytic nevus. The incidence of $B R A F^{\mathrm{V} 600 \mathrm{E}}$ mutation classified by anatomic sites was the highest in the extremities (lower and upper limbs) (15 of 27 cases, $55.5 \%$ ), followed by the trunk (11 cases, $40.7 \%$ ) and the head and neck ( 1 case, $3.7 \%)$. The $B R A F^{\mathrm{V} 600 \mathrm{E}}$ mutation was seen in 24 of $59(40.7 \%)$ female patients and in 12 of $34(35.3 \%)$ male patients and in 18 cases $(50 \%)$ with tumor depth $\leq 1.0 \mathrm{~mm}, 5(13.9 \%)$ with 1.01 to $2.0 \mathrm{~mm}, 7(19.4 \%)$ with 2.01 to $4.0 \mathrm{~mm}$, and $5(13.9 \%)$ with $>4.0 \mathrm{~mm}$. In 3 cases with moderate to intense solar elastosis available for molecular study, $B R A F^{\mathrm{V} 600 \mathrm{E}}$ mutation was not detected (Table 2).

\section{DISCUSSION}

Cutaneous melanoma is the most lethal form of skin cancer and the second most commonly diagnosed cancer, preceded only by lymphomas, among adolescents and young adults under the age of 30 years. ${ }^{5}$ The cutoff age used to define melanoma in the young varies widely in published reports. Although rare, the incidence of cutaneous melanomas in young patients has increased in many parts of the world. ${ }^{1,16,17}$ In the present study, we report 132 cases of melanoma in patients aged between 18 and 30 years with respect to clinicopathologic findings and mutational analysis of the $B R A F$ gene, more specifically, mutation in exon 15 in a single amino acid residue, usually a substitution of valine for glutamic acid (V600E) $\left(B R A F^{\mathrm{V} 600 \mathrm{E}}\right)$.

In our patients, the clinical signs and symptoms reported were change in size, alteration in color and shape of the lesion, and bleeding. The incidence was greater in the young female population $(61.4 \%)$. This has been in accordance with the previous studies examining melanoma within adolescent and young adult populations but differs from the pattern of male predominance seen at 


\begin{tabular}{|c|c|}
\hline Total & 132 \\
\hline \multicolumn{2}{|l|}{$\operatorname{Sex}[\mathrm{n}(\%)]$} \\
\hline Female & $81(61.4)$ \\
\hline Male & $51(38.6)$ \\
\hline Location $[\mathrm{n}(\%)]$ & (104) \\
\hline Trunk & $42(40.4)$ \\
\hline Upper extremity & $15(14.4)$ \\
\hline Lower extremity & $33(31.7)$ \\
\hline Head and neck & $14(13.5)$ \\
\hline \multicolumn{2}{|l|}{ Melanoma type $[\mathrm{n}(\%)]$} \\
\hline Superficia 1 spreading & $105(79.5)$ \\
\hline Nodular & $23(17.4)$ \\
\hline Acral lentiginous & $2(1.5)$ \\
\hline Lentigo maligna & $0(0)$ \\
\hline Not specified & $2(1.5)$ \\
\hline \multicolumn{2}{|l|}{ Breslow thickness $[\mathrm{n}(\%)]$} \\
\hline In situ & $7(5.3)$ \\
\hline$\leq 1.0 \mathrm{~mm}$ & $72(54.5)$ \\
\hline $1.01-2.0 \mathrm{~mm}$ & $23(17.4)$ \\
\hline $2.014 .0 \mathrm{~mm}$ & $22(16.7)$ \\
\hline$>4.0 \mathrm{~mm}$ & $8(6.1)$ \\
\hline \multicolumn{2}{|l|}{ Clark level $[\mathrm{n}(\%)]$} \\
\hline I & $11(8.3)$ \\
\hline II & $64(48.5)$ \\
\hline III & $41(31.1)$ \\
\hline IV & $13(9.8)$ \\
\hline $\mathrm{V}$ & $3(2.3)$ \\
\hline \multicolumn{2}{|l|}{ Growth phase $[\mathrm{n}(\%)]$} \\
\hline Radial & $54(40.9)$ \\
\hline Vertical & $78(59.1)$ \\
\hline \multicolumn{2}{|l|}{ Solar elastosis [n (\%)] } \\
\hline Yes & $4(3)$ \\
\hline No & $128(97)$ \\
\hline \multicolumn{2}{|c|}{ Perineural invasion $[\mathrm{n}(\%)]$} \\
\hline Yes & $3(2.3)$ \\
\hline No & $129(97.7)$ \\
\hline \multicolumn{2}{|c|}{ Angiolymphatic invasion $[\mathrm{n}(\%)]$} \\
\hline Yes & $3(2.3)$ \\
\hline No & $129(97.7)$ \\
\hline \multicolumn{2}{|l|}{ Regression $[\mathrm{n}(\%)]$} \\
\hline Yes & $22(16.7)$ \\
\hline No & $110(83.3)$ \\
\hline \multicolumn{2}{|l|}{ Satellitosis $[\mathrm{n}(\%)]$} \\
\hline Yes & $2(1.5)$ \\
\hline No & $130(98.5)$ \\
\hline \multicolumn{2}{|l|}{ Ulceration $[\mathrm{n}(\%)]$} \\
\hline Yes & $28(21.2)$ \\
\hline No & $104(78.8)$ \\
\hline \multicolumn{2}{|c|}{ Inflammatory infiltrate $[\mathrm{n}(\%)]$} \\
\hline Absent & $7(5.3)$ \\
\hline Mild & $74(56)$ \\
\hline Moderate & $44(33.4)$ \\
\hline & $7(5.3)$ \\
\hline \multicolumn{2}{|l|}{ Associated nevus $[\mathrm{n}(\%)]$} \\
\hline Yes & $25(18.9)$ \\
\hline No & $107(81.1)$ \\
\hline
\end{tabular}

older ages. 5,1822 Differences between the pathways mediated by sex in younger age versus older age patients may be an explanation for this reversal in the incidence among younger and older age groups. ${ }^{20}$ Although controversial, 1 factor that may be related to this observed age-specific incidence pattern is the female sex hormones related to the use of oral contraceptives or hormonal replacement therapy, which may be associated with an increased risk of melanoma. Specific genotypes have been

60 | www.appliedimmunohist.com

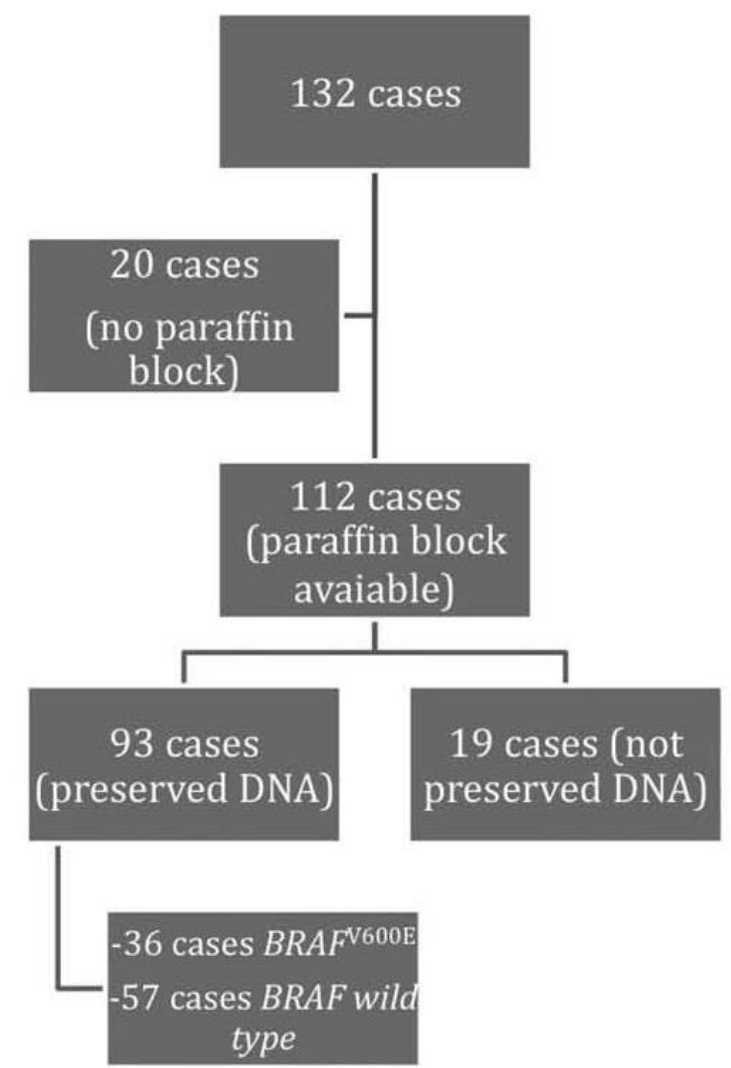

FIGURE 2. Algorithm of selected cases of cutaneous melanoma in patients between 18 and 30 years of age for the evaluation of BRAF mutation in this study.

found to be related to increased risk of melanoma among young women and may play a crucial role in the development of melanoma. ${ }^{23}$ More recently, tanning bed has been implicated in the etiology of melanoma, and this risk is greater among young women. ${ }^{24} 26$

We found that the trunk was the most frequent anatomic site of involvement for our cohort of patients, as seen also in other studies. $18,20,27,28$ In male patients, the head and neck region was the second most frequent site, and lower limbs were the most frequent sites among female patients followed by the trunk. Unfortunately, there were cases with unknown location due to the difficulty in obtaining this information from clinicians.

The main risk factors for developing melanoma in the young are large congenital nevi, family history of melanoma, numerous nevi, xeroderma pigmentosum, dysplastic nevus syndrome, and immunosuppression. ${ }^{8,29} 31$ Familial cases account for $5 \%$ to $10 \%$ of melanomas and are associated with a younger age at diagnosis compared with sporadic melanoma. ${ }^{32,33}$ In our series, only 1 patient reported a family history of melanoma with a grandfather. 


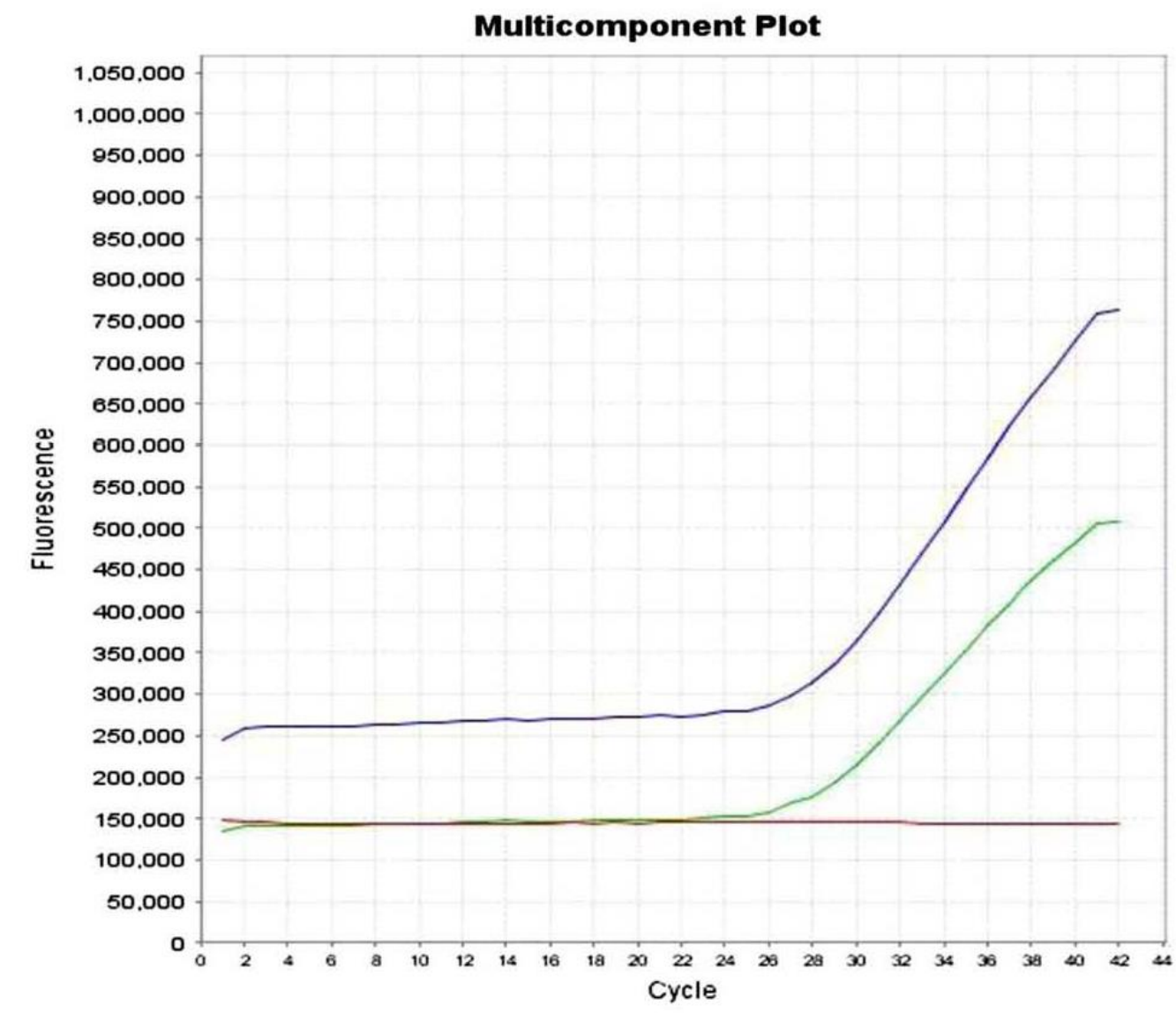

\section{$[$ Logend $\square$ VIC $\square$ FAM}

FIGURE 3. Multicomponent plot for nomal and mutated alleles of the human $B R A F^{2600 E}$. A segment of exon 15 was amplified. Templates were a known homozygote for the T allele (VIC-labeled probe), a known homozygote for the A allele (FAM-labeled probe), and a heterozygote. Fluorescence was monitored during the thermal cycling of PCR on the ABI PRISM 7700 and analyzed using the Sequence Detection System software. PCR cycle numbers are plotted against fluorescence. Red line refers to the ROX passive reference.

It is possible, however, that if a more detailed pedigree analysis was performed, we could have found more cases with a family history.

In one of our cases, melanoma developed in a background of giant congenital melanocytic nevi. The risk of progression from congenital melanocytic nevi to melanoma is still controversial. In a recent review, Paradela et $\mathrm{al}^{34}$ observed that $11.8 \%$ of childhood melanoma arose from congenital melanocytic nevi and only $3.5 \%$ of them arose from giant lesions. The risk of melanoma in children with giant congenital nevi has been estimated to be between $2 \%$ and $13 \%$, with $60 \%$ of melanomas arising in the first decade of life. ${ }^{35} 37$ There is no history of xeroderma pigmentosum in any of our cases.

Superficially spreading melanoma was the predominant histologic type in our series (79.6\%), as in several other studies, followed by nodular melanoma $(17.4 \%)$. $6,7,10,20,3840$ Other series have shown that nodular melanomas are the most common in adolescents and young adults. $18,28,41,42$ The characteristic features-absence of lentigo maligna histologic subtype, onset of the disease in young age, and absence of solar elastosis - in the majority of our cases, 


\begin{tabular}{|c|c|c|c|}
\hline \multirow{2}{*}{$\begin{array}{l}\text { Clinicopathologic } \\
\text { Features }\end{array}$} & \multicolumn{2}{|c|}{ n (\%) } & \multirow[b]{2}{*}{$P$} \\
\hline & $B R A F$ Mutated & $B R A F$ Wild & \\
\hline Sex & & & 0.77 \\
\hline Female & $24(40.7)$ & $35(59.3)$ & \\
\hline Male & $12(35.5)$ & $22(64.7)$ & \\
\hline Location & & & 0.07 \\
\hline Trunk & $11(40.7)$ & $18(40)$ & \\
\hline Upper extremity & $4(14.8)$ & $4(8.9)$ & \\
\hline Lower extremity & $11(40.7)$ & $12(26.7)$ & \\
\hline Head and neck & $1(3.7)$ & $11(24.4)$ & \\
\hline Melanoma type & & & 0.20 \\
\hline Superficial spreading & $26(72.2)$ & $48(84.2)$ & \\
\hline Nodular & $10(27.8)$ & $7(12.3)$ & \\
\hline Acral lentiginous & $0(0)$ & $1(1.75)$ & \\
\hline Lentigo maligna & $0(0)$ & $0(0)$ & \\
\hline Not specified & $0(0)$ & $1(1.75)$ & \\
\hline Breslow thickness & & & 0.35 \\
\hline In situ & $1(2.8)$ & $6(10.5)$ & \\
\hline$\leq 1.0 \mathrm{~mm}$ & $18(50)$ & $31(54.4)$ & \\
\hline $1.01-2.0 \mathrm{~mm}$ & $5(13.9)$ & $9(15.8)$ & \\
\hline $2.01-4.0 \mathrm{~mm}$ & $7(19.4)$ & $8(14)$ & \\
\hline$>4.0 \mathrm{~mm}$ & $5(13.9)$ & $3(5.3)$ & \\
\hline Clark level & & & 0.55 \\
\hline I & $1(2.8)$ & $6(10.5)$ & \\
\hline II & $19(52.8)$ & $29(50.9)$ & \\
\hline III & $12(33.3)$ & $13(22.8)$ & \\
\hline IV & $3(8.3)$ & $7(12.3)$ & \\
\hline V & $1(2.8)$ & $2(3.5)$ & \\
\hline Growth phase & & & 0.016 \\
\hline Radial & $9(25)$ & $30(52.6)$ & \\
\hline Vertical & $27(75)$ & $27(47.4)$ & \\
\hline Solar elastosis & & & 0.42 \\
\hline Yes & $0(0)$ & $3(5.3)$ & \\
\hline No & $36(100)$ & $54(94.7)$ & \\
\hline Perineural invasion & & & 0.42 \\
\hline Yes & $0(0)$ & $3(5.3)$ & \\
\hline No & $36(100)$ & $54(94.7)$ & \\
\hline Angiolymphatic invasion & & & 0.42 \\
\hline Yes & $0(0)$ & $1(1.8)$ & \\
\hline No & $36(100)$ & $56(98.2)$ & \\
\hline Regression & & & $<0.001$ \\
\hline Yes & $0(0)$ & $18(31.6)$ & \\
\hline No & $36(100)$ & $39(68.4)$ & \\
\hline Satelitosis & & & 0.77 \\
\hline Yes & $1(2.8)$ & $1(1.8)$ & \\
\hline No & $35(97.2)$ & $56(98.2)$ & \\
\hline Ulceration & & & 0.054 \\
\hline Yes & $11(30.6)$ & $8(14)$ & \\
\hline No & $25(69.4)$ & $49(86)$ & \\
\hline Inflammatory infiltrate & & & 0.02 \\
\hline Absent & $0(0)$ & $4(7)$ & \\
\hline Mild & $27(75)$ & $28(49.1)$ & \\
\hline Moderate & $8(22.2)$ & $20(35.1)$ & \\
\hline Intense & $1(2.8)$ & $5(8.8)$ & \\
\hline Associated nevus & & & 0.98 \\
\hline Yes & $7(19.4)$ & $11(19.3)$ & \\
\hline No & $29(80.6)$ & $46(80.7)$ & \\
\hline
\end{tabular}

favor the supposition that chronic sun exposure may play a less important role in the development of melanoma in this age group. It is evident that the role of chronic sun exposure in the development of melanomas in young people needs further studies.

Interestingly, data from previous studies revealed that melanoma in children have thicker tumors
( $>1.5 \mathrm{~mm}$ ) at presentation compared with adult counterparts. ${ }^{6,43}$ The thickness average in our invasive cases was $1.65 \mathrm{~mm}$. The reason for the higher incidence of thicker lesions in young patients may be explained by the lack of awareness and a delay in diagnosis probably due to the rarity of melanoma in this group age. The average size of the lesions was $7.85 \mathrm{~mm}( \pm 3.36 \mathrm{~mm})$. The Clark level was classified as I in $11(8.3 \%)$, II in $64(48.5 \%)$, III in $41(31.1 \%)$, IV in $13(9.8 \%)$, and $\mathrm{V}$ in 3 patients $(2.3 \%)$. The majority of our cases $(59.1 \%)$ presented with vertical growth phase. In the invasive cases, at least 1 mitotic figure was found in the dermal component in $68 /$ 121 cases $(56.2 \%)$.

To the best of our knowledge, there is no study evaluating $B R A F$ mutations in melanomas occurring in young adult patients. Mutations in $B R A F$ codon 600 are the most common point mutations detected in oncogenes in human cutaneous melanoma with a frequency ranging from $20 \%$ to $80 \%$ for $B R A F$ mutations in melanomas of all ages $44,45,13,46-54$ In this study, $38.7 \%$ of cases showed $B R A F^{\mathrm{V} 600 \mathrm{E}}$ mutation. These results led us to believe that these mutations may not be a key factor in melanoma tumorigenesis, and that there should be multiple alternative genetic pathways related to melanoma. Specific mutations of $B R A F$ can represent only one of the genetic alterations that contribute to the development of this neoplasm. Many studies observed high frequency of $B R A F$ mutations in benign nevi as well. ${ }^{46,55}$ In our study, we found no evidence of an increased frequency of $B R A F^{\mathrm{V} 600 \mathrm{E}}$ mutation in melanoma with a coexisting nevus $(P=0.98)$. In contrast, only 7 of $18(39 \%)$ cases of melanoma with a coexisting nevus had a $B R A F^{\mathrm{V} 600 \mathrm{E}}$ mutation. The case of melanoma associated with a giant congenital nevus was $B R A F^{\mathrm{V} 600 \mathrm{E}}$ wild type. Our data are in accordance with Maldonado et $\mathrm{al}^{51}$ who concluded that not all melanomas with a preexisting nevus present with $B R A F$ mutation. No relationship was found between sex and $B R A F^{\mathrm{V} 600 \mathrm{E}}$ mutation $(P=0.77)$. In addition, there was no significant association between $B R A F^{\mathrm{V} 600 \mathrm{E}} \mathrm{mu}-$ tation and histologic type $(P=0.20)$, the Clark level $(P=0.55)$, the Breslow index $(P=0.35)$, solar elastosis $(P=0.42)$, ulceration $(P=0.05)$, angiolymphatic and perineural invasion $(P=0.42)$, and satellitosis $(P=0.77)$. We found no $B R A F^{\mathrm{V} 600 \mathrm{E}}$ mutation in our 3 cases of melanomas associated with moderate to intense solar elastosis. Although this is a small number, the fact that no mutation was seen in this group raises the consideration that chronic sun exposure may not play a role in the frequency of $B R A F$ mutation in melanoma in the young adult population as well. Moreover, BRAF codon 600 (GTG) is not an obvious UV hotspot but is a specific site for mutational activation to the oncogenic form of the gene. Further studies with a higher number of young adults with melanoma may be needed to confirm this finding.

A $B R A F^{\mathrm{V} 600 \mathrm{E}}$ mutation was associated $(P=0.01)$ significantly with a vertical growth phase $(75 \%$ of mutated cases), a finding also seen in melanomas in all ages. ${ }^{47,56}$ Moderate and intense inflammatory infiltrates 
were related significantly with wild-type $B R A F^{\mathrm{V} 600 \mathrm{E}}$ tumors $(P=0.02)$. We found no cases of melanoma with regression phenomenon that presented with $B R A F^{\mathrm{V} 600 \mathrm{E}}$ mutation $(P=0.001)$. Ulceration was slightly more prevalent in cases with mutated $B R A F^{\mathrm{V} 600 \mathrm{E}}(P=0.05)$. $B R A F^{\mathrm{V} 600 \mathrm{E}}$ mutation frequency was low in melanomas that developed in the head and neck $(P=0.07)$. Interestingly, this negative association also has been described by others. ${ }^{51,57}$ This finding demonstrates that the $B R A F^{\mathrm{V} 600 \mathrm{E}}$ mutation is most frequent in melanoma types for which epidemiologic data suggest a pathogenetic role of intermittent sun exposure, such as that in the trunk, as opposed to chronic sun exposure. ${ }^{58,59}$

In conclusion, this study describes a large cohort of young adults with primary cutaneous melanoma specially related to the mutation analysis of the $B R A F$ gene. $B R A F^{\mathrm{V} 600 \mathrm{E}}$ was detected in $38.7 \%$ of the cases examined. In addition, the presence of $B R A F^{\mathrm{V} 600 \mathrm{E}}$ mutation correlates strongly with vertical growth phase, mild inflammatory infiltrate, and the absence of regression phenomenon at least in melanomas in this age group.

\section{ACKNWOLEDGMENT}

The authors thank Elida B. Ojopi, PhD; Luciana $H$. Silva, MS; and Lucimara C. Benine, PhD for their technical support in the evaluation of BRAF mutation and for their intellectual input concerning this study.

\section{REFERENCES}

1. Purdue MP, Freeman LE, Anderson WF, et al. Recent trends in incidence of cutaneous melanoma among US Caucasian young adults. I Invest Dermatol 2008:128:2905-2908.

2. Boddie AW Jr, Smith JL Jr, McBride CM. Malignant melanoma in children and young adults: effect of diagnostic criteria on staging and end results. South Med J. 1978;71:1074-1078.

3. Wu SJ, Lambert DR. Melanoma in children and adolescents. Pediatr Dermatol. 1997;14:87-92.

4. Borbola K, Banfalvi T, Fejos Z, et al. Etiologic factors of malignant melanoma in young adults. Orv Hetil. 2005;146:1481-1487.

5. Bleyer A, Viny A, Barr R. Cancer in 15- to 29-year-olds by primary site. Oncologist. 2006;11:590-601.

6. Ceballos PI, Ruiz-Maldonado R, Mihm MC Jr. Melanoma in children. $N$ Engl J Med. 1995;332:656-662.

7. Sander B, Karlsson P, Rosdahl I, et al. Cutaneous malignant melanoma in Swedish children and teenagers 1973-1992: a clinicopathological study of 130 cases. Int J Cancer. 1999:80:646-651.

8. Saenz NC, Saenz-Badillos J, Busam K, et al. Childhood melanoma survival. Cancer. 1999;85:750-754

9. Ferrari A, Bono A, Baldi M, et al. Does melanoma behave differently in younger children than in adults? A retrospective study of 33 cases of childhood melanoma from a single institution. Pediatrics. 2005;115:649-654.

10. Livestro DP, Kaine EM, Michaelson JS, et al. Melanoma in the young: differences and similarities with adult melanoma: a casematched controlled analysis. Cancer. 2007;110:614-624.

11. Moore-Olufemi S, Herzog C, Warneke C, et al. Outcomes in pediatric melanoma: comparing prepubertal to adolescent pediatric patients. Ann Surg. 2011;253:1211-1215.

12. Govindarajan B, Bai X, Cohen $\mathrm{C}$, et al. Malignant transformation of melanocytes to melanoma by constitutive activation of mitogenactivated protein kinase kinase (MAPKK) signaling. $J$ Biol Chem. 2003;278:9790-9795.

13. Davies $\mathrm{H}$, Bignell GR, Cox C, et al. Mutations of the BRAF gene in human cancer. Nature. 2002;417:949-954.
14. Homsi J, Kashani-Sabet M, Messina JL, et al. Cutaneous melanoma: prognostic factors. Cancer Control. 2005;12:223-229.

15. van Dongen JJ, Langerak AW, Bruggemann $M$, et al. Design and standardization of PCR primers and protocols for detection of clonal immunoglobulin and T-cell receptor gene recombinations in suspect lymphoproliferations: report of the BIOMED-2 Concerted Action BMH4-CT98-3936. Leukemia. 2003;17:2257-2317.

16. Alston RD, Rowan S, Eden TO, et al. Cancer incidence patterns by region and socioeconomic deprivation in teenagers and young adults in England. Br J Cancer. 2007;96:1760-1766.

17. Marrett LD, Frood J, Nishri D, et al. Cancer incidence in young adults in Canada: preliminary results of a cancer surveillance project. Chronic Dis Can. 2002;23:58-64.

18. de Sa BC, Rezze GG, Scramim AP, et al. Cutaneous melanoma in childhood and adolescence: retrospective study of 32 patients. Melanoma Res. 2004;14:487-492.

19. Pratt CB, Palmer MK. Thatcher N, et al. Malignant melanoma in children and adolescents. Cancer. 1981;47:392-397.

20. Weir HK, Marrett LD, Cokkinides V, et al. Melanoma in adolescents and young adults (ages 15-39 years): United States, 1999-2006. $J$ Am Acad Dermatol. 2011;65(5 Suppl 1):S38-S49.

21. Mackie RM, Watt D, Doherty V, et al. Malignant melanoma occurring in those aged under 30 in the west of Scotland 1979-1986: a study of incidence, clinical features, pathological features and survival. Br J Dermatol. 1991;124:560-564.

22. Jemal A, Saraiya $M$, Patel $P$, et al. Recent trends in cutaneous melanoma incidence and death rates in the United States, 1992-2006. $J$ Am Acad Dermatol. 2011;65(S17-25):el1-e13.

23. Firoz EF, Warycha M, Zakrzewski J, et al Association of MDM2 SNP309, age of onset, and gender in cutaneous melanoma. Clin Cancer Res. 2009;15:2573-2580.

24. Robinson JK, Rigel DS, Amonette RA. Trends in sun exposure knowledge, attitudes, and behaviors: 1986 to 1996. J Am Acad Dermatol. 1997;37:179-186.

25. Reed KB, Brewer JD, Lohse CM, et al. Increasing incidence of melanoma among young adults: an epidemiological study in Olmsted County, Minnesota. Mayo Clin Proc. 2012;87:328-334.

26. Ting W, Schultz K, Cac NN, et al. Tanning bed exposure increases the risk of malignant melanoma. Int J Dermatol. 2007;46:1253-1257.

27. Scalzo DA, Hida CA, Toth G, et al. Childhood melanoma: clinicopathological study of 22 cases. Melanoma Res. 1997;7:63-68.

28. Schmid-Wendtner $\mathrm{MH}$, Berking $\mathrm{C}$, Baumert J, et al. Cutaneous melanoma in childhood and adolescence: an analysis of 36 patients. I Am Acad Dermatol. 2002;46:874-879.

29. Whiteman DC, Valery P, McWhirter W, et al. Risk factors for childhood melanoma in Queensland, Australia. Int $J$ Cancer. 1997; 70:26-31.

30. Lefkowitz A, Schwartz RA, Janniger CK. Melanoma precursors in children. Cutis. 1999;63:321-324.

31. Silverberg NB. Update on malignant melanoma in children. Cutis. 2001;67:393-396.

32. Pappo AS. Melanoma in children and adolescents. Eur $J$ Cancer. 2003;39:2651-2661.

33. Berg P, Wennberg AM, Tuominen R, et al. Germline CDKN2A mutations are rare in child and adolescent cutaneous melanoma. Melanoma Res. 2004; 14:251-255.

34. Paradela S, Fernandez-Torres R, Fonseca E. Controversial issues in congenital nevi. Actas Dermosifiliogr. 2009;100:548-561.

35. Rhodes AR, Wood WC, Sober AJ, et al. Nonepidermal origin of malignant melanoma associated with a giant congenital nevocellular nevus. Plast Reconstr Surg. 1981;67:782-790.

36. Kaplan EN. The risk of malignancy in large congenital nevi. Plast Reconstr Surg. 1974;53:421-428.

37. Bittencourt FV, Marghoob AA, Kopf AW, et al. Large congenital melanocytic nevi and the risk for development of malignant melanom and neurocutaneous melanocytosis. Pediatrics. 2000;106:736-741.

38. Davidoff AM, Cirrincione C, Seigler HF. Malignant melanoma in children. Ann Surg Oncol. 1994;1:278-282.

39. Spatz A, Ruiter D, Hardmeier T, et al. Melanoma in childhood: an EORTC-MCG multicenter study on the clinico-pathological aspects. Int J Cancer. 1996;68:317-324.

www.appliedimmunohist.com | 63 
40. Paradela S, Fonseca E, Pita-Fernandez S, et al. Melanoma under 18 years and pregnancy: report of three cases. Eur $J$ Dermatol. 2010;20:186-188.

41. Mehregan AH, Mehregan DA. Malignant melanoma in childhood. Cancer. 1993;71:4096-4103.

42. Tamir G, Milo Y, Rothem A, et al. Cutaneous malignant melanoma in young adults under age 30. Isr J Med Sci. 1996;32:1290-1296.

43. Rao BN, Hayes FA, Pratt CB, et al. Malignant melanoma in children: its management and prognosis. J Pediatr Surg. 1990;25: 198-203.

44. Platz A, Egyhazi S, Ringborg U, et al. Human cutaneous melanoma; a review of NRAS and BRAF mutation frequencies in relation to histogenetic subclass and body site. Mol Oncol. 2008;1:395-405.

45. Lee JH, Choi JW, Kim YS. Frequencies of BRAF and NRAS mutations are different in histological types and sites of origin of cutaneous melanoma: a meta-analysis. Br $J$ Dermatol. 2011;164: 776-784.

46. Pollock PM, Harper UL, Hansen KS, et al. High frequency of BRAF mutations in nevi. Nat Genet. 2003;33:19-20.

47. Dong J, Phelps RG, Qiao R, et al. BRAF oncogenic mutations correlate with progression rather than initiation of human melanoma. Cancer Res. 2003;63:3883-3885.

48. Uribe P, WistubaII, Gonzalez S. BRAF mutation: a frequent event in benign, atypical, and malignant melanocytic lesions of the skin. Am J Dermatopathol. 2003;25:365-370.

49. Omholt K, Platz A, Kanter L, et al. NRAS and BRAF mutation arise early during melanoma pathogenesis and are preserved throughout tumor progression. Clin Cancer Res. 2003;9:6483-6488.
50. Yazdi AS, Palmedo G, Flaig MJ, et al. Mutations of the BRAF gene in benign and malignant melanocytic lesions. $J$ Invest Dermatol. 2003;121:1160-1162.

51. Maldonado JL, Fridlyand J, Patel H, et al. Determinants of BRAF mutations in primary melanomas. I Natl Cancer Inst. 2003;95: 1878-1890.

52. Shinozaki M, Fujimoto A, Morton DL, et al. Incidence of BRAF oncogene mutation and clinical relevance for primary cutaneous melanomas. Clin Cancer Res. 2004;10:1753-1757.

53. Sasaki $\mathrm{Y}$, Niu $\mathrm{C}$, Makino $\mathrm{R}$, et al. BRAF point mutations in primary melanoma show different prevalences by subtype. $J$ Invest Dermatol. 2004;123:177-183.

54. Colombino M, Capone M, Lissia A, et al. BRAF/NRAS mutation frequencies among primary tumors and metastases in patients with melanoma. $J$ Clin Oncol. 2012;30:2522-2529.

55. Kumar R, Angelini S, Snellman E, et al. BRAF mutations are common somatic events in melanocytic nevi. J Invest Dermatol. 2004; 122:342-348.

56. Greene VR, Johnson MM, Grimm EA, et al. Frequencies of NRAS and BRAF mutations increase from the radial to the vertical growth phase in cutaneous melanoma. $J$ Invest Dermatol. 2009;129:1483-1488.

57. Curtin JA, Fridlyand J, Kageshita T, et al. Distinct sets of genetic alterations in melanoma. $N$ Engl $J$ Med. 2005;353:2135-2147.

58. Bulliard JL. Site-specific risk of cutaneous malignant melanoma and pattern of sun exposure in New Zealand. Int J Cancer. 2000;85:627-632.

59. Holman CD, Armstrong BK, Heenan PJ. Relationship of cutaneous malignant melanoma to individual sunlight-exposure habits. $J$ Nat Cancer Inst. 1986;76:403-414. 